Copy No.

AEC Research and

Development Report

UC-81, Reactors - Power

(Special Distribution)

\title{
SM-2 SINGLE ELEMENT FINAL TEST REPORT
}




\section{DISCLAIMER}

This report was prepared as an account of work sponsored by an agency of the United States Government. Neither the United States Government nor any agency Thereof, nor any of their employees, makes any warranty, express or implied, or assumes any legal liability or responsibility for the accuracy, completeness, or usefulness of any information, apparatus, product, or process disclosed, or represents that its use would not infringe privately owned rights. Reference herein to any specific commercial product, process, or service by trade name, trademark, manufacturer, or otherwise does not necessarily constitute or imply its endorsement, recommendation, or favoring by the United States Government or any agency thereof. The views and opinions of authors expressed herein do not necessarily state or reflect those of the United States Government or any agency thereof. 


\section{DISCLAIMER}

Portions of this document may be illegible in electronic image products. Images are produced from the best available original document. 
APAE MEMO NO. 267

Copy No. 1 ?

AEC Research and

Development Report

UC-81, Reactors-Power

(Special Distribution)

SM-2 SINGLE ELEMENT

FINAL TEST REPORT

\begin{abstract}
By:
P. S. Krause

Approved By: R. E。 Williams, Leader, Development Test Group

W.M.S. Richards, Task Engineer

H. L. Hoover, Project Engineer
\end{abstract}

Issued: October 28,1960

Contract No。AT(30-3)-326

with U. S: Atomic Energy Commission

New York Operations Office

ALCO PRODUCTS, INC.

Nuclear Power Engineering Department

Post Office Box 414

Schenectady 1, N. Y. 
This report was prepared as an account of Government sponsored work. Neither the United States, nor the Commission, nor any person acting on behalf of the Commission:...

A. Makes any warranty or representation, expressed or implied, with respect to the accuracy, completeness, or usefulness of the information contained in this report, or that the use of any information, apparatus, method, or process disclosed in this report may not infringe privately owned rights: or

B. Assumes any liabilities with respect to the use of, or for damages resulting from the use of any information, apparatus, method, or process disclosed in this report.

As used:in the above, "person acting on behalf of the Commission" includes any employee or contractor of the Commission, or employee of such contractor, to the extent that such employee or contractor of the Commission, or employee of such contractor prepares, disseminates, or provides access to, any information pursuant to his employment or contract with the Commission, or his employment with such contractor.

\section{ALCO LEGAL NOTICE}

This report was prepared by Alco Products, Incorporated in the course of work under, or in connection with, Contract No. AT(30-3)-326, issued by U. S. Atomic Energy Commission, NYOO; and subject only to the rights of the United States, under the provisions of this contract, Alco Products, Incorporated makes no warranty or representation, express or implied, and shall have no liability with respect to this report or any of its contents or with respect to the use thereof or with respect to whether any such use will infringe the rights of others. 


\section{DISTRIBUTTION}

Copies

$1-2 \quad$ New York Operations Office

U.S. Atomic Energy Commission

376 Hudson Street

New York 14, New York

Attn: Chief, Army Reactors Branch, NYOO

3 - 5 U.S. Atomic Energy Commission

Washington 25; D. C.

Attn: Chief, Water Systems Project Branch (Army Reactors)

Division of Reactor Development

Mail Station F-311

6 U.S. Atomic Energy Commission

Chief, 'Patents Branch

Washington 25, D. C.

Attn:: Roland A。 Anderson

$7 \quad$ U.S, Atomic Energy Commission

$\therefore$ Chief, New York Patent Group

Brookhaven National Laboratory

Upton, New York

Attn: Harman Potter

8 U.S. Atomic Energy Commission

Idaho Operations Office

P.O. Box 2108

Idaho Falls, Idaho

Attn: Director, Division of Military Reactors

9. - 11 Nuclear Power Field Office

USAERDL

Fort Belvoir, Virginia

Attn: Chief, Nuclear Power Field Office 


\section{DISTRIBUTION (CONT'D)}

Copies

12 Union Carbide Nuclear Corporation

Oak Ridge National Laboratory

Y-12 Building 9704-1

P.O. Box "Y"

Oak Ridge, Tennessee

Attn: A. L. Boch

13 The Martin Company

P.o. Box 5042

Middle River, Maryland

Attn: AEC Contract Document Custodian

14 Combustion Engineering, Inc.

P.O. Box 2558

Idaho Falls, Idaho

Attn: Mr. W.B. Allred, Project Manager SL-1

$15-17$ U.S. Atomic Energy Commission

Reference Branch

Technical Information Services Extension

P.O. Box 62

Oak Ridge, Teenessee

18

U.S. Atomic Energy Commission

Washington $25, \mathrm{D} . \mathrm{C}$.

Attn: Chief, Evaluation and Planning Branch

Civilian Reactors, Division of Reactor Development

Mail Station F-311

19 Commander

Air Force Special Weapons Centers (AFSWC)

Albuquerque, New Mexico

Attn: S.W. V.

20 - 21 Alco Products, Inc.

Post Office: Box 145

Fort Belvoir, Va.

Attn: H.L.Weinberg 
Copies

22 - 42 Alco Products, Inc. Post Office Box 414

Schenectady 1, N.Y.

$\begin{array}{ll}22 & \text { K. Kasschau } \\ 23 & \text { J. Gronan } \\ 24 & \text { E. B. Gunyou } \\ 25 & \text { W. K. Stromquist } \\ 26 & \text { H. . Ho Hoover } \\ 27 & \text { J.G. Gallagher } \\ 28 & \text { J.F. Haines } \\ 29 & \text { G. R. Griffith } \\ 30 & \text { W.M.S. Richards } \\ 31 & \text { R.E. Williams } \\ 32 & \text { J.A. Christenson } \\ 33 & \text { F.T. Matthews } \\ 34 & \text { S. L. Davidson } \\ 35 & \text { P.S. Krause } \\ 36 & \text { L.A. Taylor } \\ 37 & \text { W.T. Williams } \\ 38-42 & \text { NPED File }\end{array}$




\section{THIS PAGE}

\section{WAS INTENTIONALLY \\ LEFT BLANK}




\section{ABSTRACT}

Tests were conducted on an SM-2 control rod assembly and stationary element to determine channel-to-channel coolant flow distribution and static pressure drops across both the control rod assembly and stationary element, and to select proper top and bottom core support configurations necessary to bring stationary element channel-to-channel flow distribution within prescribed limits of $+6 \%$ of element average. Results showed control rod channel-to-channel flow distribution was $+7.0 \%$ and $-.7 .4 \%$ of element average, within required $+12 \%$. Pressure drop across the control rod assembly was measured as $29.0 \mathrm{ft}$ of water $\left(80^{\circ} \mathrm{F}\right)$ at design flow rate of $331 \mathrm{gpm}$. First pass stationary element pressure drop was measured as $17.1 \mathrm{ft}$ of water $\left(80^{\circ} \mathrm{F}\right)$ at a flow rate of $272 \mathrm{gpm}$; flow distribution was $+7.7 \%$ and $-10.7 \%$ of element average, not within prescribed $+6 \%$, but since actual element flow was much higher than required by thermal design, the flow profile was felt acceptable.. Second pass stationary element pressure drop was measured as $28.8 \mathrm{ft}$ of water $\left(80^{\circ} \mathrm{F}\right)$ at a flow rate of $346 \mathrm{gpm}$; channel-tochannel flow distribution was $+4.3 \%$ and $-4.5 \%$ of average element velocity at a flow rate of $346 \mathrm{gpm}$, within prescribed limits of $\pm 6.0 \%$. 
THIS PAGE

WAS INTENTIONALLY

LEFT BLANK 
ABSTRACT $\ldots-\cdots, \ldots$ vii

1.0: SUMMARY $\ldots \ldots-\ldots$

2.0 INTRODUCTION $\ldots \ldots \ldots \ldots$

3.0 CONTROL ROD TESTING $-\cdots-\ldots$

3.1. Purpose of Tests $-\ldots$

3.2 Description of Test Rig and Instrumentation

3. 3 Test Procedure $-\ldots \ldots-\ldots, \ldots-\ldots, \ldots-\ldots$

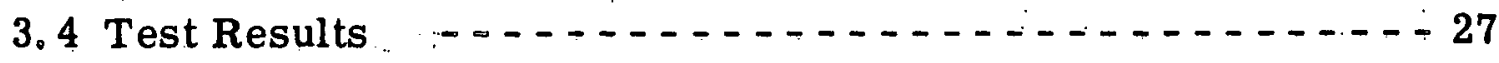

3.4.1 Test with Control Rod Assembly (Original Design) - - - -27

3.4.2 Test with First Modification - - - - - - -

3.4.3 Test with Absorber Removed - -

3.4. 4 Retest with First Modification - . - . - - - - - - - 28

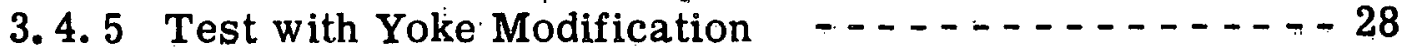

3.4.6 Retest with Fully-Welded Element - - - - - -

3.4. 7 : Pressure Drop Testing - $\ldots \ldots \ldots$

4. 0 STATIONARY ELEMENT TESTING $-\ldots \ldots$

4. 1 Purpose of Tests $\ldots \ldots \ldots$

4. 2 Description of Test Rig and Instrumentation $\ldots \ldots-\ldots 7$

4.2.1 Instrumentation for Initial Tests - - - - - - - 47

4.2.2 Instrumentation for Remainder of Testing -

4. 2 Test Procedures $\ldots \ldots-\ldots-\ldots-\ldots-\ldots$

4. 3 Test Results - $-\ldots \ldots-\ldots-\ldots-\ldots$

4.4.1 Test \#1 (1st Pass) - Style 46 Inlet, Style 46 Exit - - - 67

4.4.2 Test \#2 (1st Pass) - Style 6 Inlet, Style 6 Exit - - - - - 67

4.4.3 Test \#3 (1st Pass) - Style 9 Inlet, Style 6 Exit - - - - 67

4. 4. 4 Test \#4 (2nd Pass) - Style 9 Inlet, Style 8b Exit - - . 79

4.4.5 Test \#5 (1st Pass) - Style 9 Inlet, Style 9a Exit - - - 79

4.4.6 Test \#6 (1st Pass) - Style 9 Inlet, Style 9a Exit - . - 79 


\section{TABLE OF CONTENTS (CONT'D)}

4.4.7 Test \#7 (1st Pass) - Style 9c Inlet, Style 9a Exit 91

4.4.8 Test \#8 (1st Pass) - Style 9c Inlet, Style 9b Exit $\therefore 91$

4. 4.9 Test \#9 (1st Pass) - Style 9c Inlet, Style 9a Exit 91

4.4.10 Test \#10 (1st Pass) - Style 9c Rev. A Inlet

(Rotated $90^{\circ}$ ), Style 9a Exit 103

4.4.11 Test \#11 (1st Pass) - Style 9c Rev. A Inlet, Style 9a Exit 103

4.4.12 Test \#12 (1st Pass) - Style 12a Inlet, Style 9a Exit 110

4.4.13 Test \#13 (1st Pass) - Style 9c Revi. A(Mod.) Inlet, Style 9a Outlet

4.4.14 Test \#14 (2nd Pass) - Style 9cRev. A (Mod.) Inlet, Style $9 \mathrm{~b}$ Outlet

4.4.15 Test \#15 (2nd Pass) - Style 13 Inlet, Style 9b Exit 115

4.4.16 Test \#16(2nd: Pass) - Style $13 \mathrm{Rev}$. A Inlet, Style 9a Exit : 115

4, 4.17 Test \#17 (2nd Pass) - Style 13 Rev. A Inlet, Style 9b Exit (Rotated $180^{\circ}$ )

4. 4.18 Test \#18 (2nd Pass) - Style.13 Rev. A Inlet, Style 9b Rev. A Exit 


\section{LIST OF ILLUSTRATIONS}

Figure

Title

Page

3-1 Dwg。C9-50-1244, Control Rod Single Element Rig

3-2 SM-2 Control Rod Test Section 9

3-3 Dwg。C9-50-1107, SM-2 Control Rod Yoke Assembly 11

3-4 Dwg。C9-13-1029, SM-2 Control Rod Cap Assembly 13

3-5 Dwg. D9-13-2094, SM-2 Absorber

3-6 Dwg. C9-13-1028, SM-2 Control Rod Fuel Element 17

3-7 : Dwg。B9-50-2285, SM-2 Control Rod Rake 19

3-8 $\therefore$ Dwg. C9-13-2137, SM-2 Control Rod Tube

3-9 Dwg. AEL-485, Instrumented SM-2 Control Rod Assembly 23

3-10 SM-2 Control Rod - a.s. Instrumented (Exploded View) . 25

3-11 SM-2 Control Rod - as Instrumented (Assembled View) 26

3-12 Dwg。 AEL-445, Control Rod - Original Pre-Test Design

3-13 Graphic Profile of Channel to Channel Velocity

Distribution for SM-2 Control Rod

3-14 Dwg。 R-9-14-1005, Control Rod (with Yoke Modification)Final Design

3-15 Graphic Profile of Channel to Channel Velocity Distribution for SM-2 Control Rod

3-16 Graphic Profile of Channel to Channel Velocity

Distribution for SM-2 Control Rod with Entrance

- Deflectors and Fully Welded Element - Final Test

3-17 Static Pressure Drop Across Control Rod Cap Vs. Flow

3-18 Static Pressure Drop Across Control Rod Fuel Element and Absorber Vs. Flow

3-19 Static Pressure Drop Across SM-2 Control Rod

Assembly Vs. Flow 
LIST OF ILLUSTRATIONS (CONT'D)

Figure

$\underline{\text { Title }}$

Page

3-20 Static Pressure Drop Across Control Rod Inlet

Yoke: Vs. Flow.

44

3-21 Static Pressure Regain at Control Rod Cap Exit

Vs. Flow

45

4-1 Dwg. AES-345, Single Element Flow Test Rig Assembly

4-2 : Single Element Flow Test Rig Assembly

55

4-3 Dwg。 R9-13-1017, SM-2 Stationary Fuel Element

57

4-4 Dwg. D9-50-1117, Single Element Flow Test Rig (Subassembly)

4-5 Dwg。B9-50-1121, SM-2 Stationary Fuel Element Assembly

4-6 Dwg。C9-50-1086, Flow Adjuster Assembly

4-7 Dwg。 AES-343, Style 46 - Support Plug - 1st Pass

4-8 Stationary Element Flow Distribution (Style 46 Inlet and Style 46 Exit) - 1st Pass

4-9 $\quad$ Dwg。 AES-375, Style 6, Support Plug - 1st Pass

4-10 Stationary Element Flow: Distribution (Style 6 Inlet and Style 6 Exit) - 1st Pass

4-11 Dwg. AES-381, Style 9 - Inilet Support Plug 1st Pass:

4-12 : Stationary Element Flow Distribution (Style 9 Inlet and Style 6 Exit) - 1st Pass

4-13 :Dwg。 B9-50-2280, Style 8b - Exit Support -2nd Pass

81

4-14 Stationary Element Flow Distribution (Style 9 Inlet and Style 8b Exit) - 2nd Pass

4-15 Dwg. AES-399, Style 9a, Exit:Support Plug - 1st Pass 


\section{LIST OF ILLUSTRATIONS (CONT'D)}

Figure

Title

$\underline{\text { Page }}$

4-16 Stationary Element Flow Distribution;(Style 9 Inlet and Style 9a Exit) - 1st Pass

4-17 Dwg。 B9-50-1118, Comb

4-18 Stationary Element Flow Distribution (Style 9 Inlet and 9a Exit with Modifications to End Fixture ) - 1st Pass

4-19 Dwg。AES-474, Style 9c - Inlet Support Plug - 1st Pass

4-20 Stationary Element Flow Distribution (Style 9c Inlet and 9a Exit) - 1st Pass

4-21 Dwg. AES -453, Style 9b - Exit Support Plug - 2nd Pass

4-22 Stationary Element Flow. Distribution (Style 9c Inlet and 9b Exit) - 2nd Pass

4-23 Dwg. C9-50-1120, End Fixture Assembly

4-24 Stationary Element Flow Distribution (Style 9c Inlet and 9a Exit) - 1st Pass

4-25a Flowhole Orientation Before Rotation

4-25b : Flowhole Orientation After $90^{\circ}$ Rotation

4-26 Stationary Element Flow Distribution (Style 9c Rev. A Inlet - Rotated $90^{\circ}$ and 9 a Exit) - 1st Pass

4-27 Stationary Element Flow Distribution (Style 9c Rev A Inlet and 9a Exit) - 1st Pass

4-28 Dwg。 AES-498, Style 12a - Inlet Support Plug (1st Pass)

4-29 Stationary Element Flow Distribution (Style 12a Inlet and 9a Exit) - 1st Pass

4-30 : Stationary Element Flow Distribution (Style 9c Rev。A Modified: Inlet and 9a Exit) - 1st Pass

4-31 Stationary Element Flow Distribution (Style 9c Rev。 A Modified Inlet and 9b Exit) - 2nd Pass 


\section{LIST OF. ILLUSTRATIONS (CONT'D)}

Figure

Title

Page

4-32 Dwg. B9-50-2450, Style13-Inlet Support Plug (2nd Pass)

4-33 Stationary Element Flow Distribution (Style 13 Inlet and 9b Exit) - 2nd Pass

4-34 Stationary Element Flow Distribution (Style 13 Rev. A Inlet and 9b Exit) - 2nd Pass.

4-35 Stationary Element Flow Distribution (Style 13 Rev.A Inlet and 9b Exit Rotated $\left.180^{\circ}\right)-2$ nd Pass

4-36 Stationary Element Flow Distribution (Style 13 Rev. A Inlet $A$ and $9 b$ Rev. A Exit) - 2nd Pass

LIST OF TABLES

Table

$\underline{\text { Title }}$

$\underline{\text { Page }}$

Velocity: Flow Distribution. Results for Final SM-2

Control Rod Assembly Test

4-1 Final Test Results for Stationary Element Testing

4-2 Velocity Flow Distribution Results for Final 1st Pass Stationary Element Test

4-3 Velocity Flow Distribution Results for Final 2nd Pass Stationary Element Test 


\subsection{SUMMARY}

The report gives results of single element low pressure flow testing conducted on an SM-2 control rod assembly and stationary fuel element as part of SM-2 Core and Vessel Task 6.0. Objectives of testing were:

1. To determine channel-to-channel coolant flow distribution for both the control rod and stationary element.

2. To determine static pressure drops across both the control rod and stationary element. First pass pressure drop across the stationary element was required to be as low as possible while second pass pressure drop was to match that of the control rod assembly,

3. To determine proper top and bottom core support conf igurations necessary to bring stationary element channel-to-channel flow distribution within prescribed limits of $\pm 6 \%$ of element average.

\subsection{CONTROL ROD ASSEMBLY TESTING}

Control rod pressure drop was experimentally measured as $29.0 \mathrm{ft}$ of water $\left(80^{\circ} \mathrm{F}\right)$ at the design flow rate of $331 \mathrm{gpm}$. Flow velocity distribution for the control rod was within prescribed limits of $+12 \%$ of average, actual results being $+7.0 \%$ and $-7.4 \%$ of average. Individual control rod component pressure drops are tabulated in Section 3.4.7.

\subsection{STATIONARY ELEMENT TESTING}

Bottom and top core support configurations experimentally selected for the first pass stationary element were Styles 9c Rev. A (Fig。4-19) and 9a'(Fig. 4-15) respectively. For second pass stationary elements, the bottom and top core support configurations selected were Styles 13 Rev. A (Fig. 4-32) and 9b Rev。 A' (Fig. 4-21) respectively. Overall stationary element pressure drop for first pass was $17.1 \mathrm{ft}$ of water $\left(80^{\circ} \mathrm{F}\right)$ at a flow-rate of $272 \mathrm{gpm}$ while second pass stationary element pressure drop was measured as $28.8 \mathrm{ft}$.of water $\left(80^{\circ} \mathrm{F}\right)$ at a flow rate of $320 \mathrm{gpm}$. The selected core support design met the objectives of low first pass pressure drop, and a second pass pressure drop which matched that of the control rod assembly.

The first pass combination of top and bottom core support configurations resulted in channel-to-channel flow distribution with $+7.7 \%$ and $-10.7 \%$ of average channel velocity. This was not with in the target limits of $+6 \%$; but since first pass channel flow rate is actually $20 \%$ higher than required by thermal design, the above limits were believed acceptable for first pass flow. 
Second pass channel flow distribution was $+4.3 \%$ and $-4.5 \%$ of average channel velocity, which was within $\pm 6 \%$ imposed by design requirements.

The selected core support design gave optimum flow distribution for both first and second pass sections of the core, with the required minimum first pass pressure drop across stationary elements and second pass pressure drop matching that of the control rod assembly. 


\subsection{INTRODUCTION}

Single element low pressure flow testing was performed in the Alco General Engineering Laboratory at Schenectady, New York, as part of SM-2 Core and Vessel Task 6.0 - Core Hydraulic Analysis and Test. Testing was done on a loop previously used in similar testing for the SM-1A reactor.

Objectives of the test program were to experimentally determine both flow distribution and pressure drop data of an SM-2 control rod assembly and stationary element. The program was also to result in experimental selection of a bottom and top cor e support configuration which would give optimum flow distribution for both first and second pass sections of the core.

The target limits for both first and second pass channel-to-channel flow distribution were $+6 \%$ of element average. First pass flow distribution requirements were not as stringent as second pass due to excess total flow. Good channel-to-channel flow distribution was necessary because maldistribution would present a serious problem to core thermal design by introducing channel hot spots. Average or better than average flow in the lattice region was required because high flux peaks were expected to occur in this region.

Experimentally determined pressure drop data would be used in selection of a top and bottom core support configuration. First pass stationary element pressure drop was to be minimum while second pass stationary element pressure drop had to match that of the control rod assembly.

Many different combinations of bottom and top core support configurations were tested before selecting the: combination which gave both the required pressure drop and flow distribution for first and second pass regions of the core. 
THIS PAGE

\section{WAS INTENTIONALLY \\ LEFT BLANK}




\subsection{CONTROL ROD ASSEMBLY TESTING}

\subsection{PURPOSE OF TESTS}

The purpose of single element flow testing of the control rod assembly was:

1. To determine experimentally the pressure drops through the complete SM-2 control rod assembly and its various components.

2. To determine the channel-to-channel flow distribution within the fuel element of this control rod:

3. To recommend and test any design modifications necessary to bring flow distribution within the prescribed limits of deviation from average。

\subsection{DESCRIPTION OF TEST RIG: AND INSTRUMENTATION}

The test rig used for this testing consisted of a straight section of pipe into which the control rod assembly" was inserted. "Large plenum chambers at each end of the straight section served as flow straighteners and provided regions for static pressure measurements (overall control rod pressure drop). The space between the control rod and pipe was sealed to force total loop flow through the rod, simplifying total flow measurement. The test $r$ ig is shown in Fig. 3-1 and 3-2... Various control rod components and sub-assemblies and the instrumented control rod itself are shown in Fig. 3-3 through 3-11.

Instrumentation consisted of both static and total pressure probes. During initial testing, a fuel element containing removable. instrumented plates was used but it was found that, due to handling difficulties and pressure gradients, these plates were.being distonted during testing and causing erroneous velocity measurements. This fuel element was then replaced by a standard SM-2 control rod element having all plates welded. Instrumentation of the fuel element was then achieved by total and static pressure . probes mounted in rakes and located at the exit of the fuel element, with both a total and static pressure probe located in each channel. Individual static pressure prubes were also located so that static pressure differentials could be obtained across the following:

1.. Inlet yoke

2. Fuel element and absorber

3. Cap

4.. Exit

5. Plenum to plenum (overall) - see Fig. 3-9. 
THIS PAGE

\section{WAS INTENTIONALLY \\ LEFT BLANK}




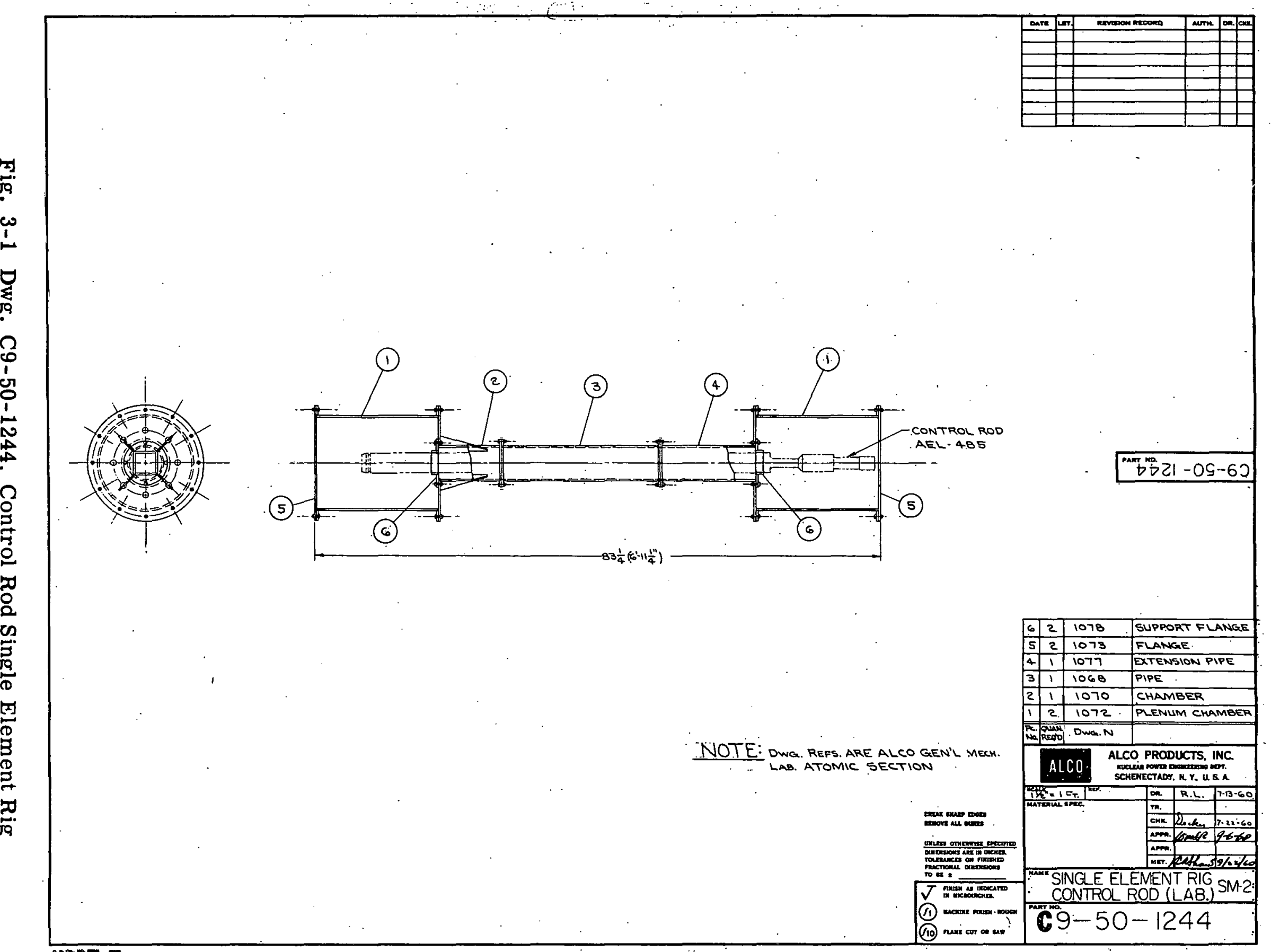




\section{THIS PAGE \\ WAS INTENTIONALLY \\ LEFT BLANK}




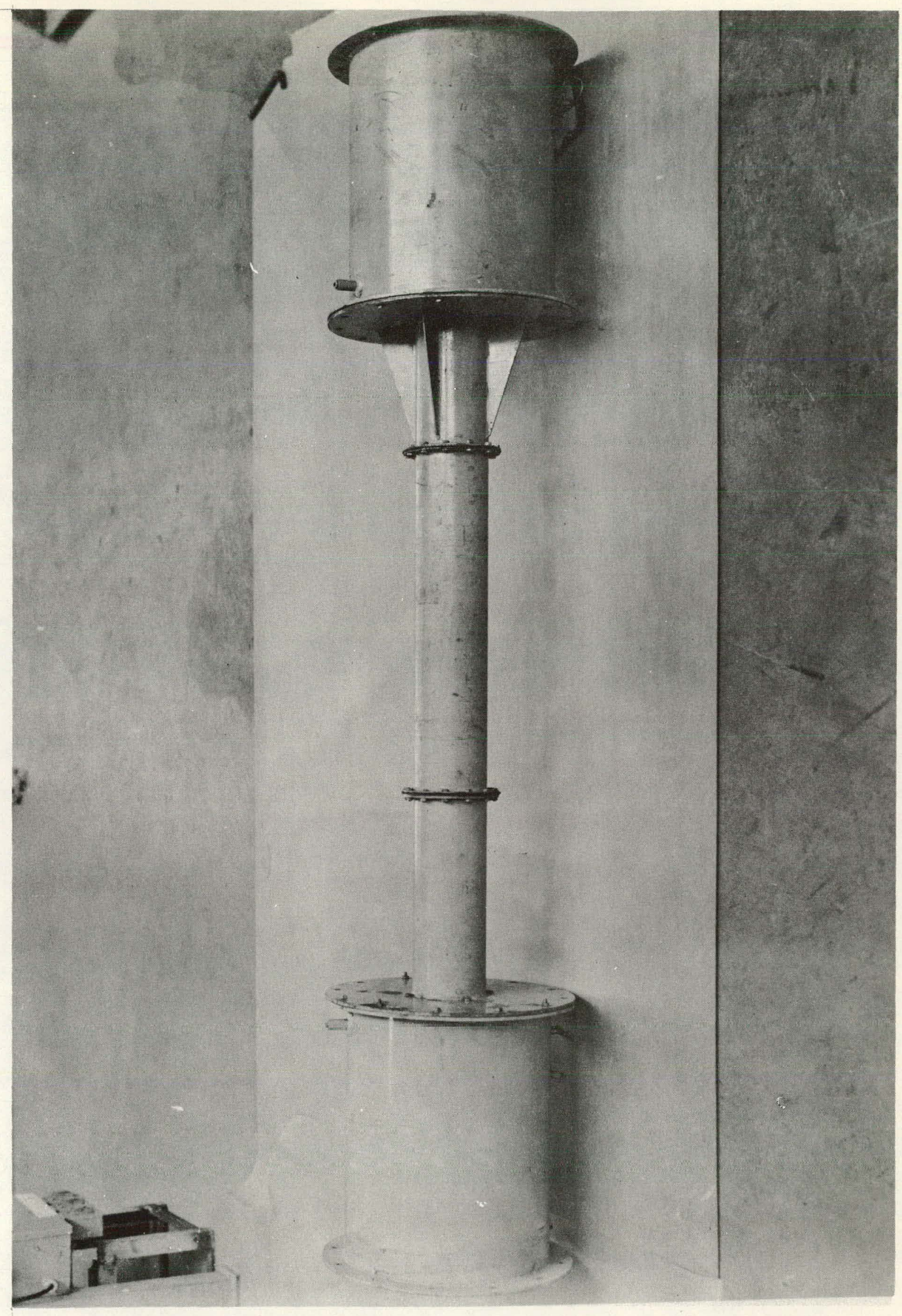

Fig. 3-2 SM-2 Control Rod Test Section 
THIS PAGE

\section{WAS INTENTIONALLY LEFT BLANK}




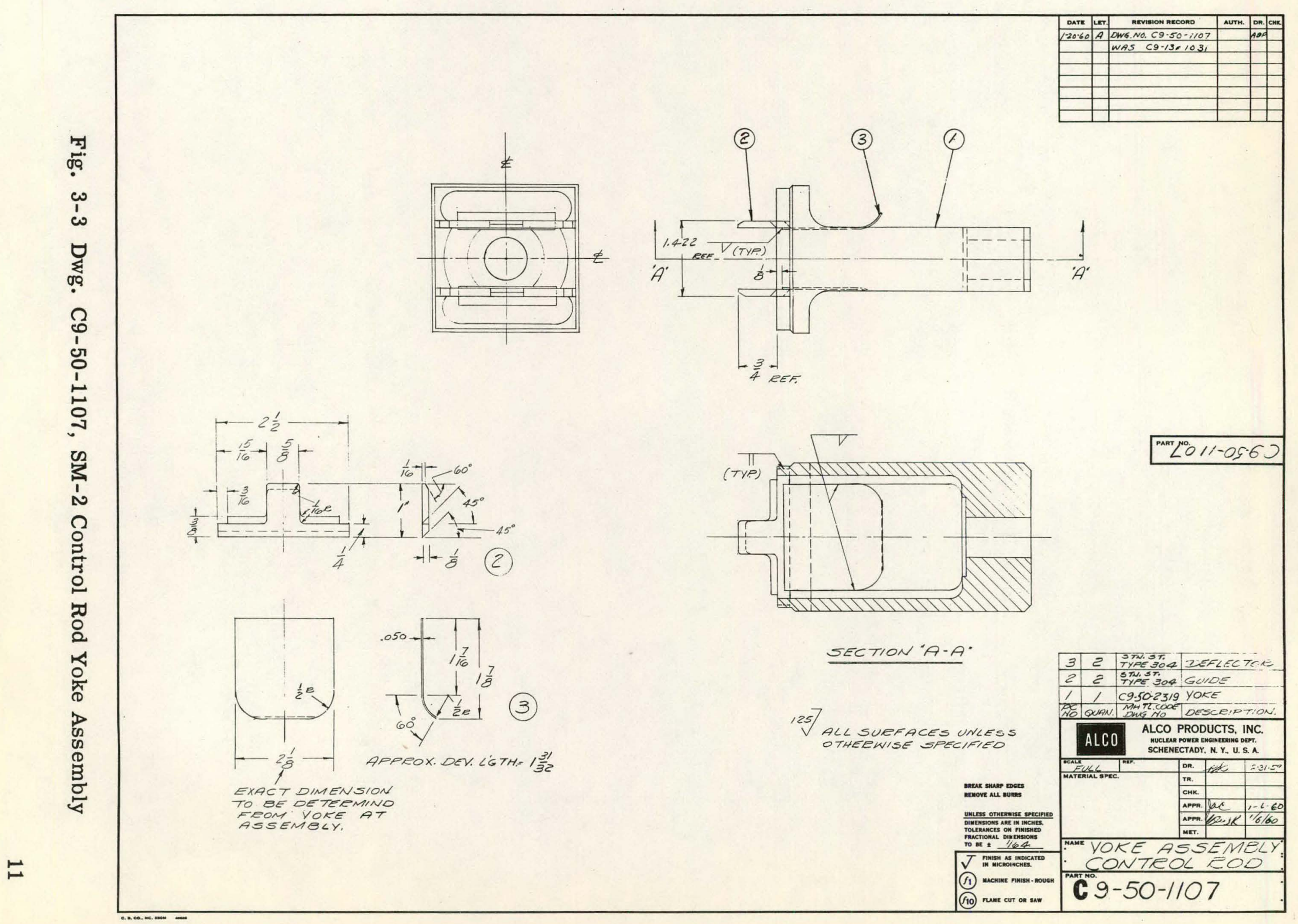


THIS PAGE

\section{WAS INTENTIONALLY \\ LEFT BLANK}




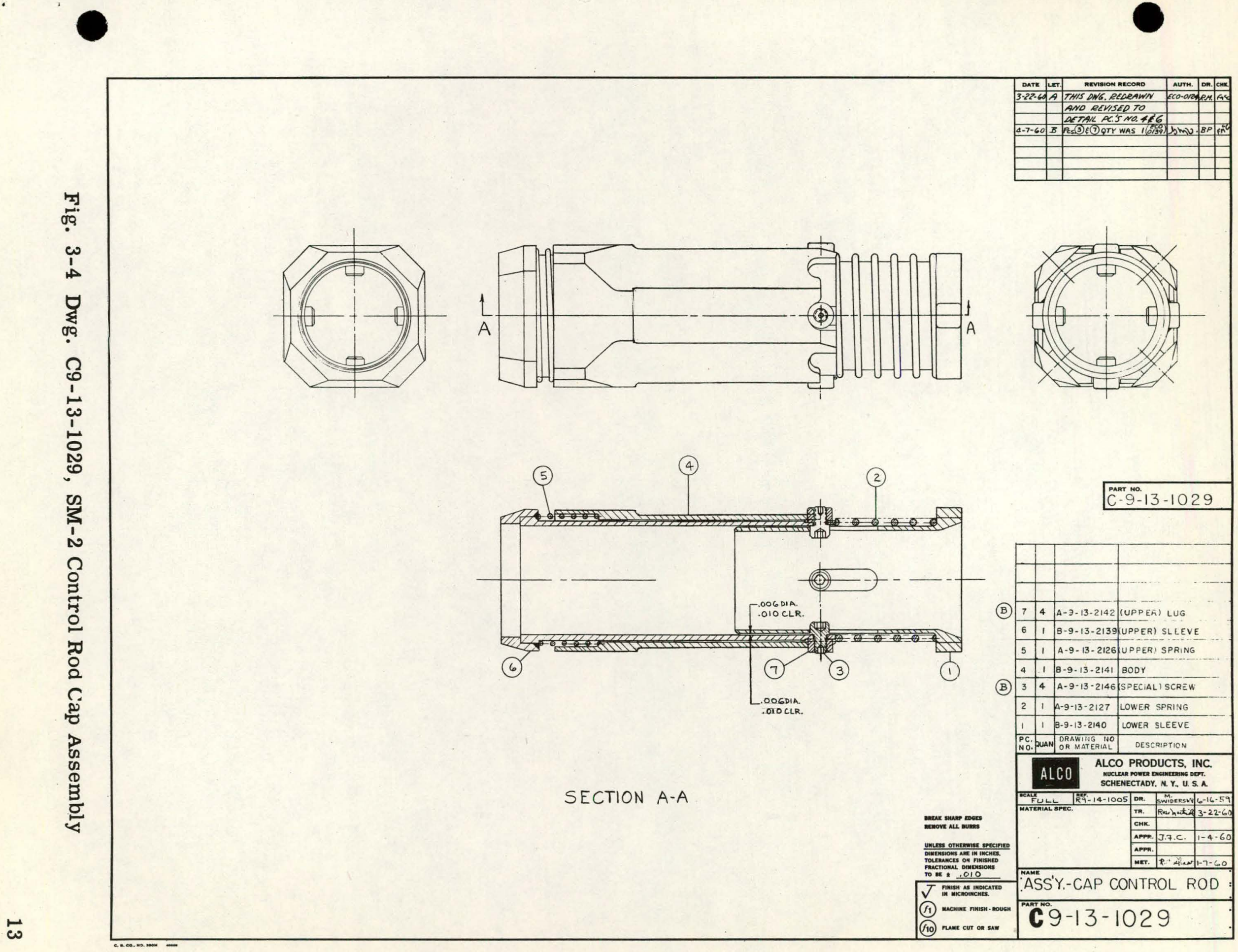


THIS PAGE

\section{WAS INTENTIONALLY LEFT BLANK}


(B)

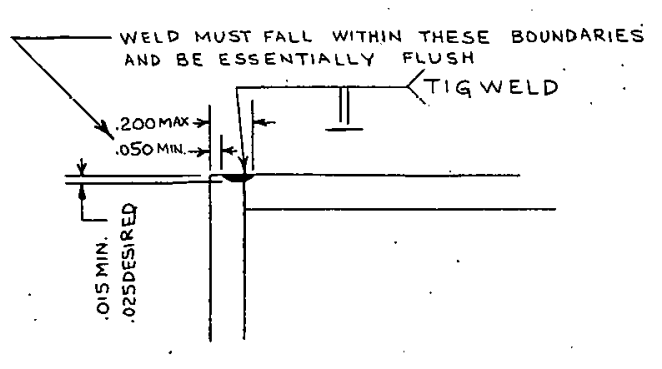

ENLARGED VIEW OF WELD

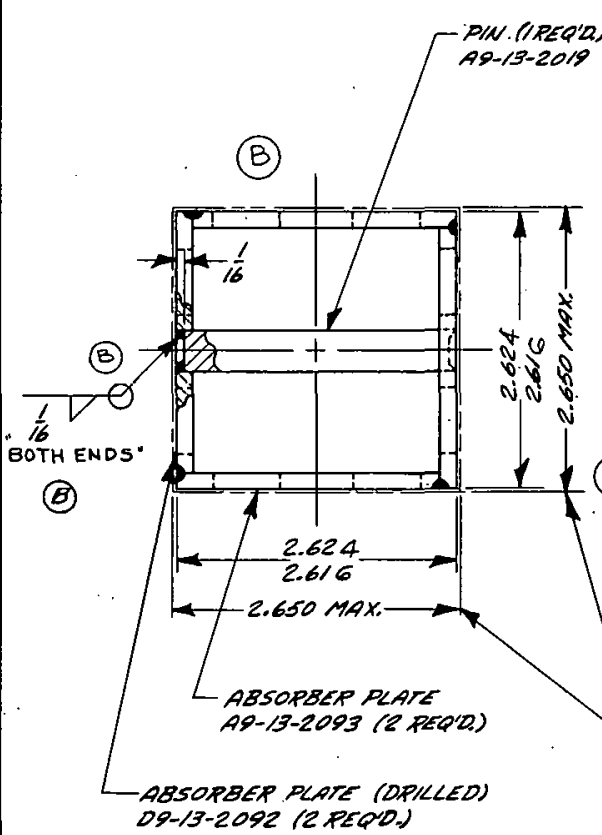

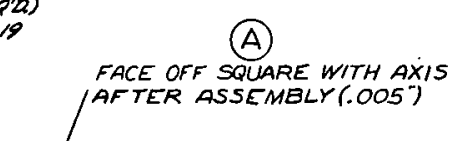

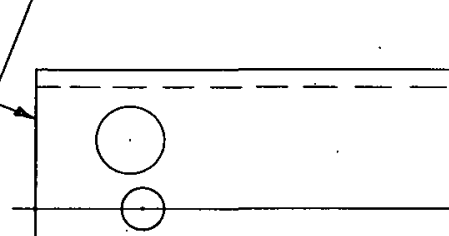

0

(B) 
THIS PAGE

\section{WAS INTENTIONALLY \\ LEFT BLANK}




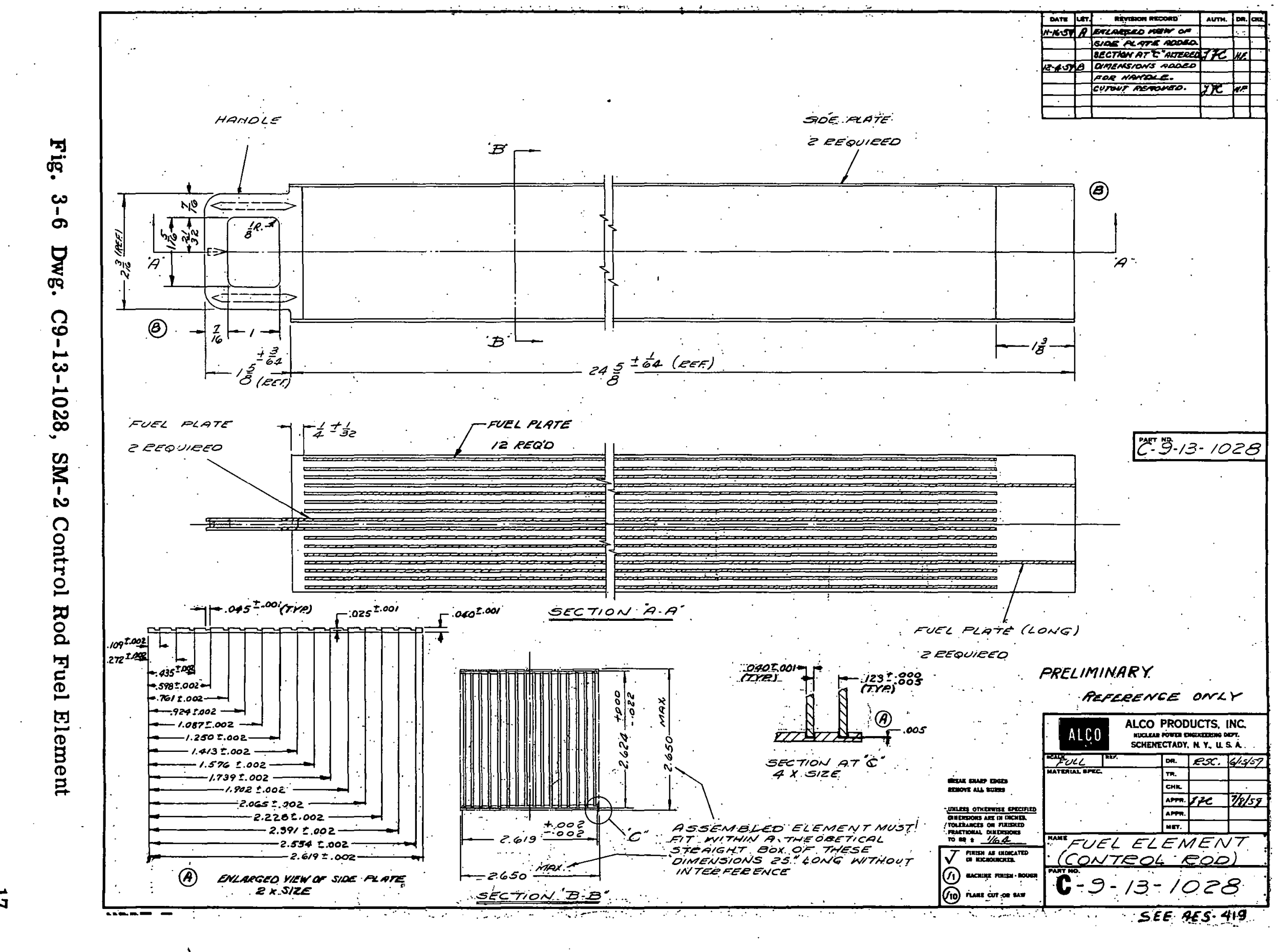


THIS PAGE

\section{WAS INTENTIONALLY \\ LEFT BLANK}




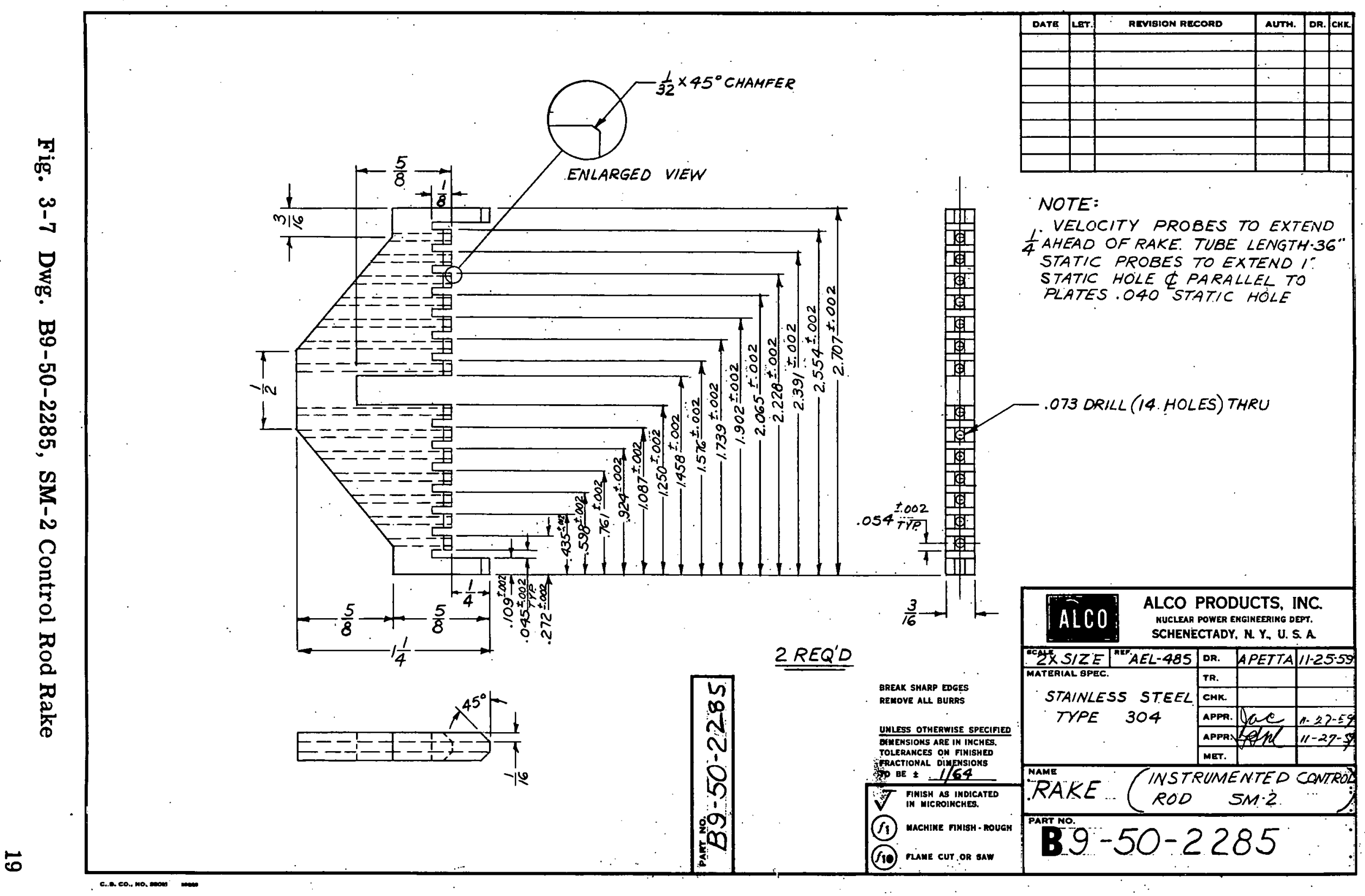


THIS PAGE

\section{WAS INTENTIONALLY LEFT BLANK}




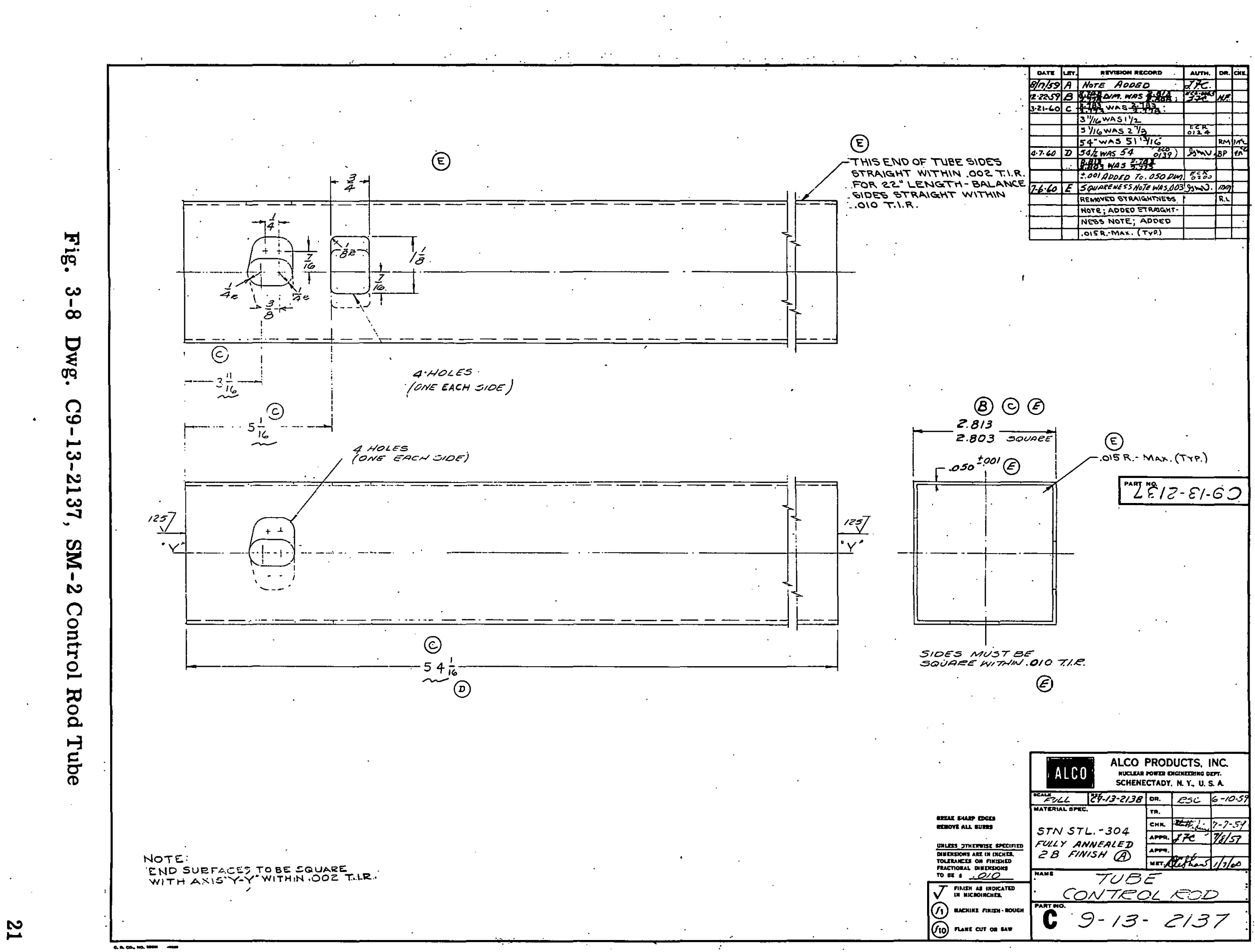


THIS PAGE

\section{WAS INTENTIONALLY LEFT BLANK}







THIS PAGE

WAS INTENTIONALLY

LEFT BLANK 


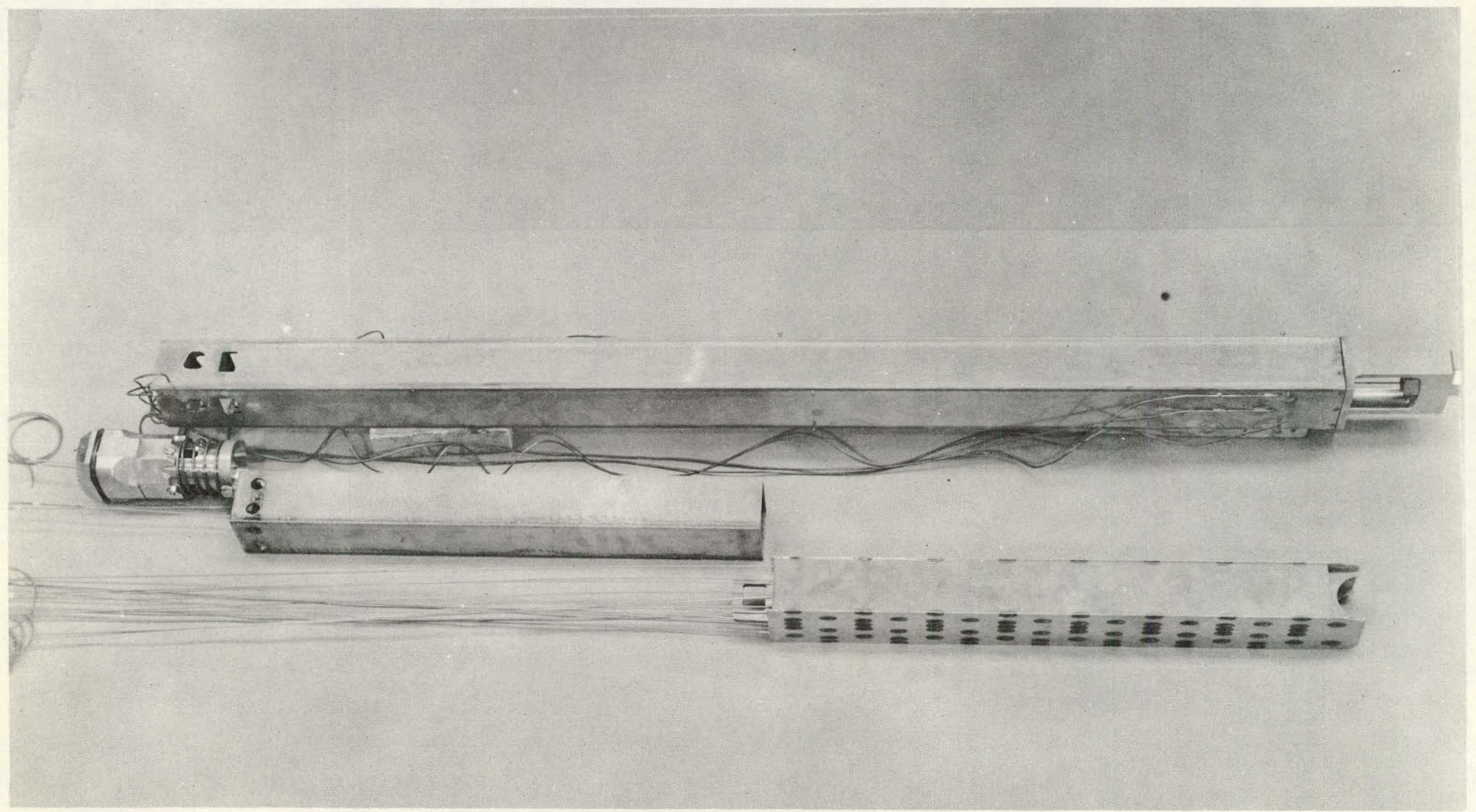




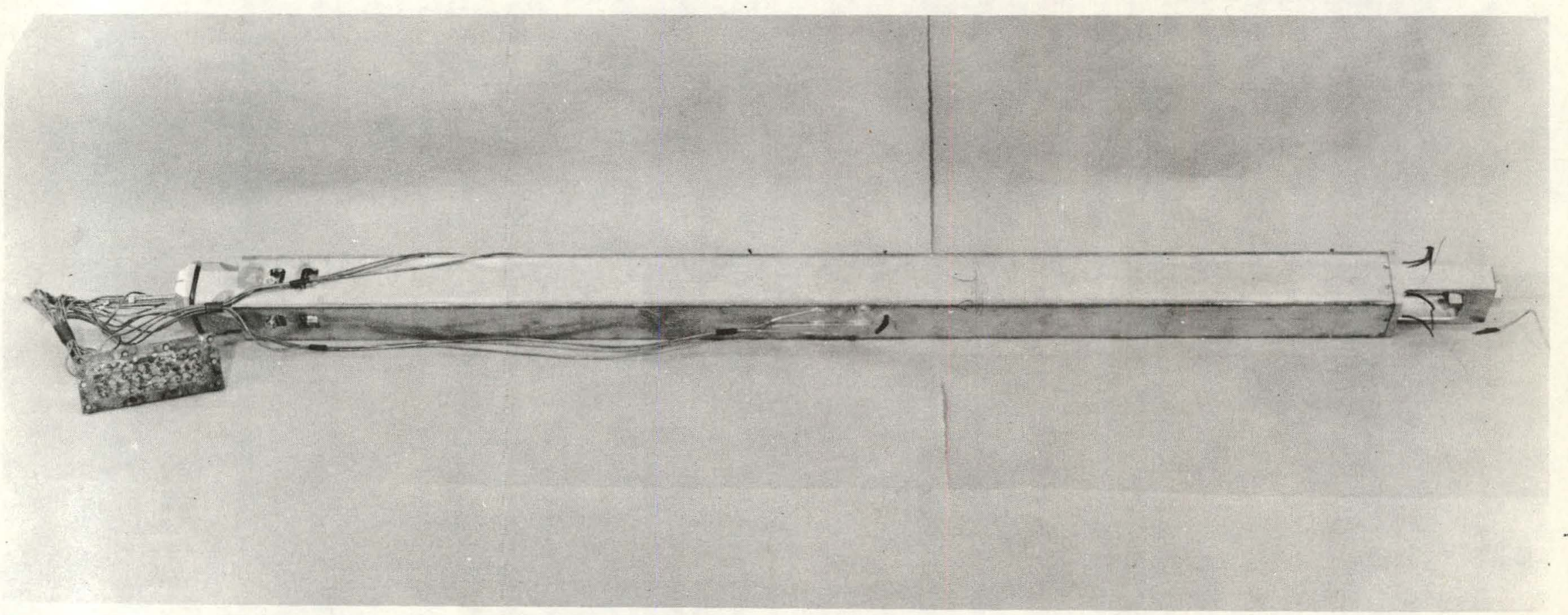

Fig. 3-11 SM-2 Control Rod - As Instrumented (Assembled View) 
Pairs of velocity probes were also located in the cap and absorber (see Fig. 3-9). All probes were connected to a bank of $U$-tube manometers for indication purposes.

\section{3: 3 TEST PROCEDURE}

The test consisted of varying flow rate through the control rod assembly while recording the following data at each flow rate:

1. Total loop flow-gpm

2. Water temperature $={ }^{\circ} F$

3. Velocity pressure - in. $\mathrm{Hg}$
a. In each channel
b. In absorber
c. In cap

4. Static pressure differentials - in. $\mathrm{Hg}$

a. Across inlet yoke

b. Across fuel element and absorber

c. Across cap

d. At exit

e. Overall

Flow rates for this test were $250,300,350$, and $400 \mathrm{gpm}$. A minimum of three comparable runs were taken during each test.

\subsection{TEST RESULTS}

Control rod testing can essentially be described in seven different steps. Each progressive step is described in detail below.

\subsubsection{Test with Control Rod Assembly}

The control rod as originally designed (see Fig. 3-12) gave outer channel flow deficiency greater than $20 \%$ at the design flow rate of $331 \mathrm{gpm}$ when tested. Static pressure drop at this flow rate was $31.5 \mathrm{ft}$ of water at $80^{\circ} \mathrm{F}$.

\subsubsection{Test with First Modification}

To force more flow to the outer channels, the semicircular (radius = 1 in.) cutouts in the front of the two long fuel plates were closed with inserts. 
This raised the velocity in the outer channels slightly and lowered the center channel velocity. No measurable change in static pressure drop from the asdesigned condition was observed.

\subsubsection{Test with Absorber Removed}

The next progressive step in the test program was to determine the effect of the absorber section on outer channel flow of the fuel element. To accomplish this, a test was run with the absorber section removed.

The absorber removal resulted in raising the outer channel velocity to approximately average element velocity。

At this stage of the test program, average channel velocity was not a true average of all element channels since not every channel was instrumented.. Before the next test was run, new instrumentation was installed which featured velocity measuring probes in each of the element flow channels. A more complete picture of the actual flow pattern could then be obtained.

\subsubsection{Retest with First Modification}

The first test using the new instrumentation was made on the control rod as modified for previous tests (see Sec. 3.4.2). Channel flow distribution during this test is shown graphically in Fig. 3-13. Maximum variation from average during this test was $+8 \%$ and $-13.5 \%$ at a flow rate of $350 \mathrm{gpm}$. Since thermal design calculations were based on a maximum control rod flow deviation of $+12 \%$ including actual reactor vessel plenum chamber effects not reproducible in this test, it was apparent that the results obtained in this test were not satisfactory.

\section{4. 5 Test with Yoke Modification}

Since the previous test indicated that the outer channels were receiving insufficient flow (see Fig. 3-13), the next progressive step was to try to improve this outer channel flow deficiency.

To improve flow, deflectors or turning vanes were installed in the yoke section of the control rod (see Fig. 3-14). Channel flow distribution for this test is shown graphically in Fig。 3-15. Comparing the results with the previous test, the improvement in outer channel flow was considerable. The maximum deviation from average was $+7.8 \%$ and $-8.1 \%$ at $350 \mathrm{gpm}$, exclusive of channels 0 and $P$ which were felt to be questionable.

Inspection of the fuel element after testing revealed that the fuel plate between the two questionable channels ( 0 and $P$ ) had actually jumped out of the mating side plate groove. This fuel plate was one of the seven remov- 
able plates which had to be filed to a slightly undersized width in order to be easily removable. It was felt that this was the cause of the questionable flow readings obtained above; so, a retest was initiated.

\subsection{6 . Retest with Fully-Welded Fuel Element}

The test element described above (Sec. 3.4.5) was replaced by a fully welded element to confirm that the abnormal flow distribution was due to the test element itself. Results of this test are shown in Fig. 3-16. Distribution was $+7.0 \%$ and $-7.4 \%$ from the average. A complete tabulation of data obtained from this test is given in Table 3-1.

TABLE 3-1

VELOCITY FLOW DISTRIBUTION RESULTS FOR FINAL SM-2 CONTROL ROD ASSEMBLY TEST

Channel

Identification

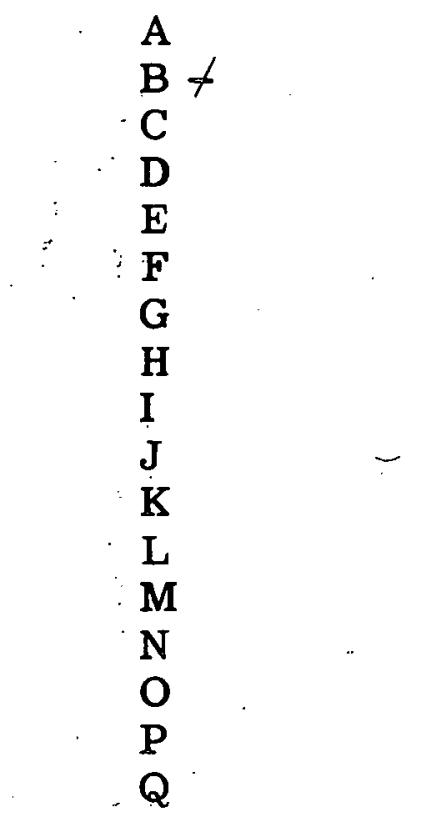

Average

* $=$ High $+7.0 \%$

\begin{tabular}{|c|c|c|c|}
\hline \multicolumn{4}{|c|}{ Nominal Flow Rate - gpm } \\
\hline 250 & $\underline{300}$ & $\underline{350}$ & $\underline{400}$ \\
\hline 16.6 & 19.8 & 23.2 & 26.5 \\
\hline $16.2 t$ & $19.1 t$ & $22.5 t$ & 24.6 \\
\hline 17.5 & 20.6 & 24.2 & 27.5 \\
\hline 18.0 & 21.4 & 25.1 & 28.5 \\
\hline 16.3 & 19.3 & 22.6 & 24. 7 \\
\hline 17.6 & 20.9 & 24.6 & 27.9 \\
\hline 17.7 & 21.0 & 24.6 & 28.0 \\
\hline 17.5 & 20.8 & 24.3 & 27.3 \\
\hline 18.4 & 21.8 & 25.7 & 29.0 \\
\hline 17.3 & 20.6 & 24.2 & 27.5 \\
\hline 17.5 & 20.7 & 24.3 & 27.07 \\
\hline 17. 55 & 20.8 & 24.3 & 27.7 \\
\hline 18.5 $5^{*}$ & 22.2 * & 26.0 * & $29.5 \%$ \\
\hline 17.6 & 21.0 & 24.3 & 27.75 \\
\hline 17.2 & 20.2 & 23.7 & 27.0 \\
\hline 18.0 & 21.5 & 25.3 & 29.4 \\
\hline 17.5 & 20.7 & 24.3 & 27.5 \\
\hline
\end{tabular}


THIS PAGE

\section{WAS INTENTIONALLY LEFT BLANK}




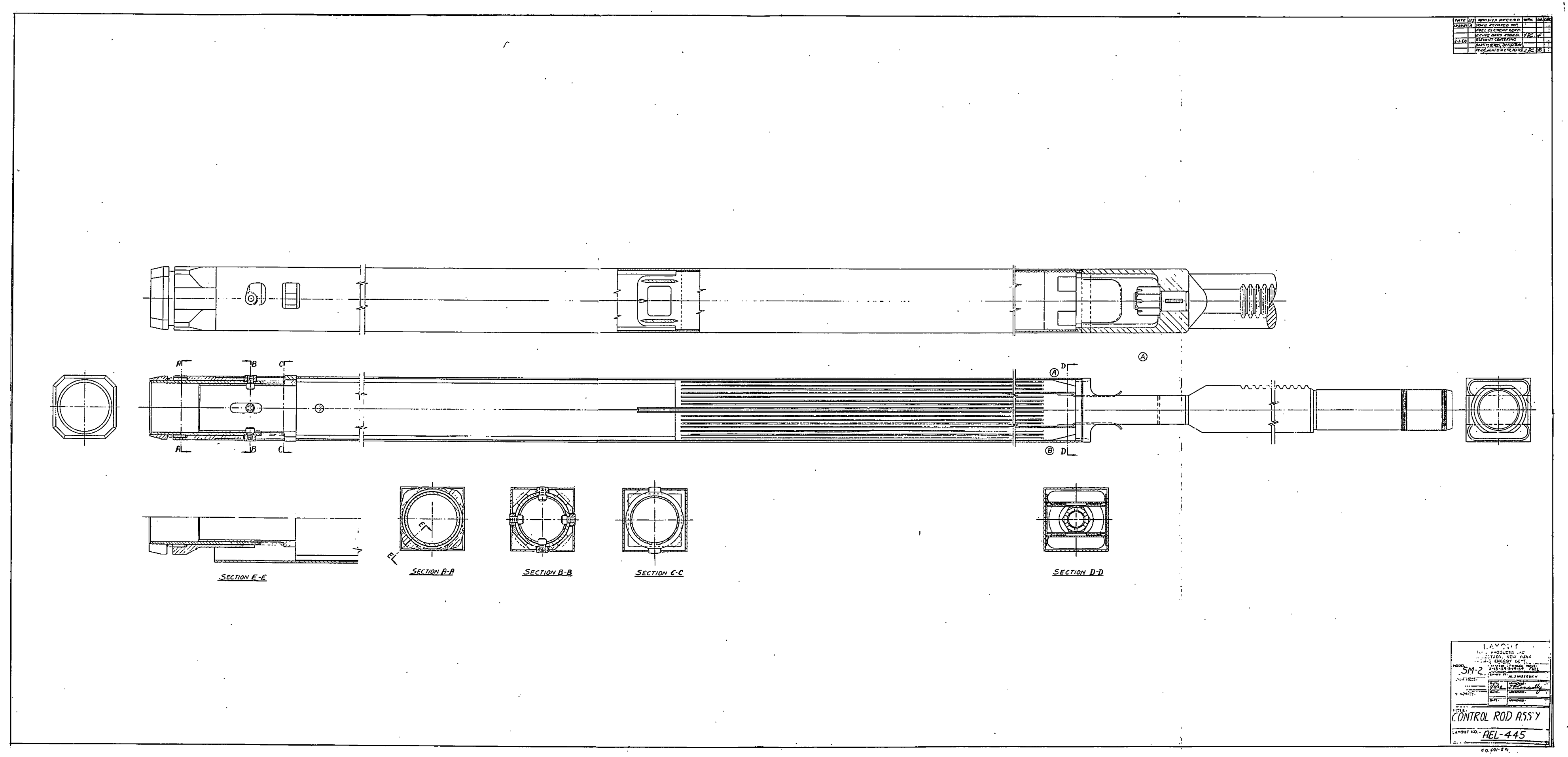

Fig. 3-12 Dwg. AEL-445, Control Rod - Original Pre-Test Design 
THIS PAGE

\section{WAS INTENTIONALLY LEFT BLANK}




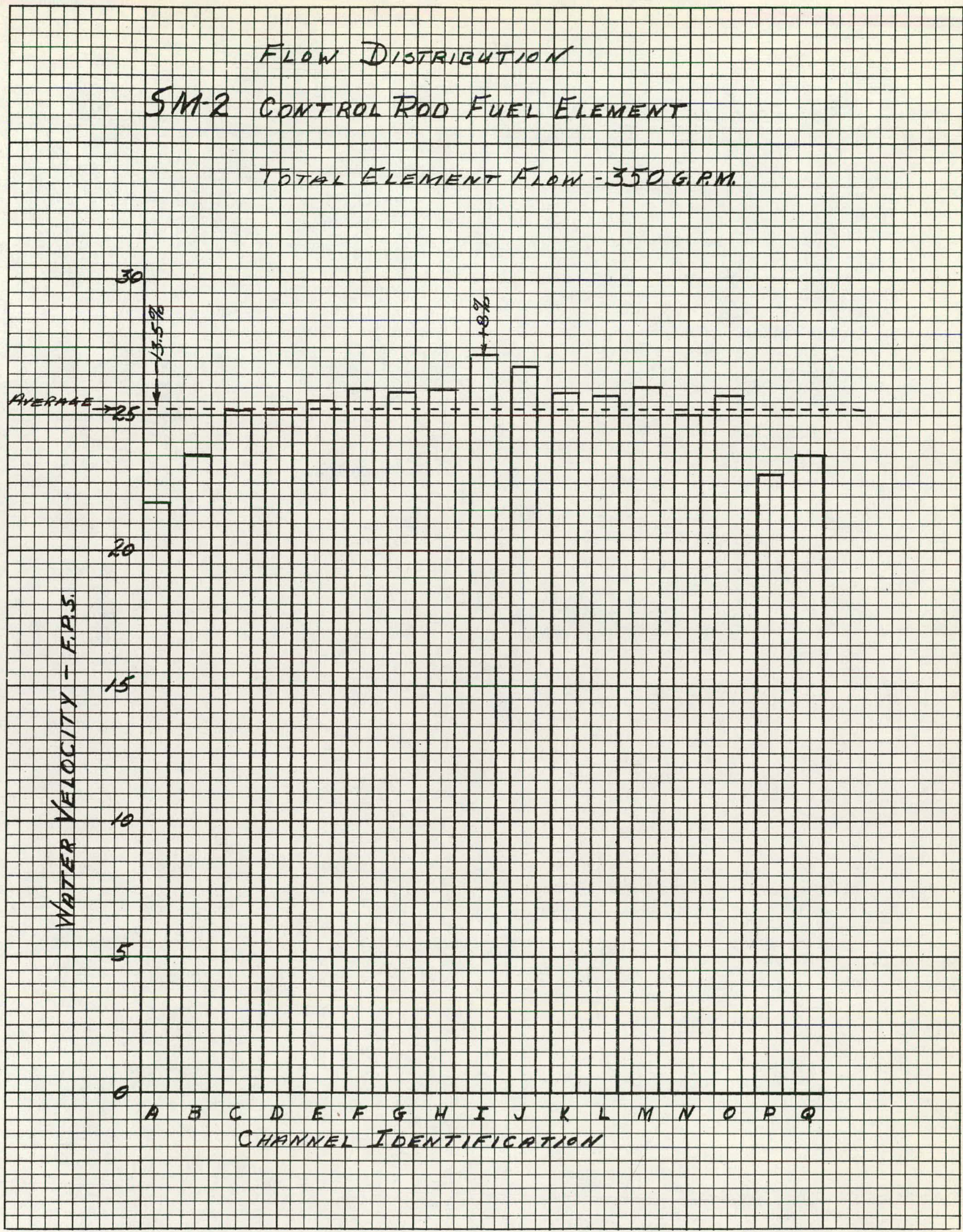

Fig. 3-13 Graphic Profile of Channel to Channel Velocity Distribution For SM-2 Control Rod 


\section{THIS PAGE \\ WAS INTENTIONALLY \\ LEFT BLANK}




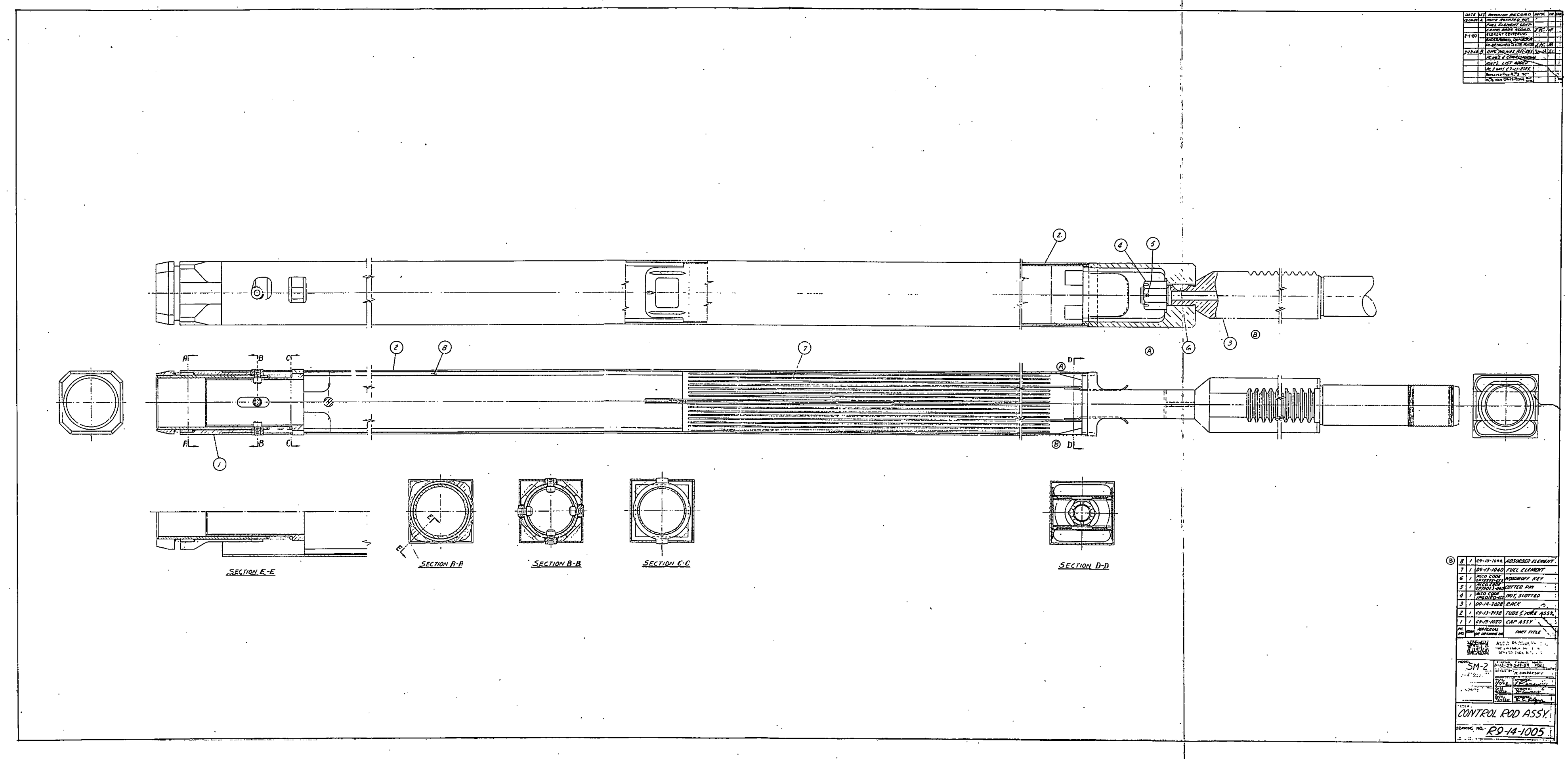

Fig. 3-14 Dwg. R-9-14-1005, Côntrol Rod (With Yoke Modification) Final Design 


\section{THIS PAGE WAS INTENTIONALLY \\ LEFT BLANK}




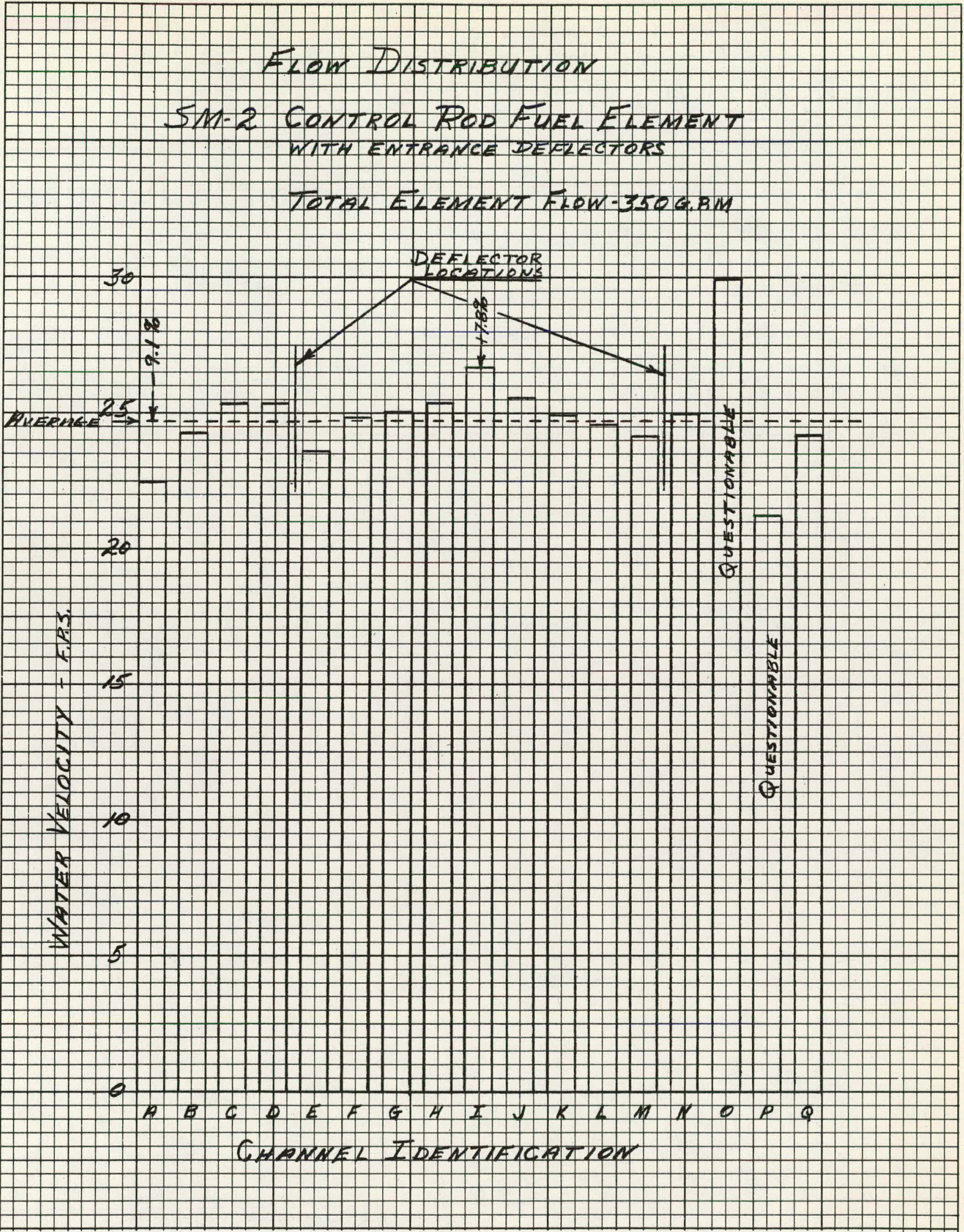

Fig. 3-15 Graphic Profile of Channel to Channel Velocity Distribution for SM-2 Control Rod 


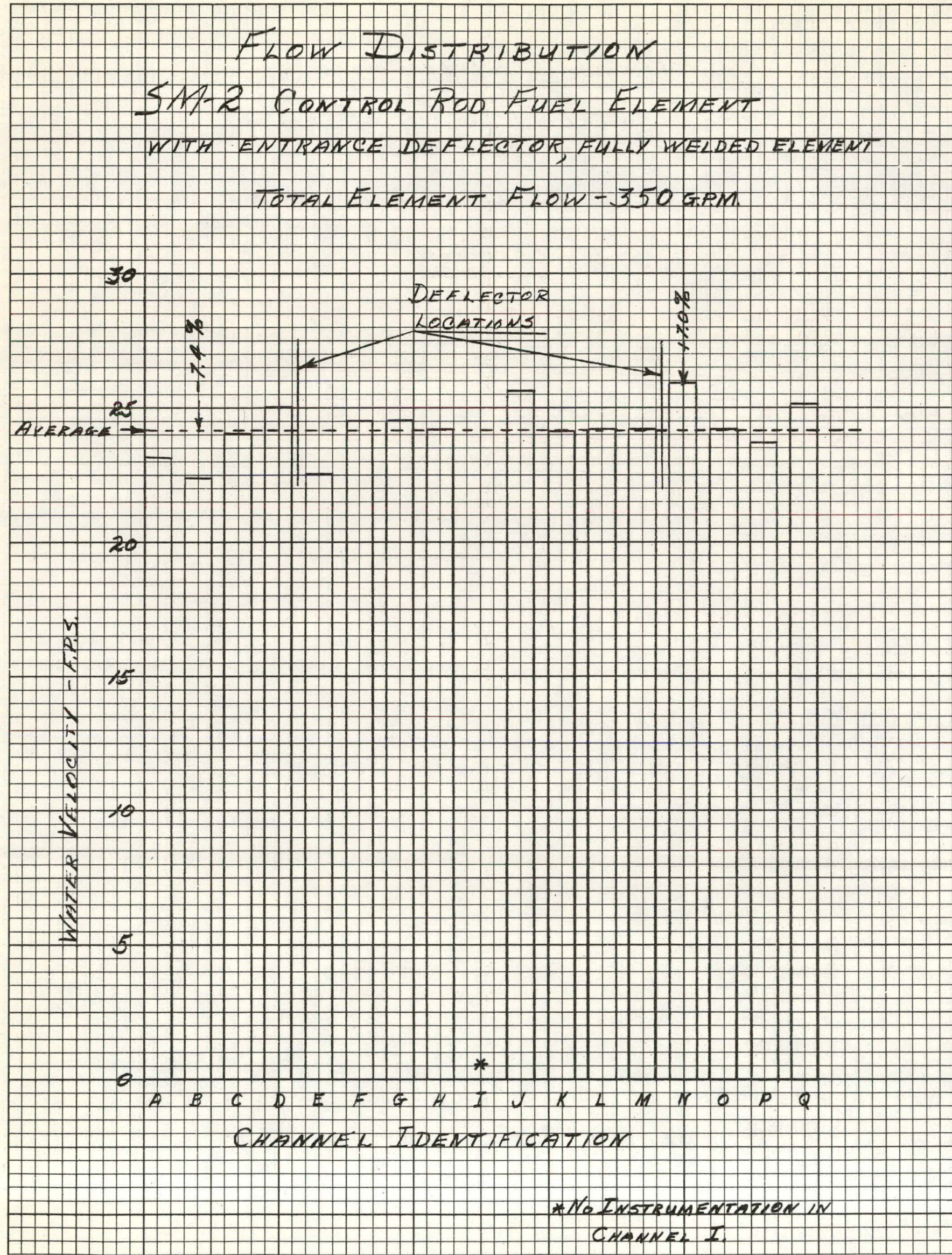

Fig. 3-16 Graphic Profile of Channel to Channel Velocity Distribution for SM-2 Control Rod with Entrance Deflectors and Fully Welded Element - Final Test 
Testing to achieve satisfactory flow distribution ended when the results of the above test were obtained. It was felt that the flow distribution shown in $F_{i g}, 3-16$ is fully adequate to meet SM-2 design requirements. This can be substantiated by two observations:

a. In Fig. 3-15 and 3-16, channels to the right side of the figure have higher flow rates than corresponding channels to the left . This phenomenon has been noticed in previous tests performed in the same test section and is thought to be caused by a maldistribution of flow entering the test section. Therefore, since the control rod is symmetrical about the center channel, if flow through channels $\mathrm{B}$ and $\mathbf{P}$ and $\mathrm{D}$ and $\mathrm{N}$ are averaged, maximum deviation from element average becomes $\pm 5.0 \%$ 。

b. Outer channels (A and $Q$ ), where flux peaks occur, receive essentially average element flow rates (see Fig. $3-15$ and $3-16$ ), This is a considerable improvement over the condition shown in Fig. 3-13 where channel A was $13.5 \%$ below average.

\subsubsection{Pressure Drop Testing}

Static pressure losses through the various components were measured during each of the above flow distribution tests. This was done to evaluate the effect of design changes on pressure drop even though the readings were known to be in error because of the heavy concentration of velocity probes and their leads.

For the final test of the program, the velocity instrumentation was removed from the fuel element to obtain accurate pressure drop data.

Results of the above described test are shown graphically in Fig. 3-17 through 3-21. Based on these curves the following are the experimenatal values of static pressure drop at a rod flow of $331 \mathrm{gpm}$ and $80^{\circ} \mathrm{F}$ 。

Overall pressure drop (plenum to plenum)

Pressure drop across inlet yoke $=29.0 \mathrm{ft} \mathrm{H}_{2} \mathrm{O}$

Pressưfe drop across fuel element and absorber $=8.4 \mathrm{ft} \mathrm{H}_{2} \mathrm{O}$

Pressure drop through cap (up to discharge plane)

Exit static pressure regain

* Negative pressure loss indicates a static pressure regain as flow expands into the exit plenum chamber. 


\section{THIS PAGE WAS INTENTIONALLY LEFT BLANK}




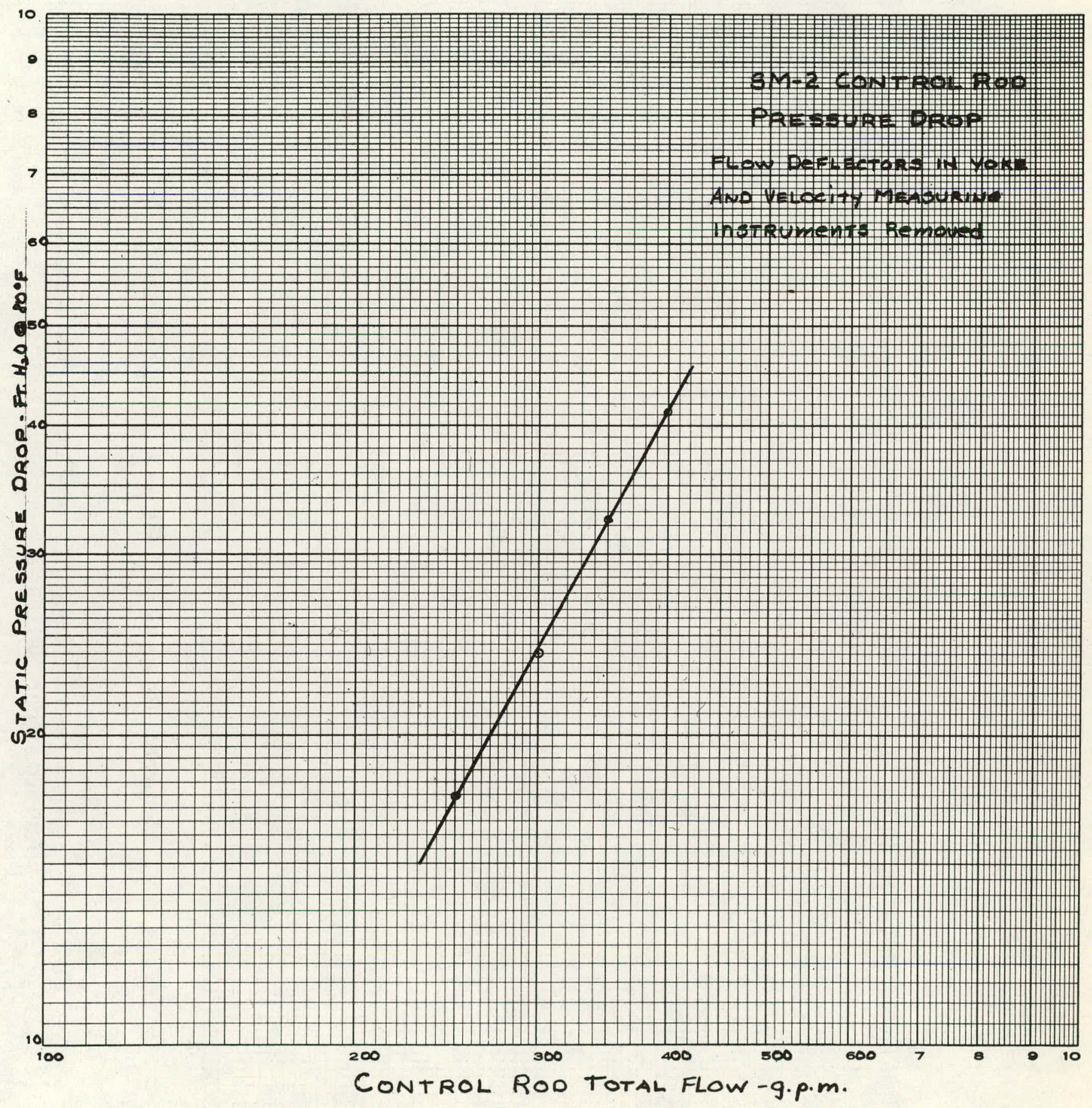

Fig. 3-17 Static Pressure Drop Across Control Rod Cap Vs. Flow 


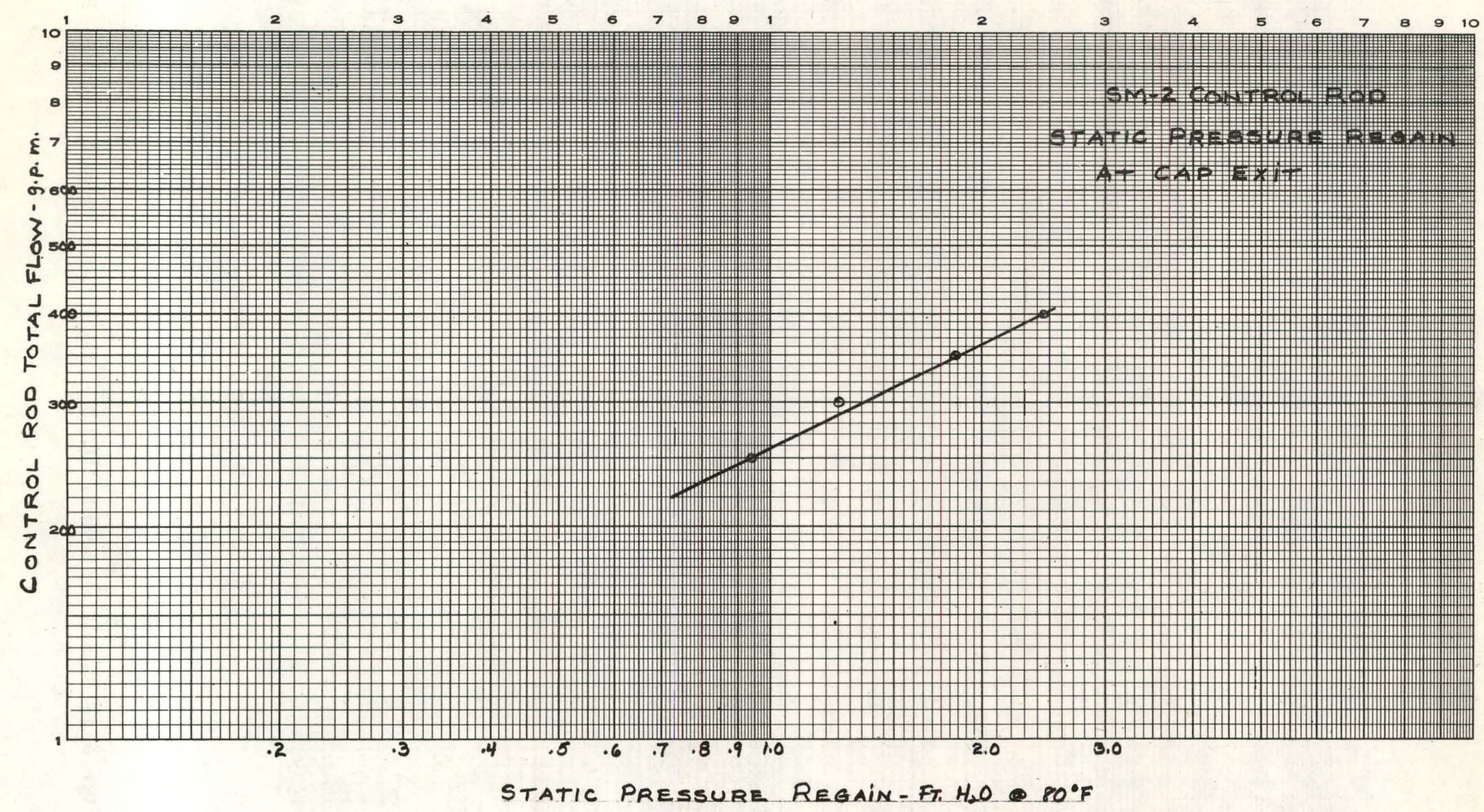

Fig. 3-18 Static Pressure Drop Across Control Rod Fuel Element And Absorber Vs. Flow 


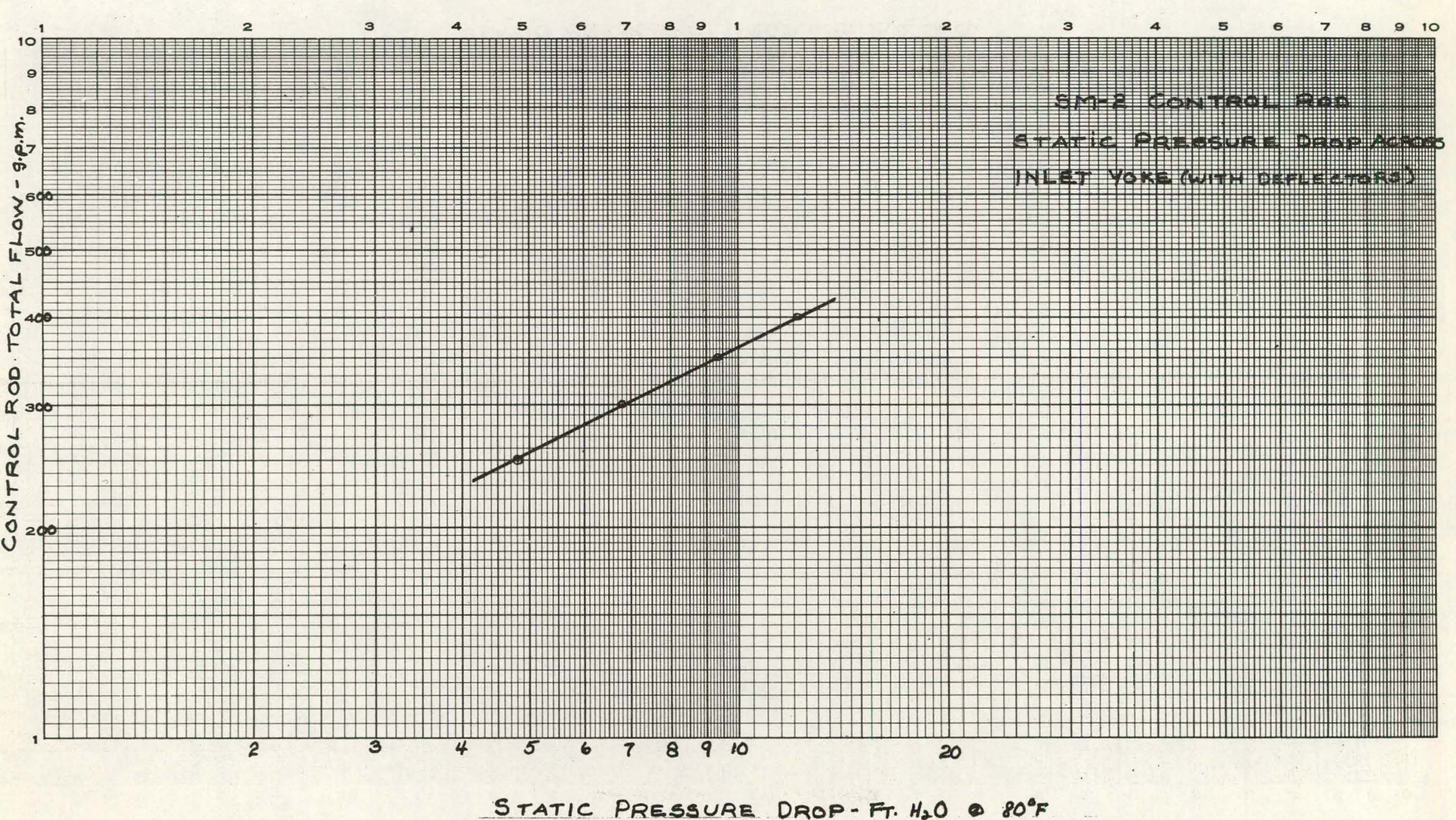




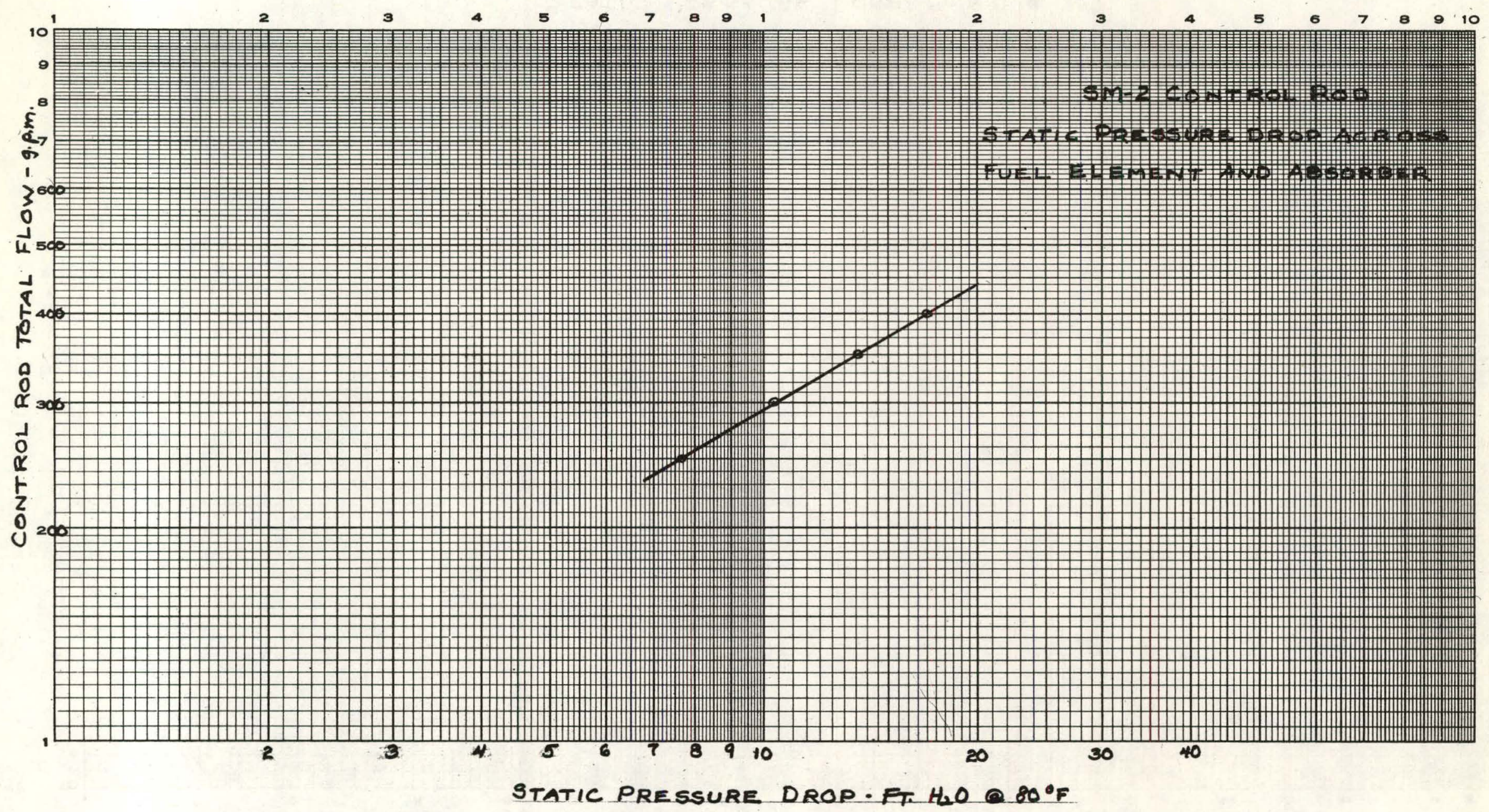

Fig. 3-20 Static Pressure Drop Across Control Rod Inlet Yoke Vs. Flow 


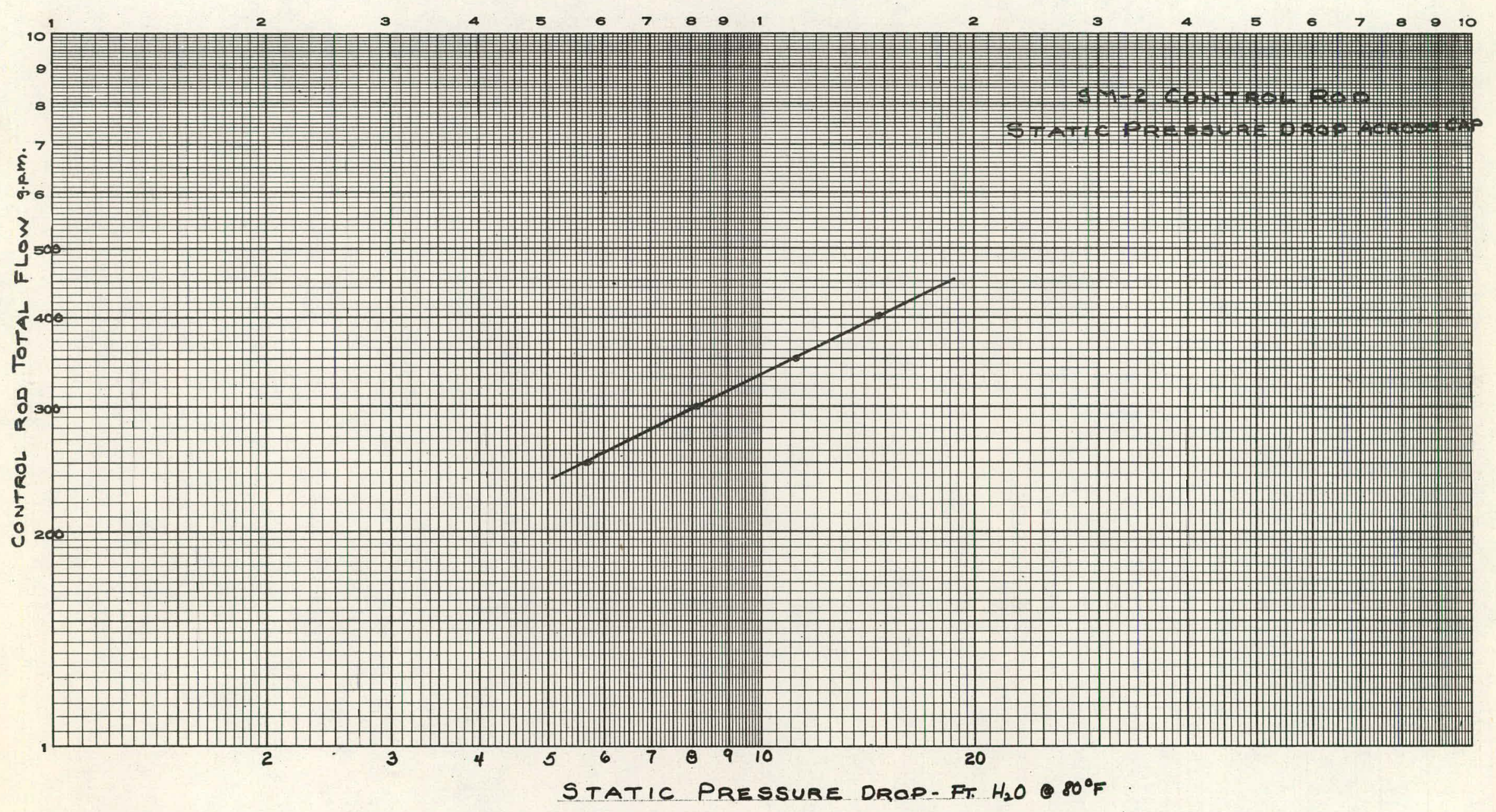


THIS PAGE

\section{WAS INTENTIONALLY \\ LEFT BLANK}




\section{0 STATIONARY FUEL ELEMENT TESTING IN SINGLE ELEMENT TEST RIG}

\section{1 PURPOSE OF TESTS}

Single element flow testing of stationary fuel elements had the following basịc objectives:

a. Experimentally determine the coolant flow distribution within the element for various core support designs. - Distribution tolerance for the SM-2 was set at $\pm 6 \%$ of element average.

b. Exper imentally determine static pressure drops across the stationary element for various core support designs. The objective of first pass design was minimum pressure drop. Second pass pressure drop had to match control rod pressure drop of $29 \mathrm{ft} \mathrm{H}_{2} \mathrm{O}$ at $331 \mathrm{gpm}$ and $80^{\circ} \mathrm{F}$.

\section{2 DESCRIPTION OF TEST RIG AND INSTRUMENTATION}

The test rig used to perform this testing is shown in Fig, 4-1 and 4-2. The four adjustable by-pass lines on this rig are used to simulate the sharing of flow feed holes by adjacent stationary elements. The stationary. element itself is shown in Fig. 4-3 through 4-5." After the test program was begun, a flow adjuster, shown in Fig. 4-6, was added in an effort to correct maldistribution of flow entering the test section and to give a more direct measure of static pressure in this region.

Unlike control rod testing which had no lattice flow, a lattice box was added which simulated lattice flow in both the active and inactive lattices of the stationary element. The function of the inlet and exit plugs used in each test was to provide a flow hole pattern which represented a small section of both top and bottom core support configurations,

\section{2.1 Instrumentation for Initial Tests}

Instrumentation consisted of static, total and velocity head probes, Static probes were located at the following points during initial testing:

1.: $\mathrm{S}_{1}$ - in entrance plenum chamber

2. $\mathrm{S}_{2}-3 / 4$ in . from inlet plate in lattice " $\mathrm{X}$ " *

3. $\mathrm{S}_{3}-3 / 4$ in $_{\mathrm{o}}$ : from inlet plate within element

4. $\mathrm{S}_{4}-3 / 4$ in. from inlet plate in lattice "Y" $*$

* Lattices " $\mathrm{X}$ " and " $\mathrm{Y}$ " refer to flow passages adjacent to the two outer fuel plates of the element. 


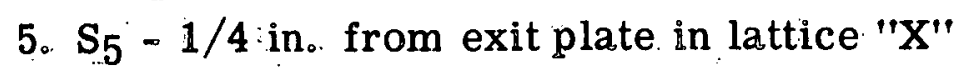

6. $S_{6}-1 / 4$ in. from exit plate within element

7. $57-1 / 4$ in. from exit plate in lattice " $Y$ "

8. $S_{8}$ - in outlet plenum chamber

Total pressure probes were located at the following points during initial testing:

1. T.1 - at inlet plate

2. $\mathrm{T}_{2}$ - at inlet plate, inside element adjacent to $\mathrm{T}_{1}$

3. $\mathbf{T}_{3}$ - at inlet plate inside element adjacent to $\mathbf{T}_{\mathbf{4}}$

4. $\mathrm{T}_{4}$ - at inlet plate outside of lattice. "X"

5. $\mathrm{T}_{5}$ - at center of element in same plane as $\mathrm{T}_{1}$ and $\mathrm{T}_{4}$

Velocity probes were located in a plane near the exit of the plate bundle.

4.2.2 Instrumentation for Remainder of Testing

After the fourth test was run, a change was made in the instrumentation which was used throughout all remaining tests.

Static pressure probes were now located at the following points:

1. $S_{1}$ - inlet plenum chamber

2. $S_{2}$ - inlet - flow adjuster

3. S3 - inlet - fuel element

4. $\mathbf{S}_{4}$ - outlet - fuel element

5. $S_{5}$ - outlet - 5 in. tube

6. $\mathrm{S}_{6}$ - outlet plenum chamber

The total pressure probes were replaced by two pitot tubes:- one adjacent to the " $X$ " lattice and one adjacent to the " $Y$ ". lattice which are considered active lattice passages. Velocity probes were still located in a plane near the exit of the plate bundle. All probes were connected to a bank of $U$-tube 
manometers for indication purposes.

The above mentioned instrumentation was retained throughout the re mainder of the test program.

\section{3 TEST PROCEDURE}

Testing consisted of varying the flow rate through the stationary element while recording the following data at each flow rate:

A. Total loop flow - gpm

B. Water temperature $-{ }^{\mathrm{O}} \mathbf{F}$

C. Velocity pressure head in each channel - in. $\mathrm{Hg}$

D. Static pressure differentials - in. $\mathrm{Hg}$

1. During initial testing (1st four tests)
a. $S_{1}-S_{2}$
b.: $S_{3}-S_{6}$
e. $S_{3}-S_{4}$
c. $S_{1}-S_{3}$
f. $S_{6}-S_{5}$
$d_{\text {. }} \mathrm{S}_{3}-\mathrm{S}_{2}$
g. $\mathrm{S}_{6}-\mathrm{S}_{7}$
h. $S_{6}-S_{8}$

See Section 4, 2:1 for identification of above probes,

2. For remainder of test program
a: $S_{1}-S_{6}$
b. $S_{2}-S_{5}$
c. $\mathrm{S}_{3}-\mathrm{S}_{4}$
d. $\mathrm{s}_{1}-\mathrm{S}_{2}$
e. $S_{5}-S_{6}$

See Section 4.2,2 for identification of above probes.

E. Total Pressures - in. Hg (see Section 4.2.1 and 4.2.2 for identification and location).

Flow rates for this test were $200,250,300,350$, and 400 gpm. A minimum of three comparable runs were taken during each test. 
Before running each test; both test loop and manometers were purged of air to insure correct readings. The loop was purged of air by opening bleed-off valves at various points on the loop until a solid stream of water was running out. "- These valves were then closed. The manometers were purged of air by opening the valve on one leg of the monometer and forcing the column of mercury to full height in the adjacent leg. This procedure was also followed for purging the other leg of the monometer.

\subsection{TEST RESULTS}

The entire stationary element test program cons isted of eighteen different tests which were performed with various styles and combinations of inlet and exit core configurations. A tabulation of these tests is shown below and a complete description of each test will follow. 
TABLE 4-1

FINAL TEST RESULTS FOR STATIONARY ELEMENT TESTING

\begin{tabular}{|c|c|c|c|c|c|}
\hline \multirow{2}{*}{$\begin{array}{l}\text { Test } \\
\text { No. } \\
\end{array}$} & \multirow[b]{2}{*}{ Pass } & \multicolumn{2}{|c|}{$\begin{array}{l}\text { Core Configuration } \\
\text { Style } \\
\end{array}$} & \multirow{2}{*}{$\begin{array}{l}\text { Flow Distribution } \\
\text { Results } \\
\end{array}$} & \multirow{2}{*}{$\begin{array}{l}\text { h Ft } \mathrm{H}_{2} \mathrm{O} \\
\text { at } 350 \\
\text { gpmńnom.Modification - if any }\end{array}$} \\
\hline & & Inlet & Exit & & \\
\hline 1 & $1 \mathrm{st}$ & 46 & 46 & $\begin{array}{l}+9.9 \%,-1.6 \% \\
\text { Lattices: }-21 \&-40 \%\end{array}$ & \\
\hline 2 & $1 \mathrm{st}$ & 6 & 6 & $\begin{array}{l}+3 \%,-5.5 \% \\
\text { Lattices: } 5-10 \% \text { low }\end{array}$ & 19.7 \\
\hline
\end{tabular}

\begin{tabular}{|c|c|c|c|c|}
\hline 3 & 1st & 9 & 6 & $\begin{array}{l}+9 \%,-6.5 \% \\
\text { Low lattice flow }\end{array}$ \\
\hline 4 & 2nd & 9 & $8 b$ & Good lattice flow \\
\hline 5 & 1st & 9 & $9 a$ & $\begin{array}{l}+12 \%,-14.4 \% \\
\text { Lattices above avg. }\end{array}$ \\
\hline 6 & 1st & 9 & $9 a$ & $+10.2 \%,-13.2 \%$ \\
\hline 7 & $1 \mathrm{st}$ & $9 c$ & $9 a$ & $+12.3 \%,-13.9 \%$ \\
\hline 8 & 2nd & $9 c$ & $9 b$ & $+13.2 \%,-15.4 \%$ \\
\hline 9 & 1st & $9 c$ & $9 a$ & $\begin{array}{l}+15.8 \%,-10 \text {. } 1 \% \\
\text { Good lattice flow }\end{array}$ \\
\hline
\end{tabular}

17.9. Added new flow adjuster assem. for this test. See Fig. 4-6

41. 4 New fully welded element used

18. 5 Used fully weldedelement but went to 23 ". outer fuel plates; changed instrumentation as described in Sec. 4. 2. 2; also added end fix's.

18.1 Modified end fixtures

21.6

34

23. 5 Moved end fixture struts from over $3 r d$ to over 5 th plate of element

$\begin{array}{rrrrl}10 & 1 \text { st } & 9 \text { c Rev. A } & 9 a & \begin{array}{l}+7 \%,-9.6 \% \\ \text { Good lattice flow }\end{array} \\ 711 & \text { 1st. } & 9 \mathrm{c} \text { Rev. A } & 9 a & \begin{array}{l}+7.7 \%,-10.7 \% \\ \text { Good lattice flow }\end{array}\end{array}$

24. 6 Rotated inletplug $90^{\circ}$

22.5 Inlet plug back in normal position with continuous pads added along side plate

\begin{tabular}{|c|c|c|c|c|c|c|}
\hline 12 & 1st & $12 \mathrm{a}$ & $9 a$ & $\begin{array}{l}+6 \%,-8.4 \% \\
\text { "X" lattice } 6 \% \text { be- } \\
\text { low average }\end{array}$ & 22.9 & Rotated plug $90^{\circ}$ \\
\hline 13 & 1st & $\begin{array}{l}\text { 9c Rev. A } \\
\text { Modified }\end{array}$ & $9 a$ & $+9.3 \%,-14.4 \%$ & 21.7 & $\begin{array}{l}\text { Made } 4 \text { breakout } \\
\text { holes in plug }\end{array}$ \\
\hline 14 & 2nd & $\begin{array}{l}\text { 9c Rev. A } \\
\text { Modified. }\end{array}$ & $9 b$ & $+10 \%,-8.2 \%$ & & \\
\hline 15 & 2nd & 13 & $9 b$ & $+5.8 \%,-8.2 \%$ & 31.6 & \\
\hline 16 & 2nd & 13 Rev. A & $9 \mathrm{~b}$ & $+5.01 \%,-9 \%$ & 31.1 & \\
\hline 17 & 2nd & 13 Rev. A & $9 \mathrm{~b}$ & $+5.02 \%,-8.6 \%$ & 31.1 & $\begin{array}{l}\text { Exit plug rotated } 180^{\circ} \\
\text { to check instrumenta- } \\
\text { tion }\end{array}$ \\
\hline$* 18$ & 2nd & 13a Rev. A & $\begin{array}{l}\text { 9b } \\
\text { Rev. A }\end{array}$ & $+4.3 \%,-4.5 \%$ & 28.8 & $\begin{array}{l}\text { Three holes in exit } \\
\text { plug opened up to re- } \\
\text { duce overall pressure } \\
\text { drop }\end{array}$ \\
\hline
\end{tabular}

* Final 2nd pass test. \# Final 1st pass test. 
THIS PAGE

\section{WAS INTENTIONALLY \\ LEFT BLANK}




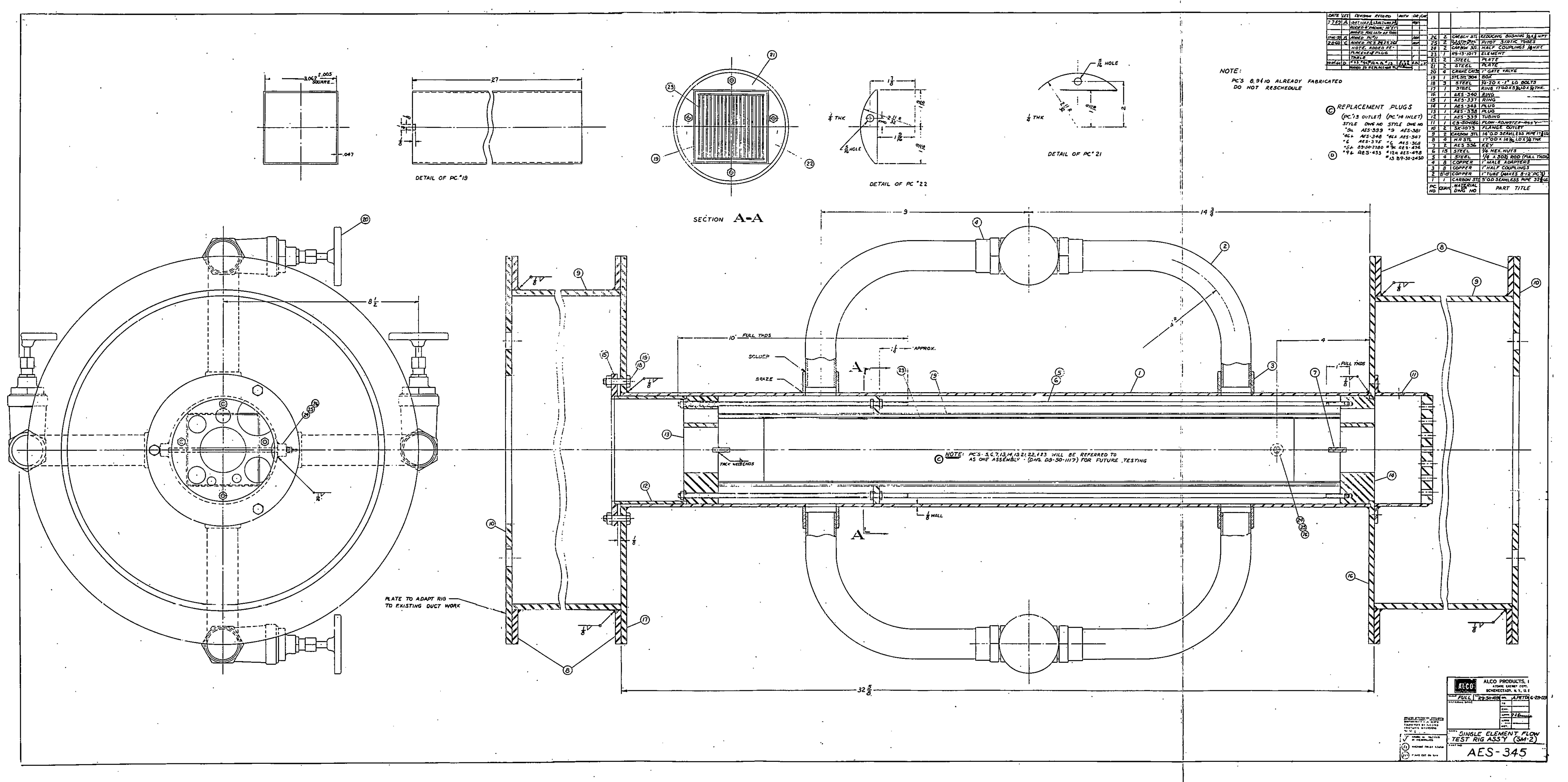




\section{THIS PAGE WAS INTENTIONALLY LEFT BLANK}



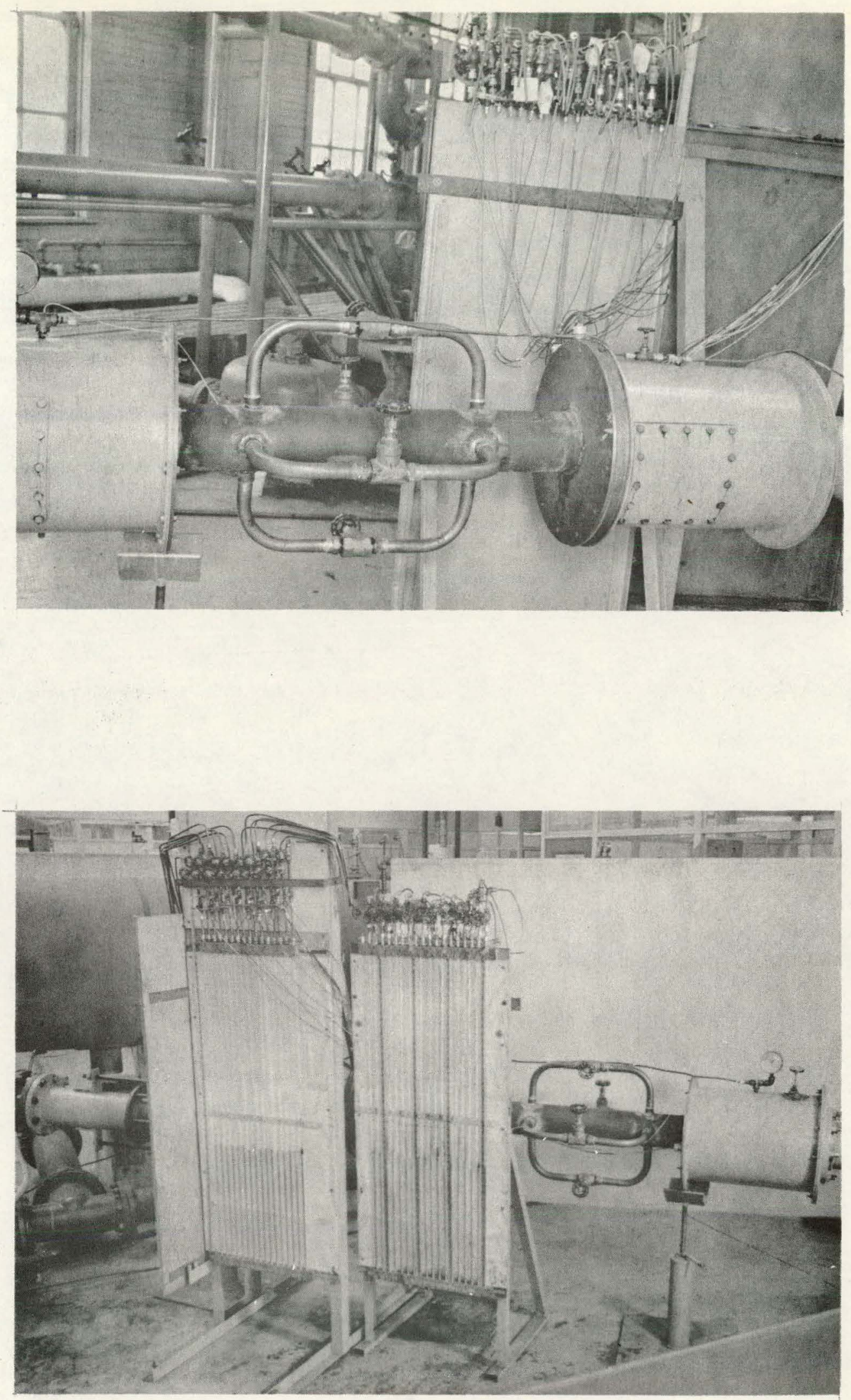

Fig. 4-2 Single Element Flow Test Rig Assembly 


\section{THIS PAGE WAS INTENTIONALLY \\ LEFT BLANK}




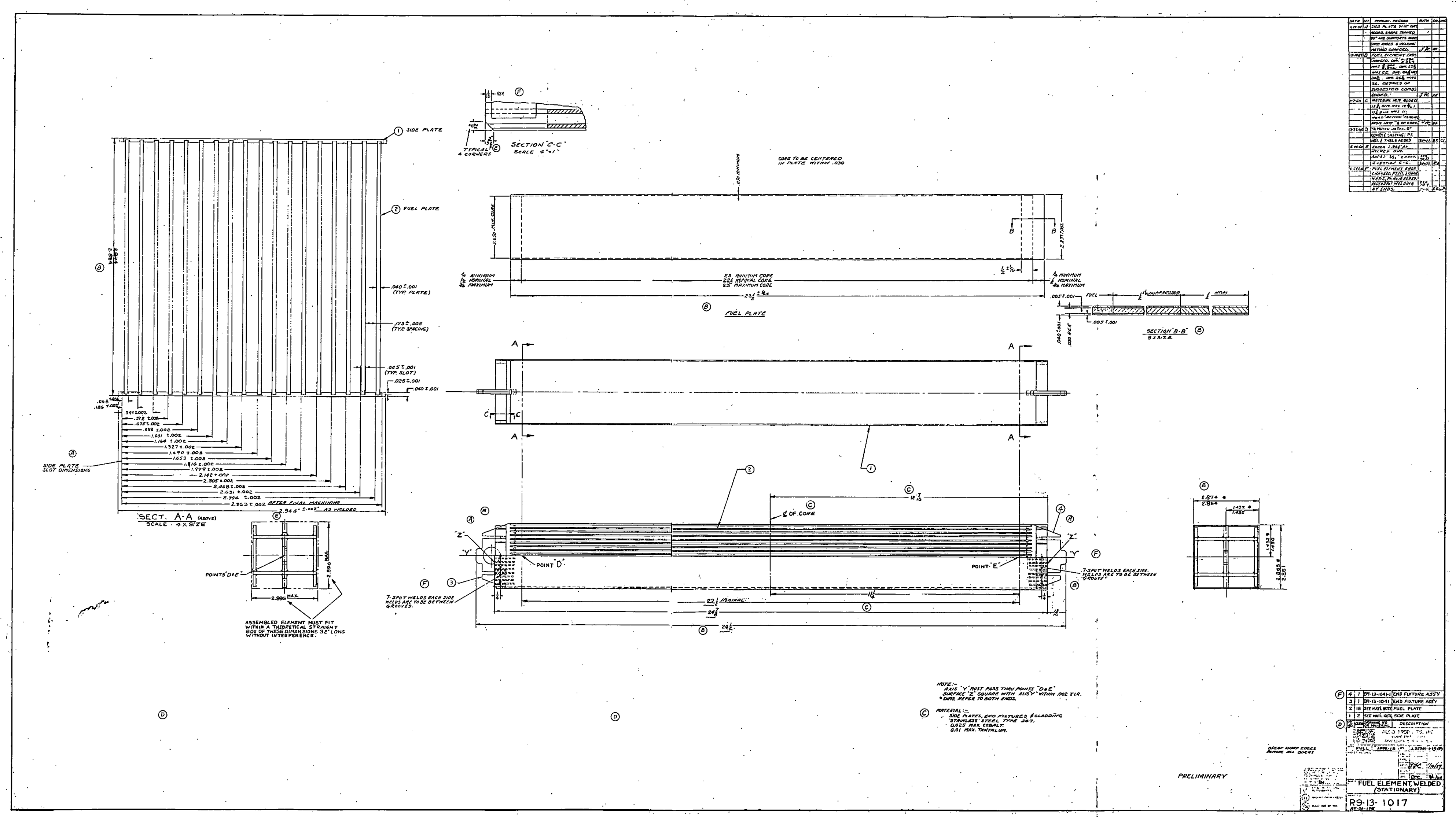


THIS PAGE

\section{WAS INTENTIONALLY \\ LEFT BLANK}




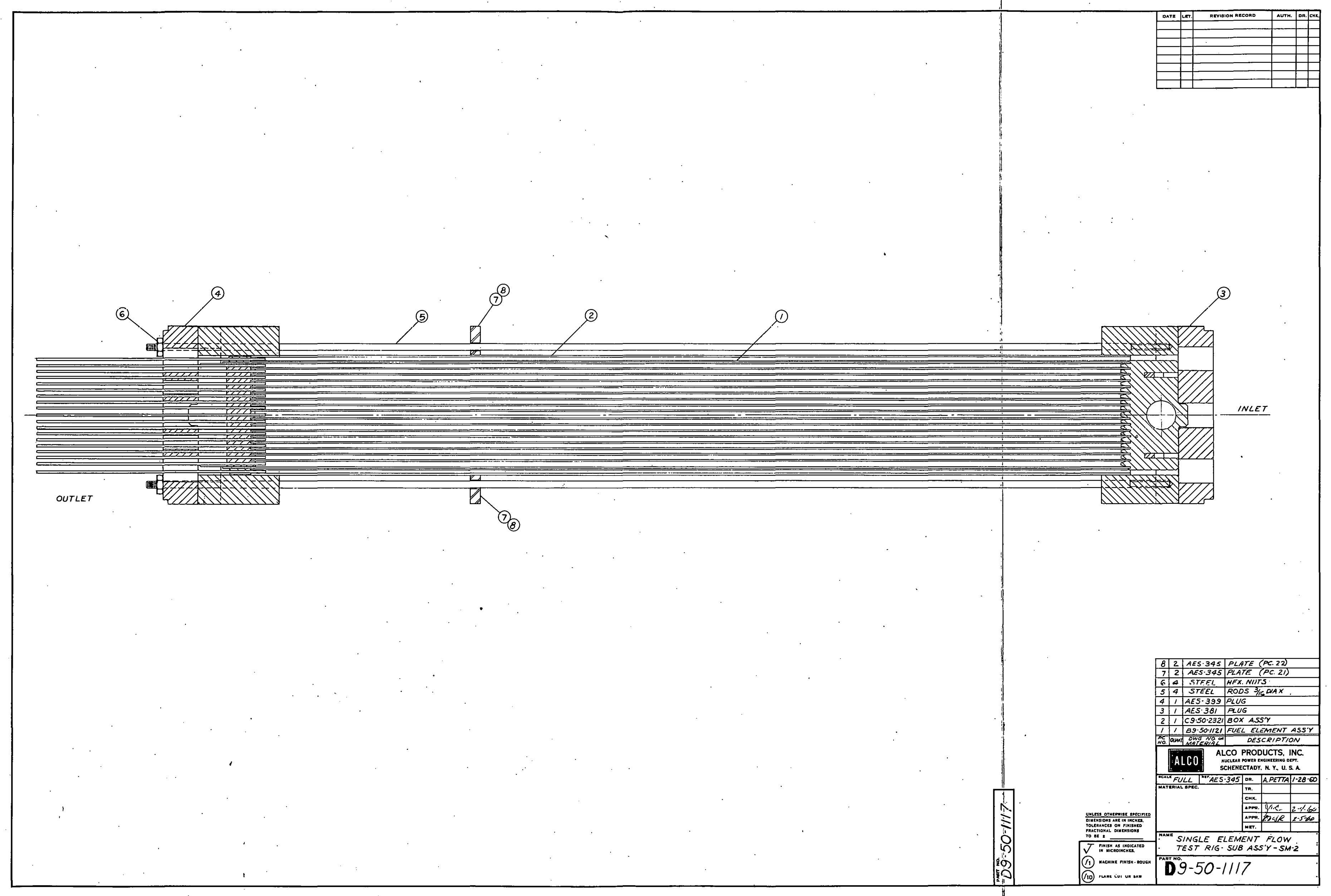

Fig. 4-4 Dwg. D9-50-1117, Single Element Flow Test Rig (Subassembly) 


\section{THIS PAGE WAS INTENTIONALLY LEFT BLANK}




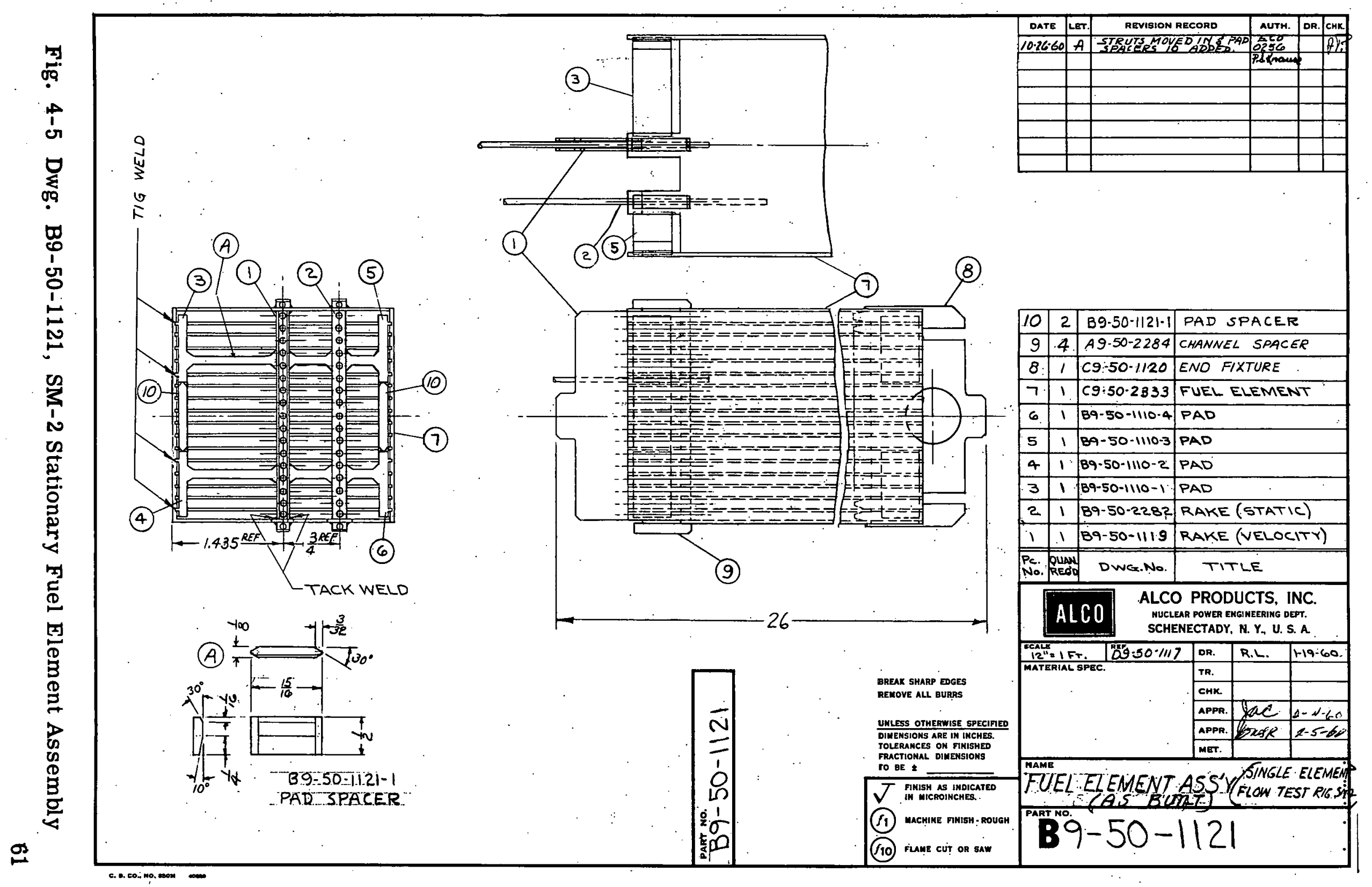




\section{THIS PAGE}

\section{WAS INTENTIONALLY \\ LEFT BLANK}




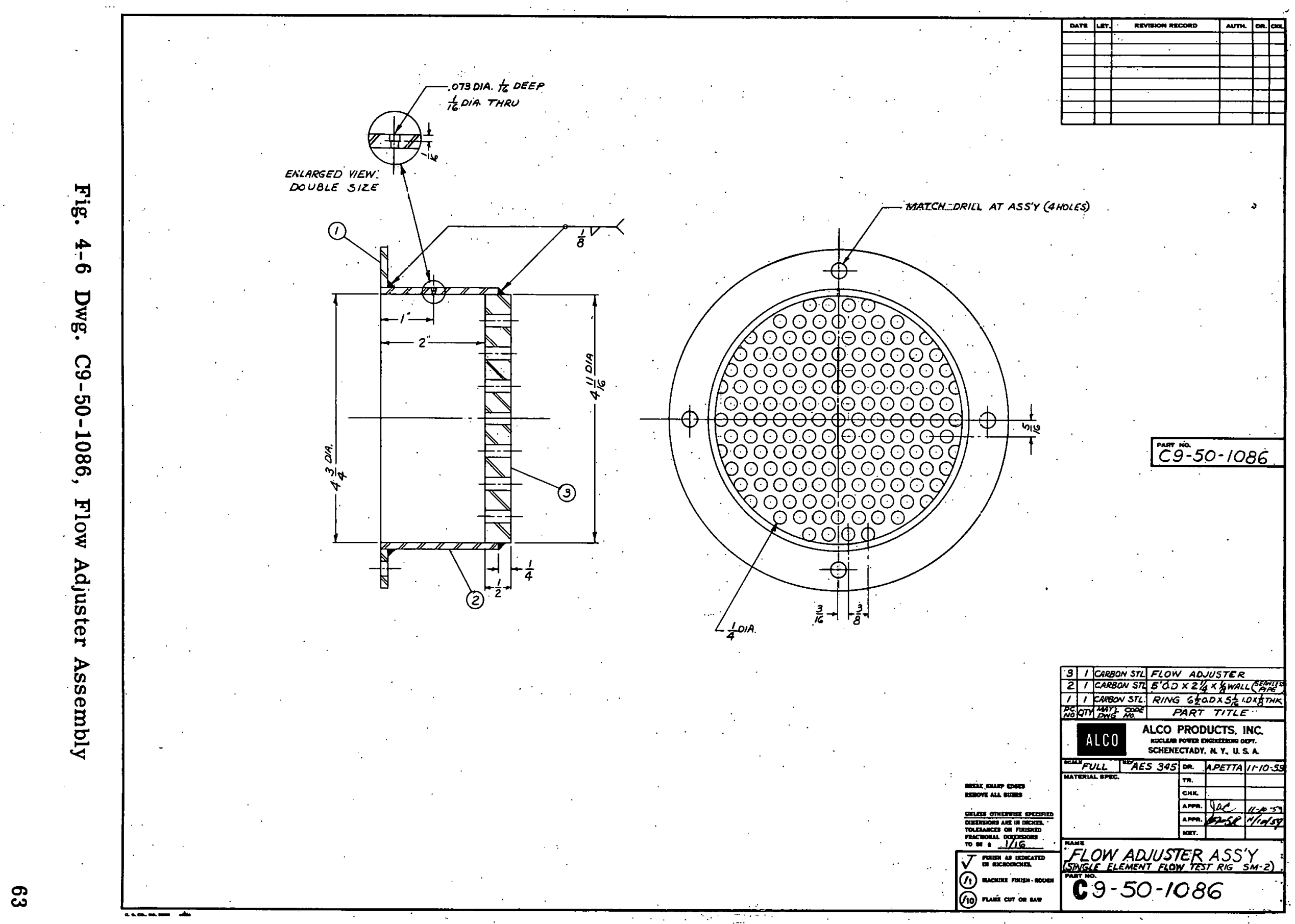




\section{THIS PAGE \\ WAS INTENTIONALLY \\ LEFT BLANK}




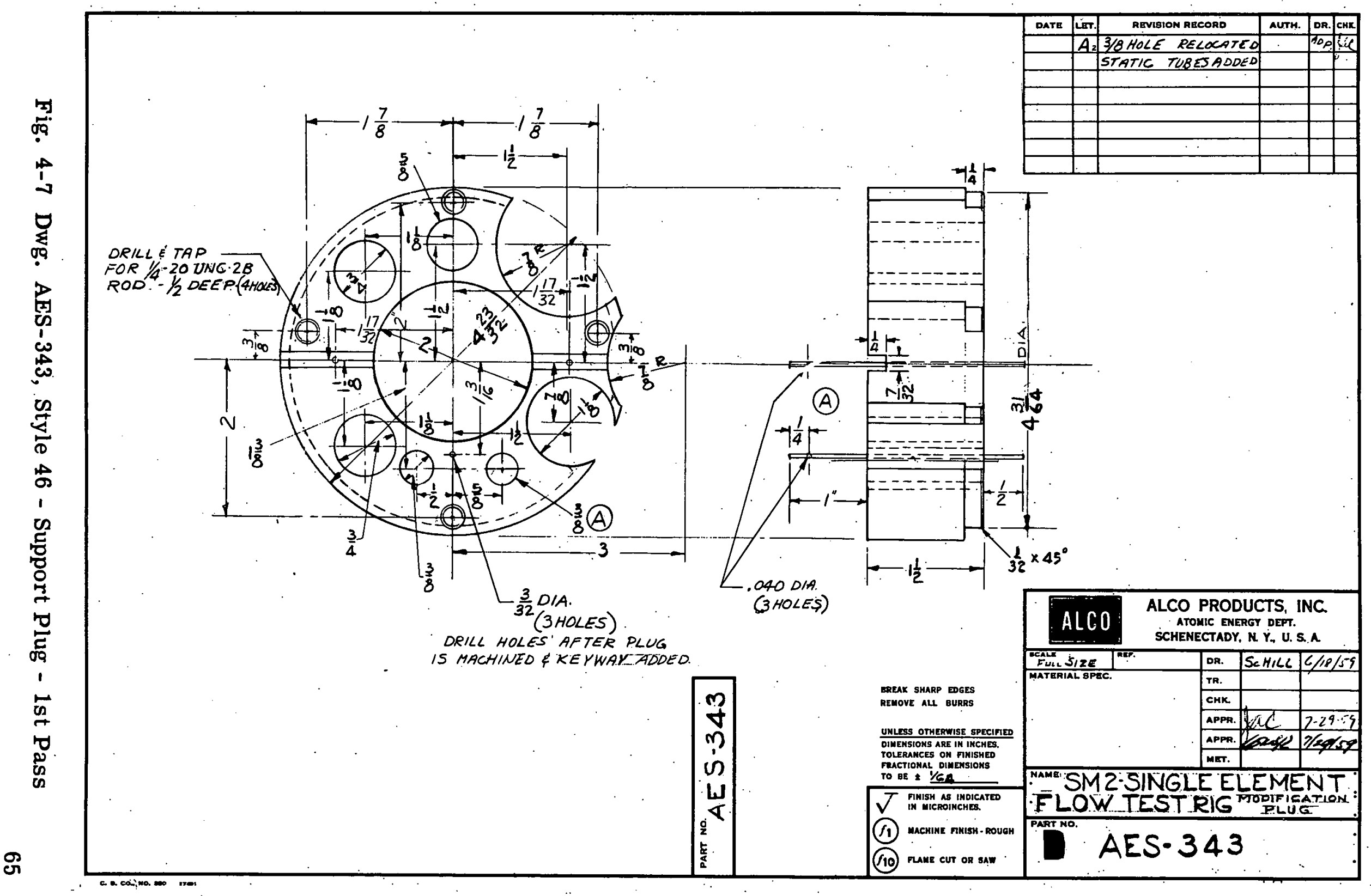




\section{THIS PAGE \\ WAS INTENTIONALLY \\ LEFT BLANK}




\subsection{Test \#1 Style 46 Inlet, . Style 46 Exit (1ist Pass)}

For the first test, a first pass element position at the corner of the core was selected because this position represents the most difficult location for providing adequate feed holes: Style " 46 " (combined features of styles 4 and 6) was the configuration used for both top and bottom core support plates in this test (see Fig. 4-7).

Results of this test at $350 \mathrm{gpm}$ nominal flow rate are plotted in Fig: 4-8. Extremes in the variation of channel velocities were from $+9.9 \%$ to $-1.6 \%$ of average velocity. However, the maximum deviations from average velocity in the two lattices were $-21 \%$ and $-40 \%$ in the " $X$ " and "Y" lattice respectivèly.

Static pressure differentials were measured during this test but proved to be inconclusive since the component pressure drops did not match the overall measured pressure drop.

\section{4. 2 Test \#2 - Style 6 Inlet, Style:6 Outlet (1st Pass)}

For this test, a style 6 grid type core support configuration was used for both top and bottom core plates (see Fig. 4-9).. This design was tested because it was thought to have the best possible chance of meeting the required flow distribution. Test results, plotted in Fig。 4-10, show the lattice flow to be approximately 5 to $10 \%$ below element average. Flow distribution within the element was between $+3 \%$ and $-5.5 \%$ of average at a nominal flow rate of $350 \mathrm{gpm}$.

Overall pressure drop at $350 \mathrm{gpm}$ nominal was $19.7 \mathrm{ft}$ of water.

\subsubsection{Test \#3 - Style 9 Inlet, Style 6 Outlet (1st Pass)}

A modification was made to the test rig prior to the running of this test. The modification consisted of adding a flow adjuster (see Fig. 4-6) at the inlet plenum chamber in an attempt to provide more accurate pressure drop information because the original design caused a contraction pressure loss to be included in the overall drop which was not representative of reactor conditions.

This combination of top and bottom core support plates (see Fig. 4-11 and 4-9) was tested to evaluate the performance of the bottom plate with the least possible influence by the top plate... Velocity distribution was within $+9 \%$ and $-6,5 \%$ of average at a nominal flow rate of $350 \mathrm{gpm}_{\text {. }}$ Velocities are shown plotted in Fig. 4-12. Overall pressure drop at a nominal flowrate of $350 \mathrm{gpm}$ was $17.9 \mathrm{ft}$ water $\left(80^{\circ} \mathrm{F}\right)$. 
THIS PAGE

\section{WAS INTENTIONALLY LEFT BLANK}




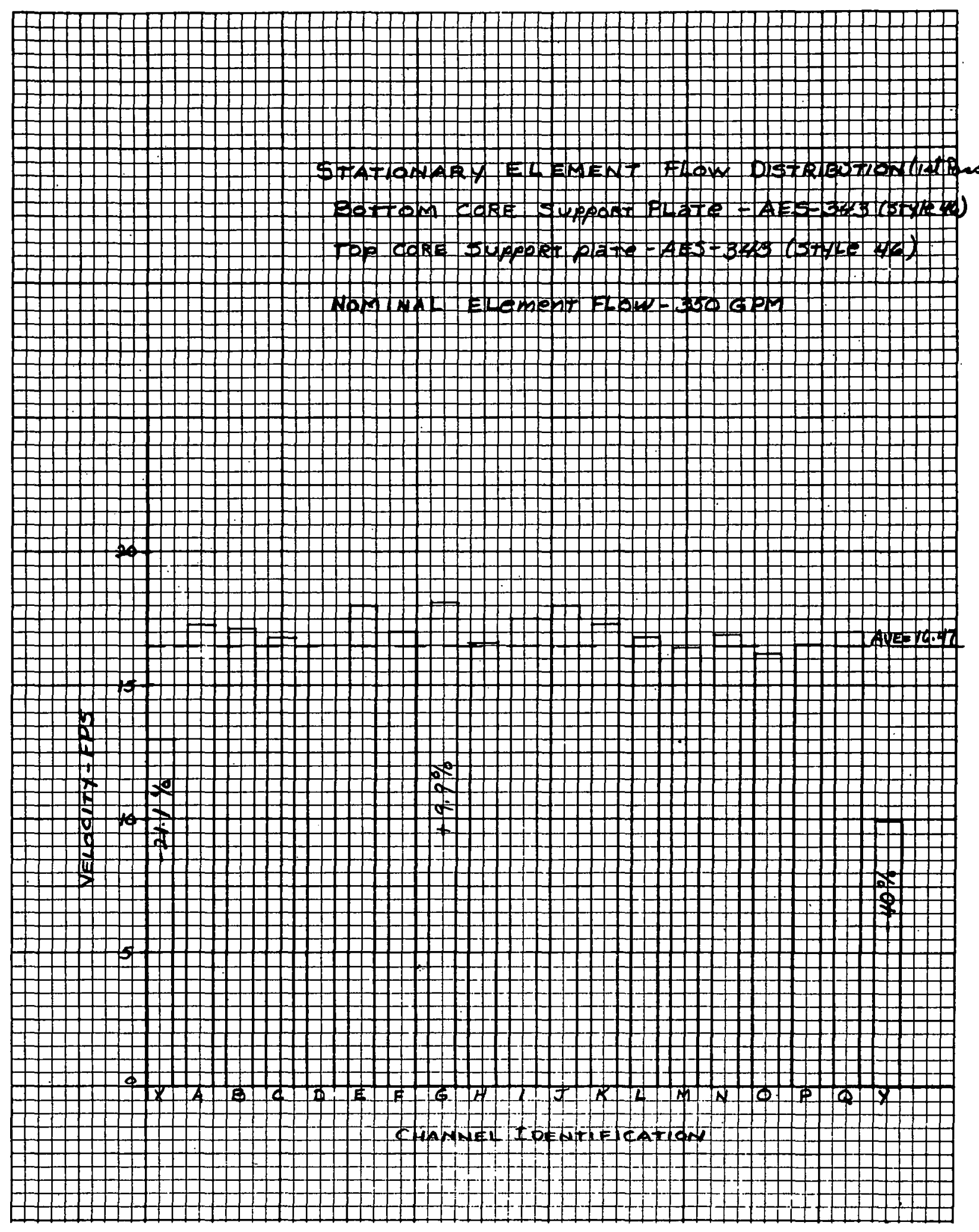

Fig. 4-8 Stationary Element Flow Distribution (Style 46 Inlet And Style 46 Exit) - 1st Pass 
THIS PAGE

\section{WAS INTENTIONALLY LEFT BLANK}




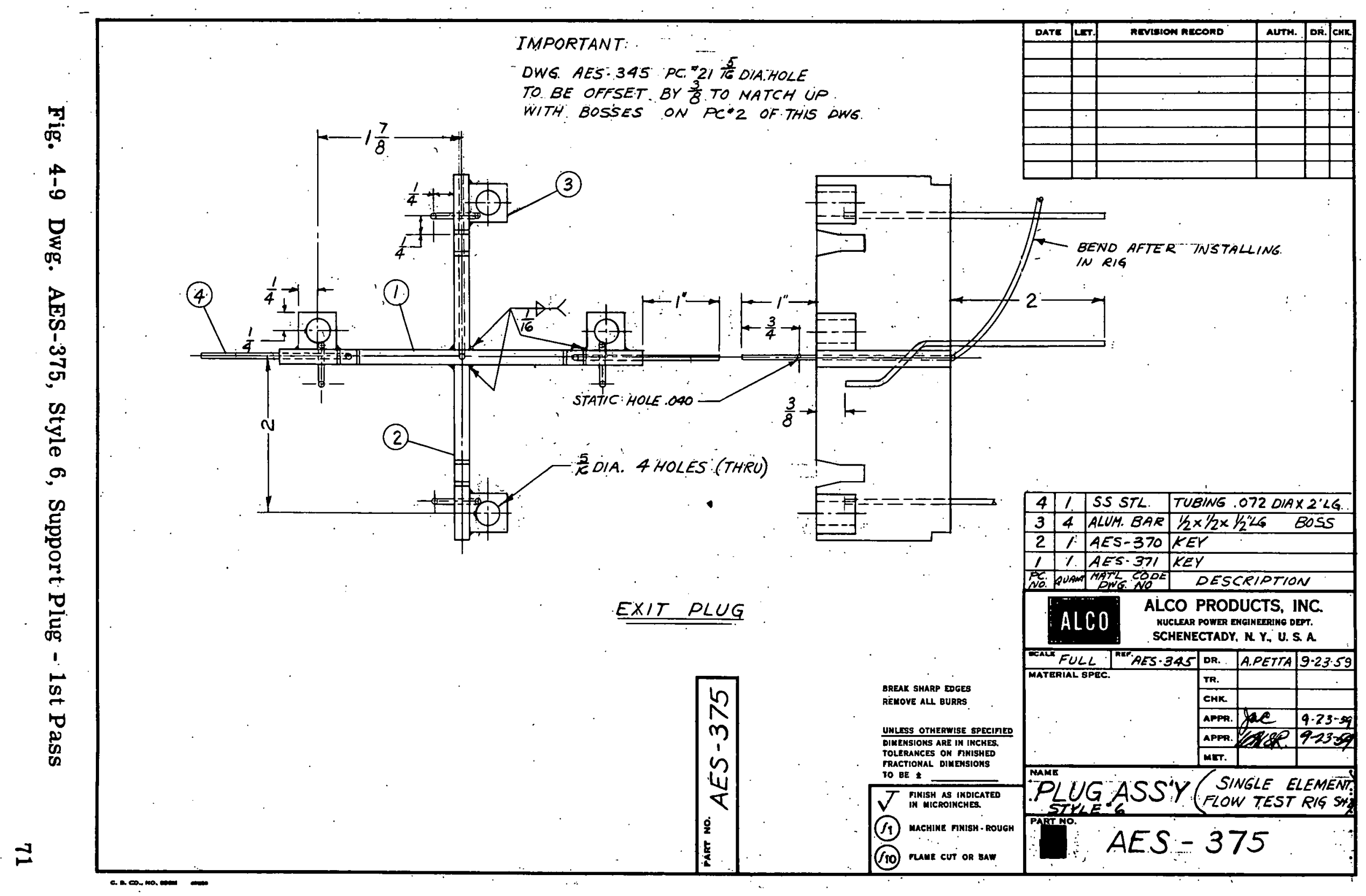




\section{THIS PAGE \\ WAS INTENTIONALLY \\ LEFT BLANK}




\section{STATIONARY ELEMENT FLOW DISTRIBUTION \\ BOTTOM CORE SUPPDRT PLATE: AEL-393 (STRLE 6) \\ TOP CORE SUPPORT PLATE: AEL-393 (STYLE 6)}

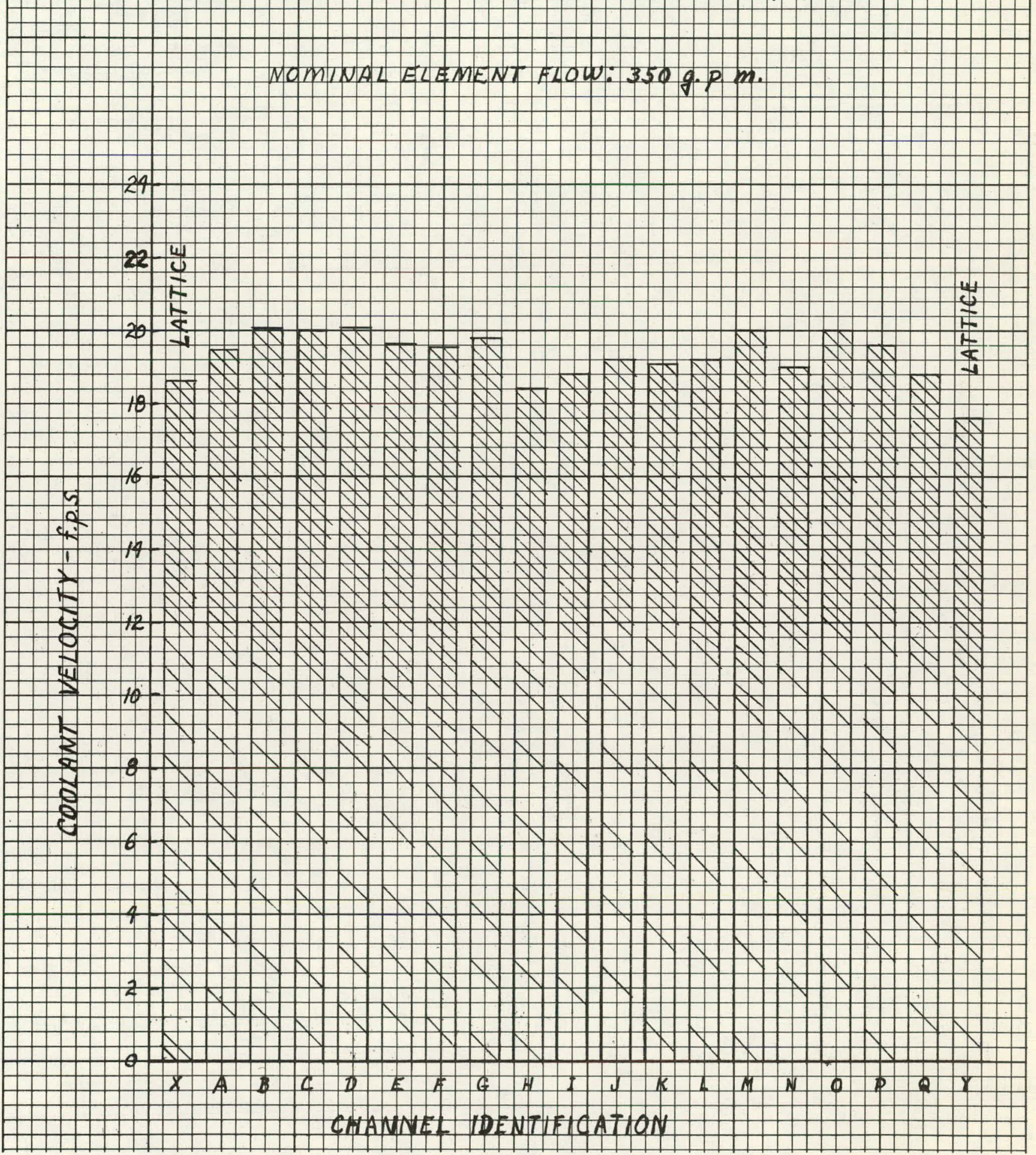

Fig. 4-10 Stationary Element Flow Distribution (Style 6 Inlet and Style 6 Exit) - 1st Pass 
THIS PAGE

WAS INTENTIONALLY

LEFT BLANK 


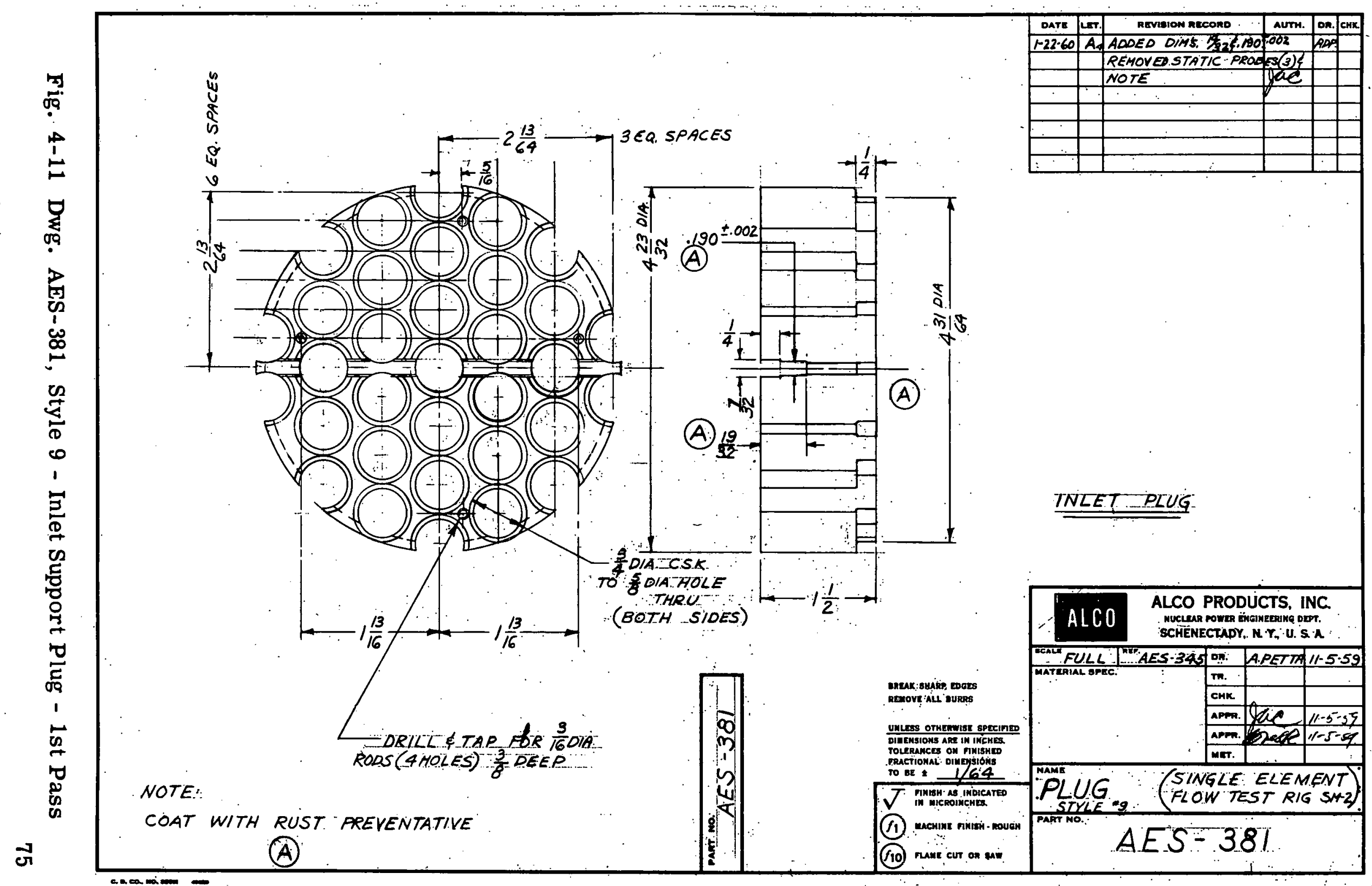


THIS PAGE

\section{WAS INTENTIONALLY \\ LEFT BLANK}




\title{
STATIONARY ELEMENT FLOW DISTRIBUTION
}

\author{
BOT TOM CORE SUPPORT PLATE: AEL - 523 \\ TOP CORE SUPPOKT PLATE: AEL-393
}

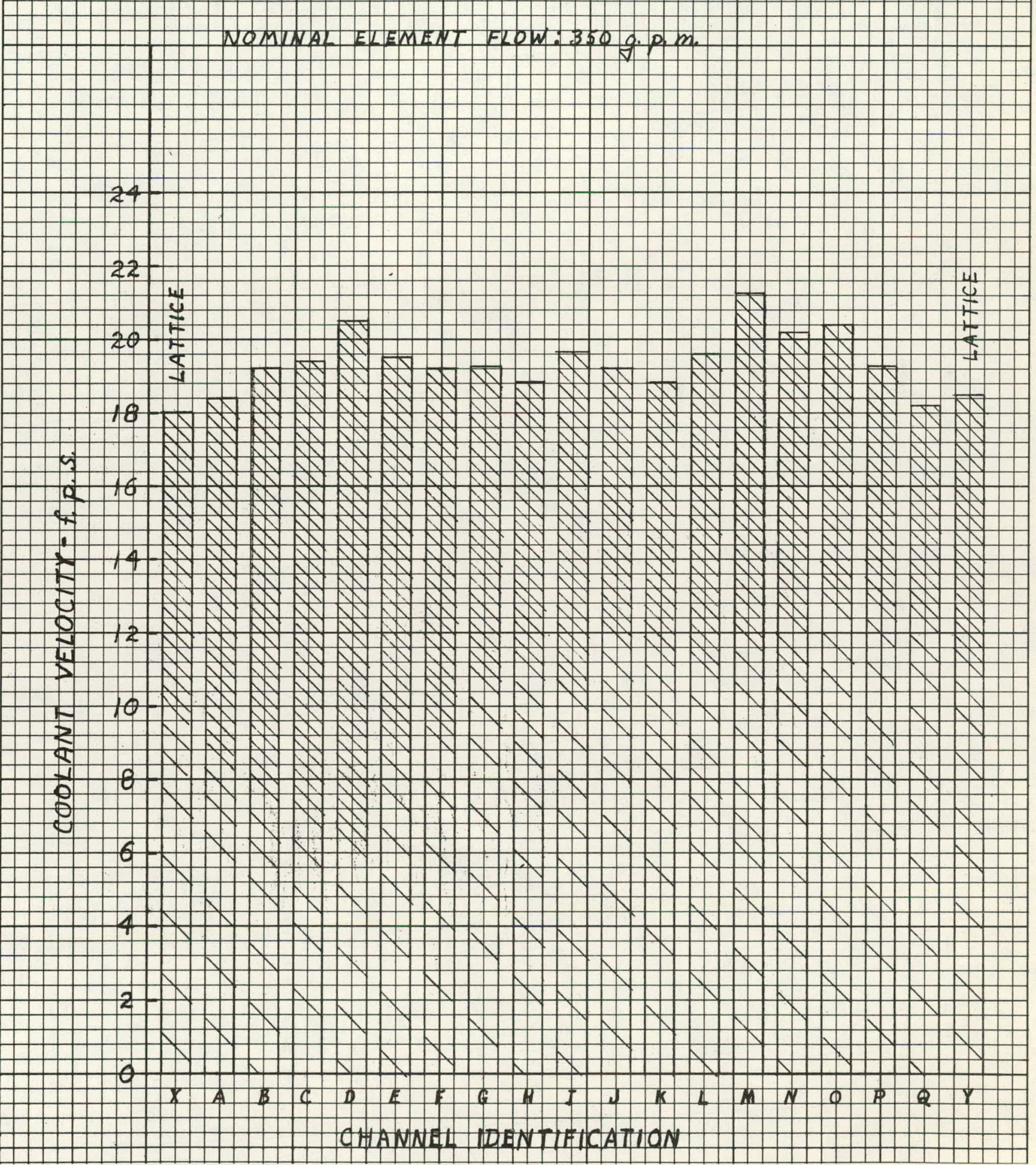

Fig. 4-12 Stationary Element Flow Distribution (Style 9 Inlet And Style 6 Exit) - 1st Pass 
THIS PAGE

\section{WAS INTENTIONALLY \\ LEFT BLANK}


Inspection of the test element and instrumentation after disassembly of $\cdots$ the rig revealed that the lattice passage had become distorted due to numerous: assemblies and disassemblies. Consequently, lattice flow measur ements were below true values. A new element and instrumentation were used for the next test. The new instrument supports provided more accurate positioning of the velocity and static pressure probes, and control of lattice passage width.

\subsubsection{Test \#4 - Style 9 Inlet, Style 8b Outlet (2nd Pass)}

The next combination of top and bottom core configuration tested was style 9 inlet (Fig, 4-11) and style $8 \mathrm{~b}$ exit (Fig。4-13)。 This test was the first one run with a.second pass top plate configuration (style $8 \mathrm{~b}$ ). Overall pressure drop through this combination was $41.4 \mathrm{ft}$ of water at $350 \mathrm{gpm}$ nominal, 26.6 ft of this occurring across the top support plate. This pressure drop was obviously excessive as it would result in the stationary elements having a higher pressure drop than the control rods at rated flow.

In flow distribution, lattice flow was noticeably better than any previous combination. A plot of channel velocity distribution at $350 \mathrm{gpm}$ nominal is given in Fig。4-14. The extremely high pressure drop across the top plate caused damage to the velocity measuring instruments. As a result no data is available for several channels.

\subsubsection{Test \#5 - Style 9. Inlet, Style 9a Outlet (1st Pass)}

For this test, a fully welded element with 23 in. outer fuel plates and attached end fixtures was used. At this point a change was also made in the instrumentation (see Sec. 4.2.2).

The top and bottom core support plate configurations are shown in Fig。 4-11 and 4-15 respectively. Velocity distribution at $350 \mathrm{gpm}$ nominal flow rate was within $+12 \%$ and $-14.4 \%$ of average with the two lattices showing above average velocity. Velocities are shown plotted in Fig. 4-16. The major reason for the increase in maldistribution over earlier tests was the for eshortening of the fuel element. The shortening reduced the redistribution of flow between the inlet support plate and the entrance to the plate bundle. Overall pressure drop for this combination of top and bottom core support configurations was $18,5 \mathrm{ft}$ of water at a nominal flow rate of $350 \mathrm{gpm}$.

\subsubsection{Test \#6 - Style 9 Inlet, Style 9a Outlet (1st Pass)}

Before conducting this test, a slight modification was made to the end fixture comb shown in Fig. 4-17. This modification was made in an attempt to improve upon the flow distribution observed in the previous test. 
THIS PAGE

\section{WAS INTENTIONALLY \\ LEFT BLANK}




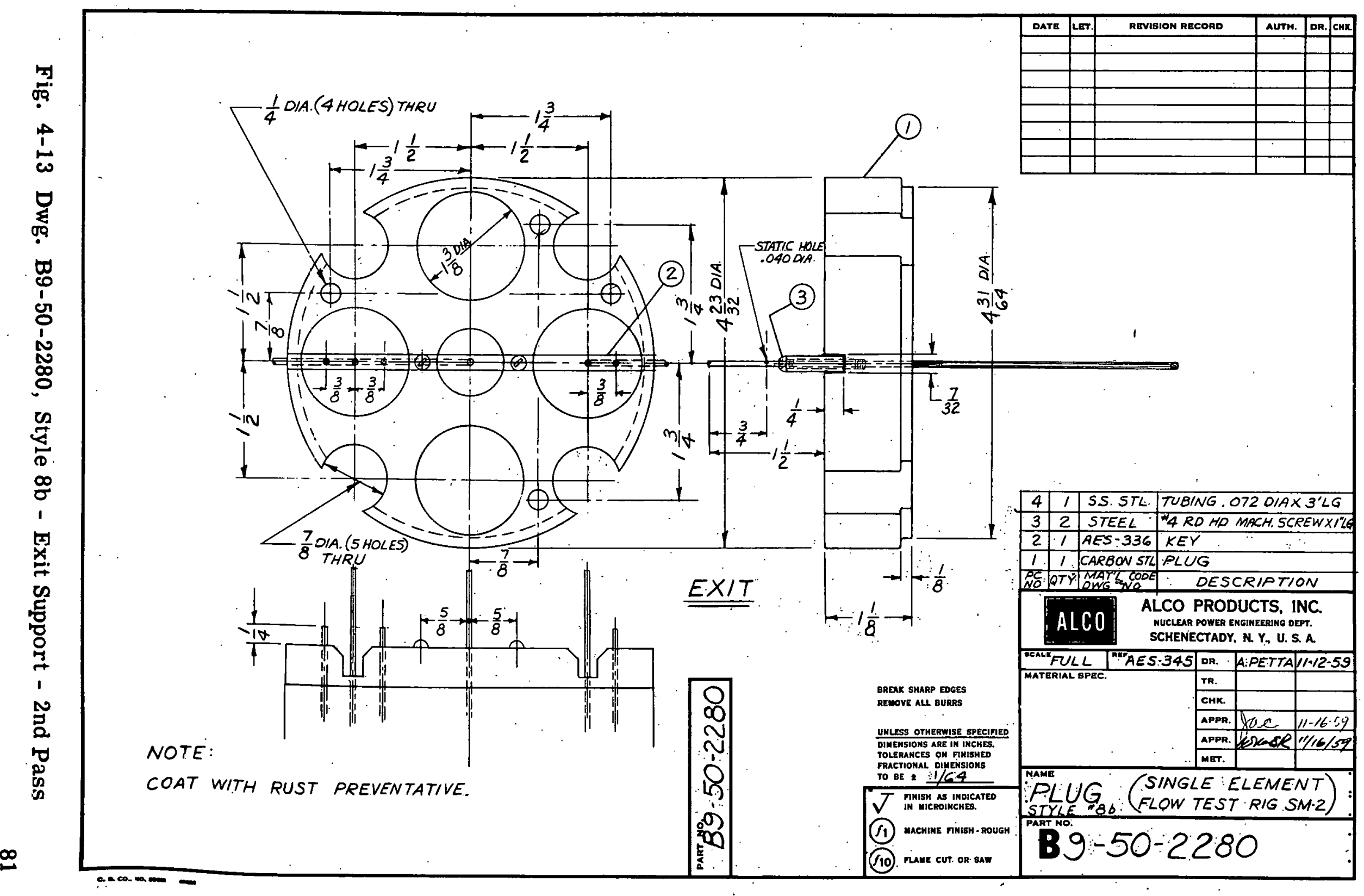




\section{THIS PAGE}

\section{WAS INTENTIONALLY LEFT BLANK}




\section{STATIONARY ELLMENT FLOW DISTRLBUTION}

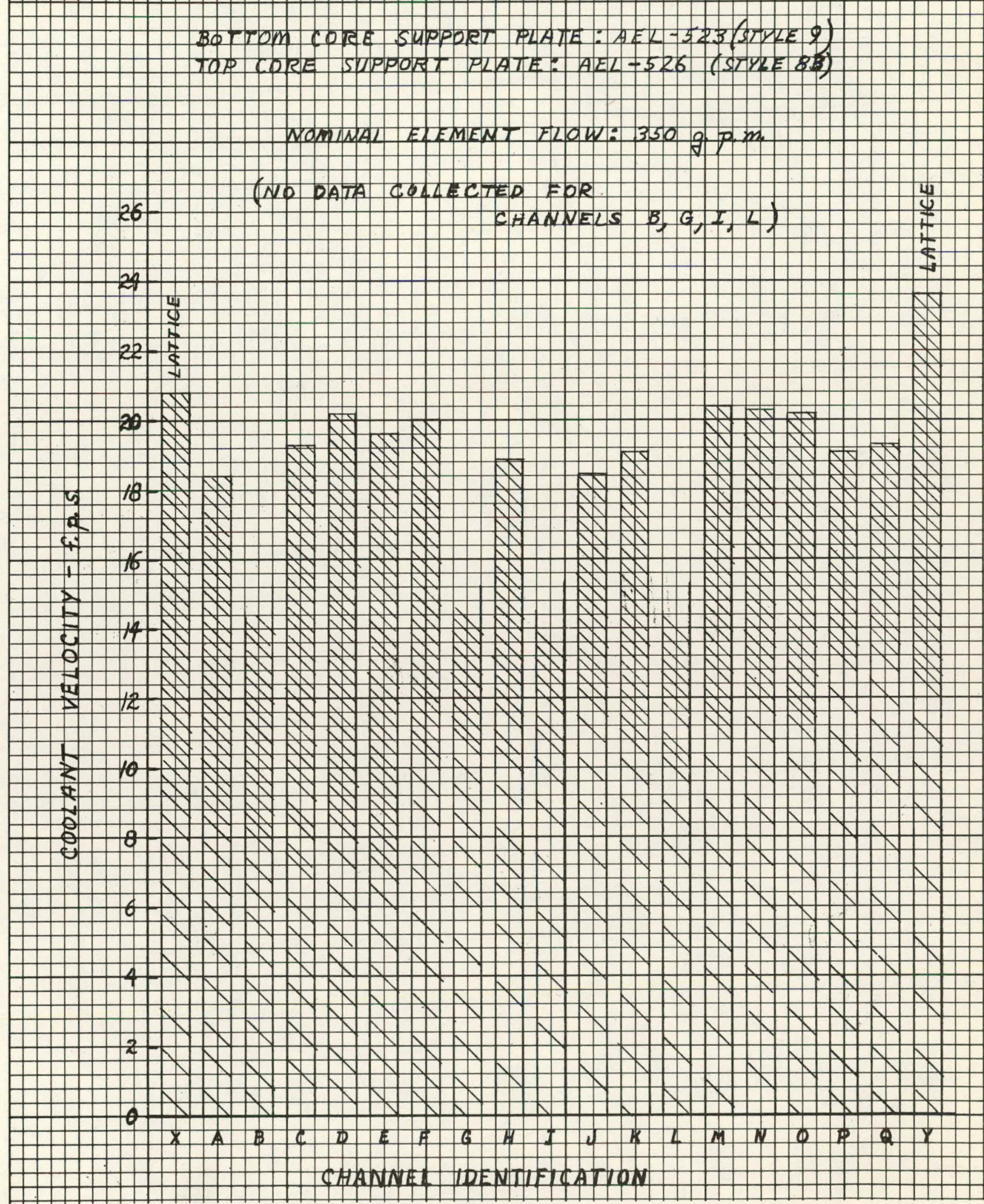

Fig. 4-14 Stationary Element Flow Distribution (Style 9 Inlet and Style 8b Exit) - 2nd Pass 


\section{THIS PAGE}

\section{WAS INTENTIONALLY \\ LEFT BLANK}




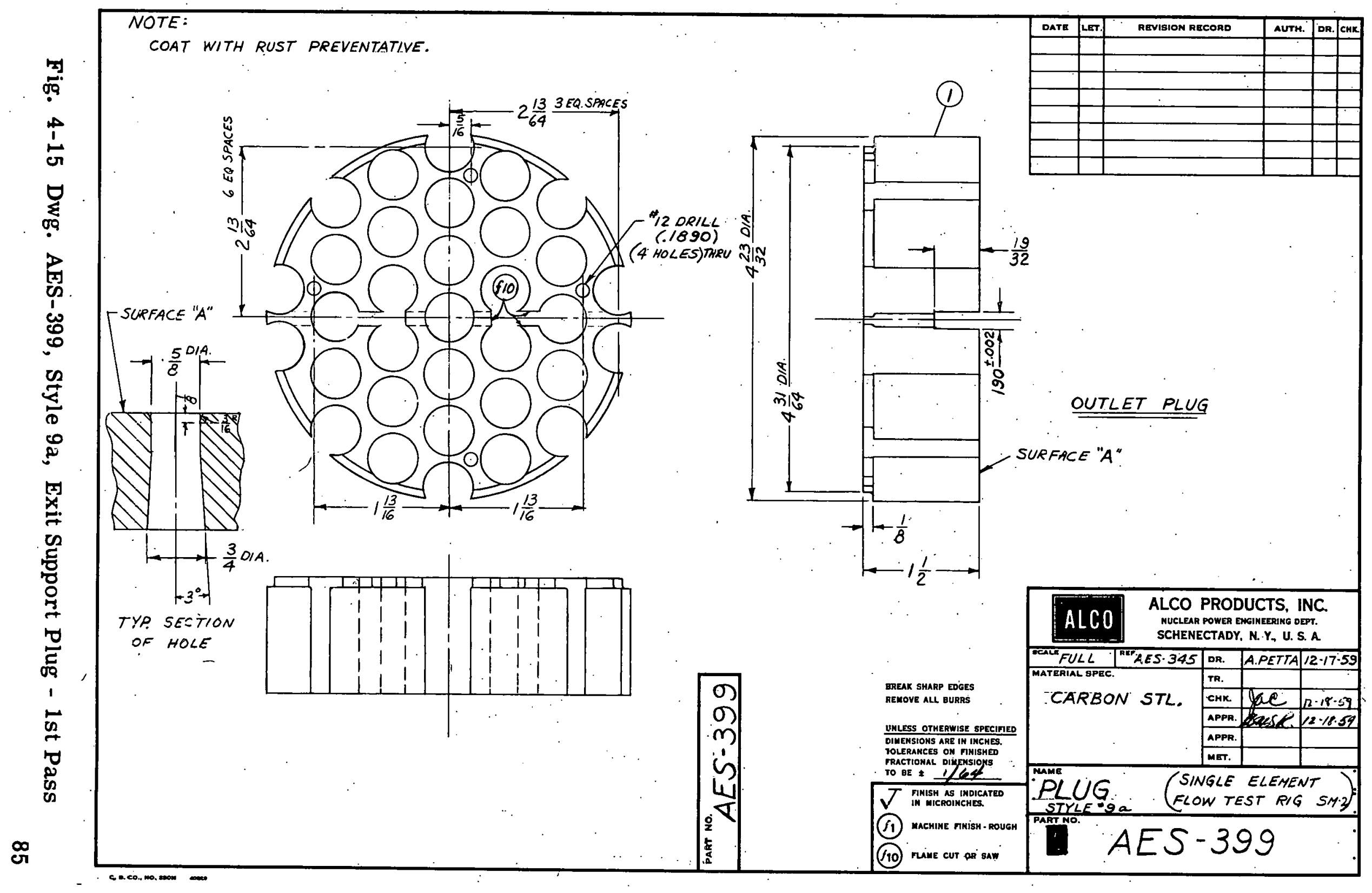




\section{THIS PAGE}

\section{WAS INTENTIONALLY \\ LEFT BLANK}




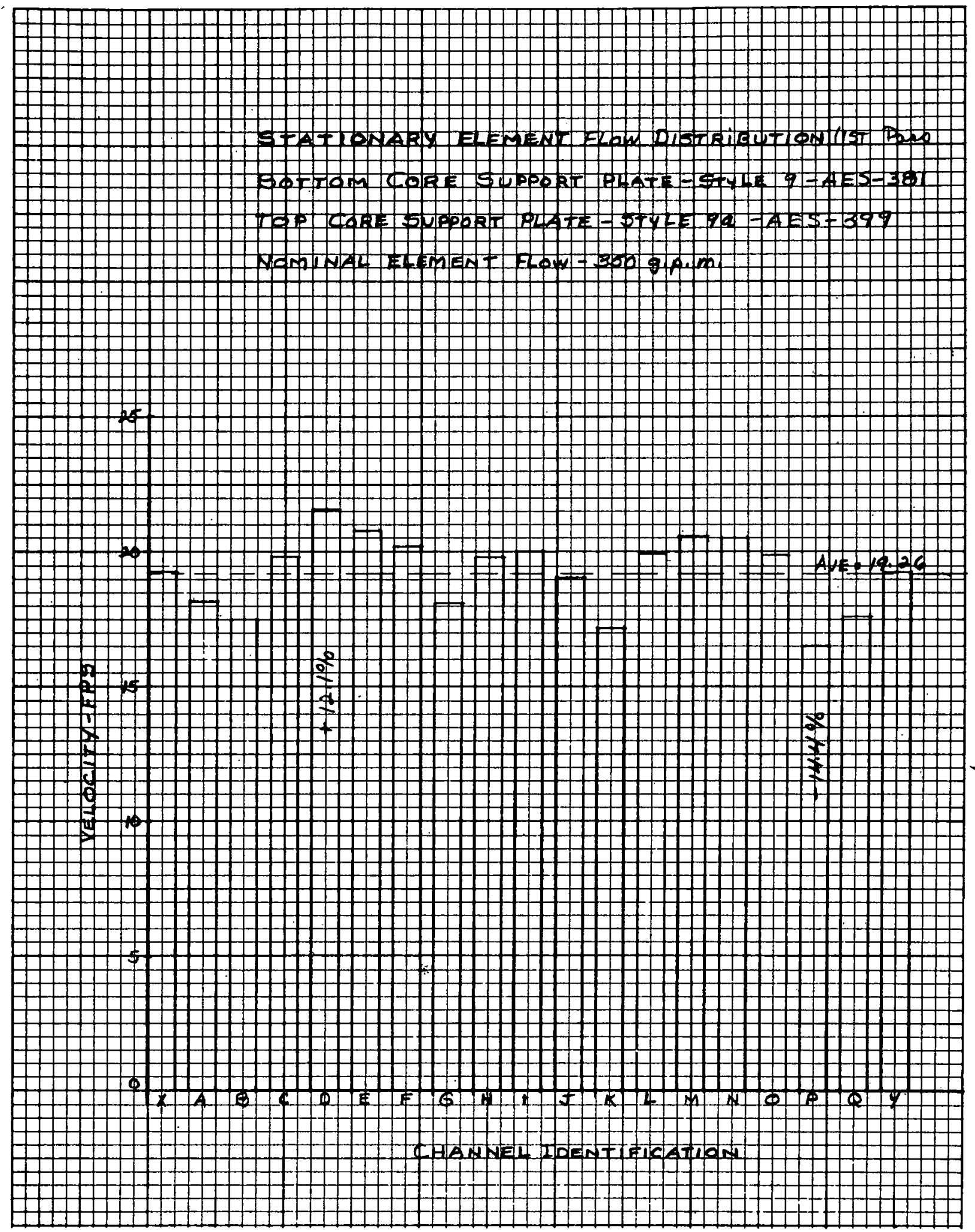

Fig. 4-16 Stationary Element Flow Distribution (Style 9 Inlet and Style 9a Exit) - 1st Pass 
THIS PAGE

\section{WAS INTENTIONALLY \\ LEFT BLANK}




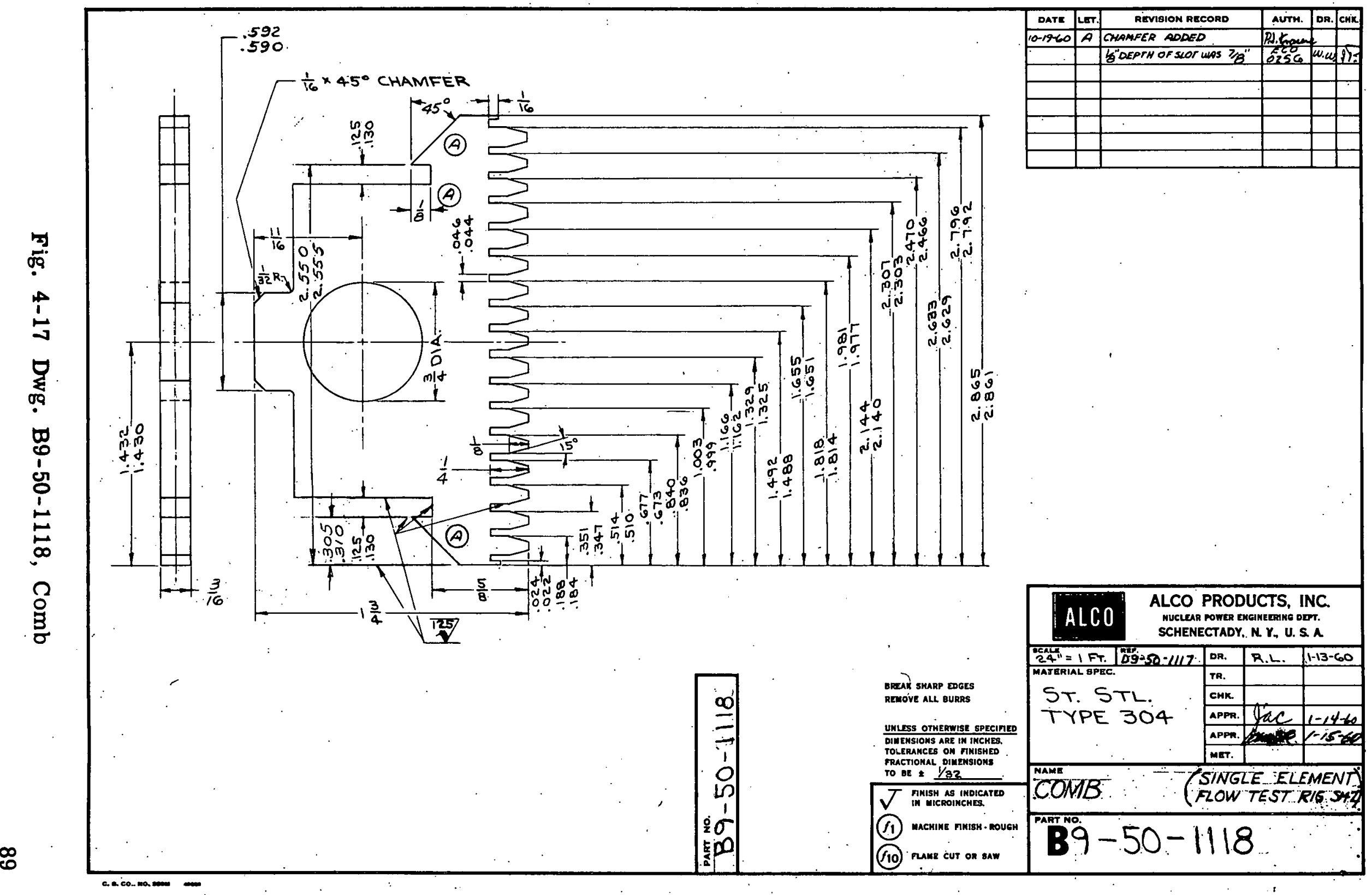


THIS PAGE

\section{WAS INTENTIONALLY \\ LEFT BLANK}


This test was run with the same top and bottom core support configuration described in Sec. 4.4.5.-Velocity distribution at a nominal flow rate of $300 \mathrm{gpm}$ is shown in Fig. 4-18. Velocity distribution was within +10 . $2 \%$ and $-13.2 \%$ of average. Overall pressure drop for this test at $350 \mathrm{gpm}$ nominal flow rate was $18.1 \mathrm{ft}$ of water.

\section{4.7: Test \#7 - Style 9c Inlet, Style 9a Outlet (1st Pass)}

In a further attempt to improve upon channel flow distribution, a style $9 c$ inlet conf iguration was tested in combination with a style 9 a outlet. Style 9c hole configuration is shown in Fig. 4-19.

The velocity flow distribution for this test was within $+12.3 \%$ and $-13.9 \%$ of average at a nominal flow rate of $300 \mathrm{gpm}$. Velocities are shown plotted in Fig. 4-20。 Overall pressure drop for this combination of top and bottom plate configurations was $21.6 \mathrm{ft}$ of water at $350 \mathrm{gpm}$ nominal flow rate.

\subsubsection{Test \#8. - Style 9c Inlet, Style 9b Outlet (2nd Pass)}

For this test, a combination of a first pass bottom plate configuration (Fig. 4-19) and a second pass top plate configuration (Fig。 4-21) was used. Channel to channel velocity distribution at $300 \mathrm{gpm}$ nominal flow rate, plotted in. Fig. $4-22$, was within $+13.2 \%$ and $-15.4 \%$ of average. Both lattices were within $=2.4 \%$ of average. Overall pressure drop for this combination of top and bottom plates was $34 \mathrm{ft}$ of water at $350 \mathrm{gpm}$ nominal flow rate which did not match the required control rod pressure drop of $29 \mathrm{ft}$ of water.

\subsubsection{Test \#9 - Style 9c Inlet, Style 9a Outlet - with Modification To End Fixture (1st Pass)}

In an attempt to improve upon the low flow velocities obtained in channels adjacent to the lattices (channels B, C, 0 and $P$ ) in the previous test (Sec. 4.4.7), the end fixture struts were moved from over the third and sixteenth plates to over the fifth and fourteenth plates (see Fig。:4-23 and 4-5).

- The effect of this modification was to raise the flow velocities of the deficient channels nearer to the average. Flow velocities were then within $+15.8 \%$ and $-10.1 \%$ of average. Figure $4-24$ is a plot of velocity distribution at a nominal flow rate of $300 \mathrm{gpm}$. Overall pressure drop for this test was $23.5 \mathrm{ft}$ of water at a nominal flow rate of $350 \mathrm{gpm}$. 


\section{THIS PAGE}

\section{WAS INTENTIONALLY LEFT BLANK}




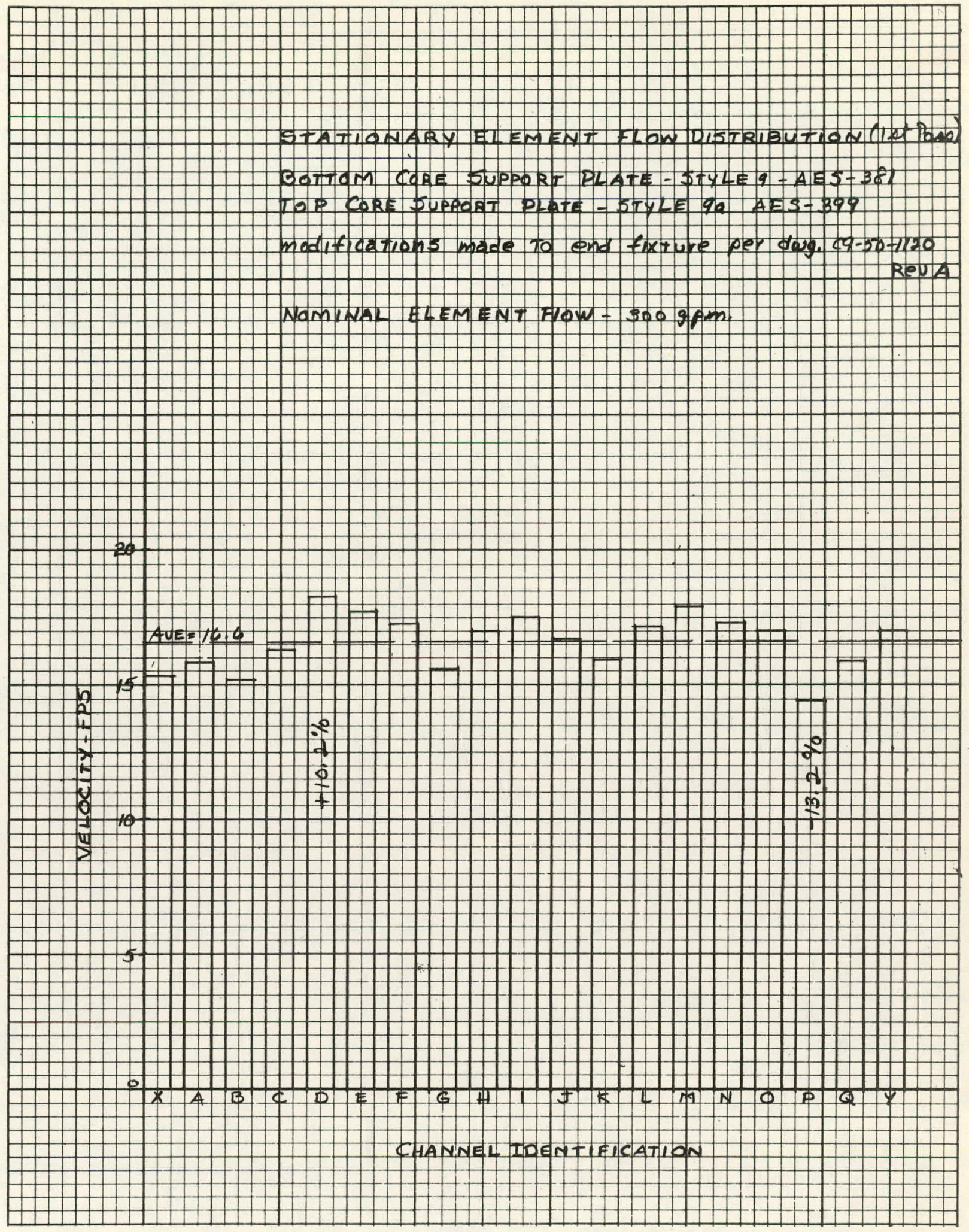

Fig. 4-18 Stationary Element Flow Distribution (Stȳle 9 Inlet and 9a Exit with Modifications to End Fixture) - 1st Pass 
THIS PAGE

\section{WAS INTENTIONALLY LEFT BLANK}




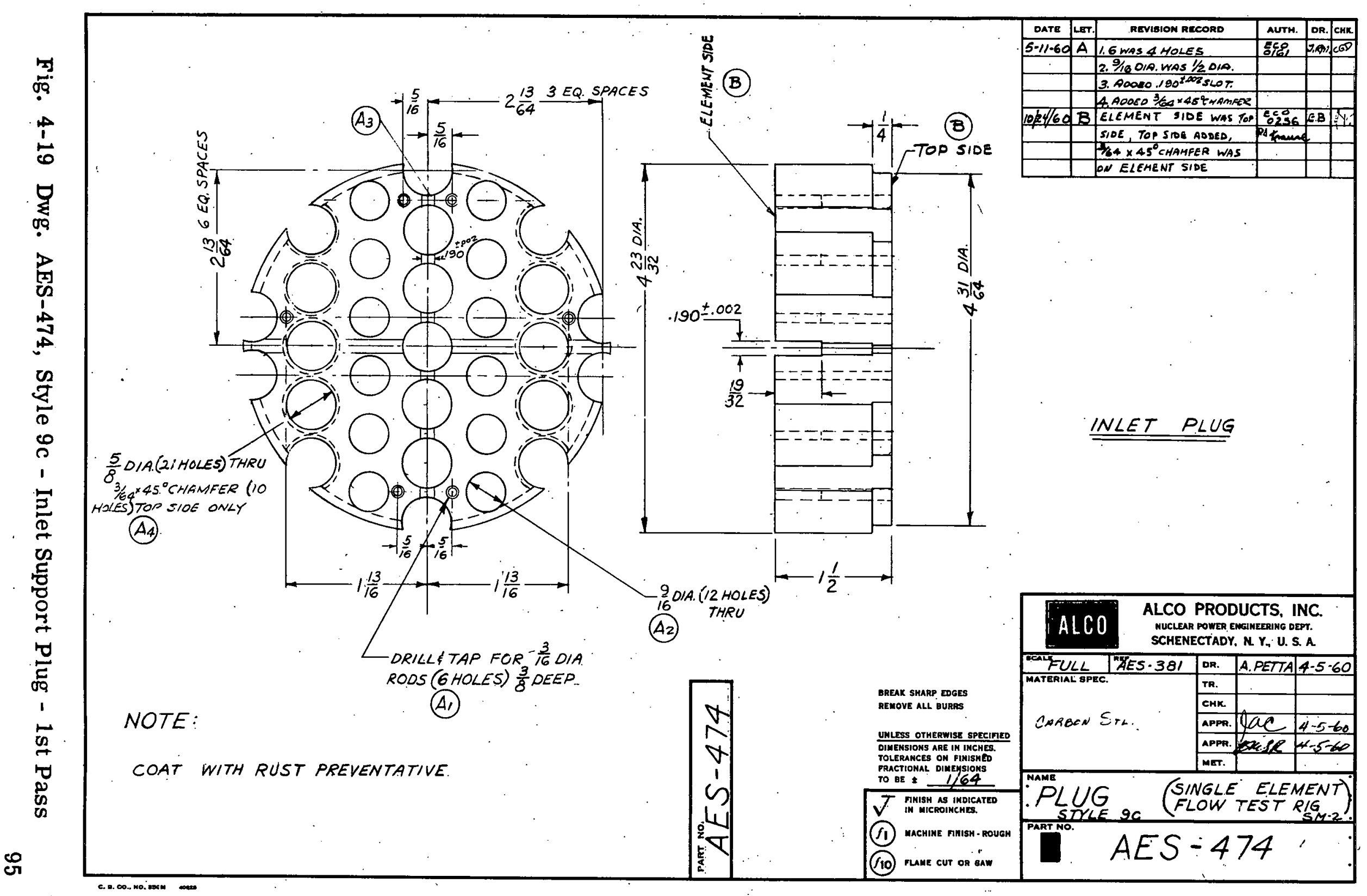


THIS PAGE

WAS INTENTIONALLY

LEFT BLANK 


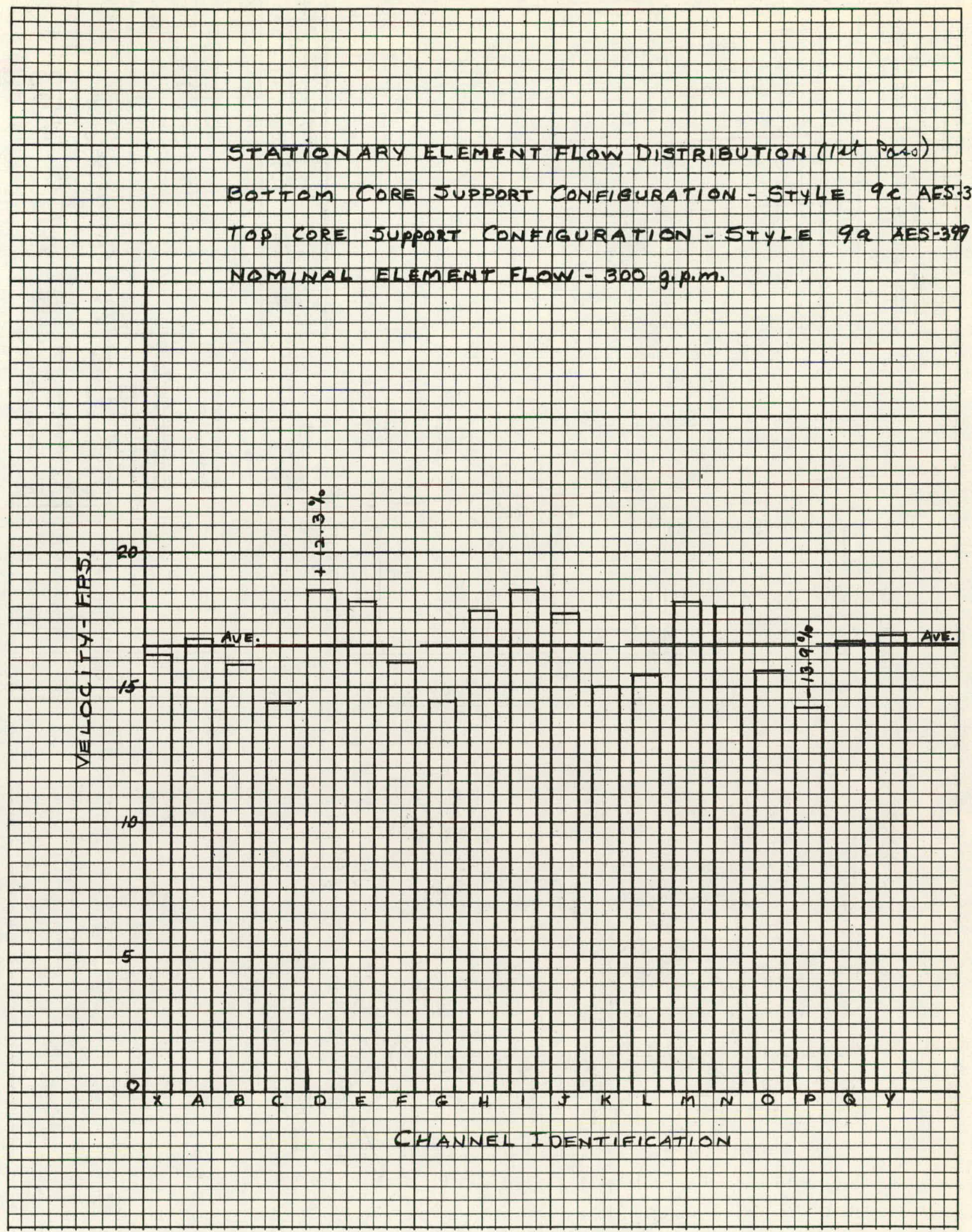

Fig. 4-20 Stationary Element Flow Distribution (Style 9c Inlet and 9a Exit) - 1st Pass 
$\infty$

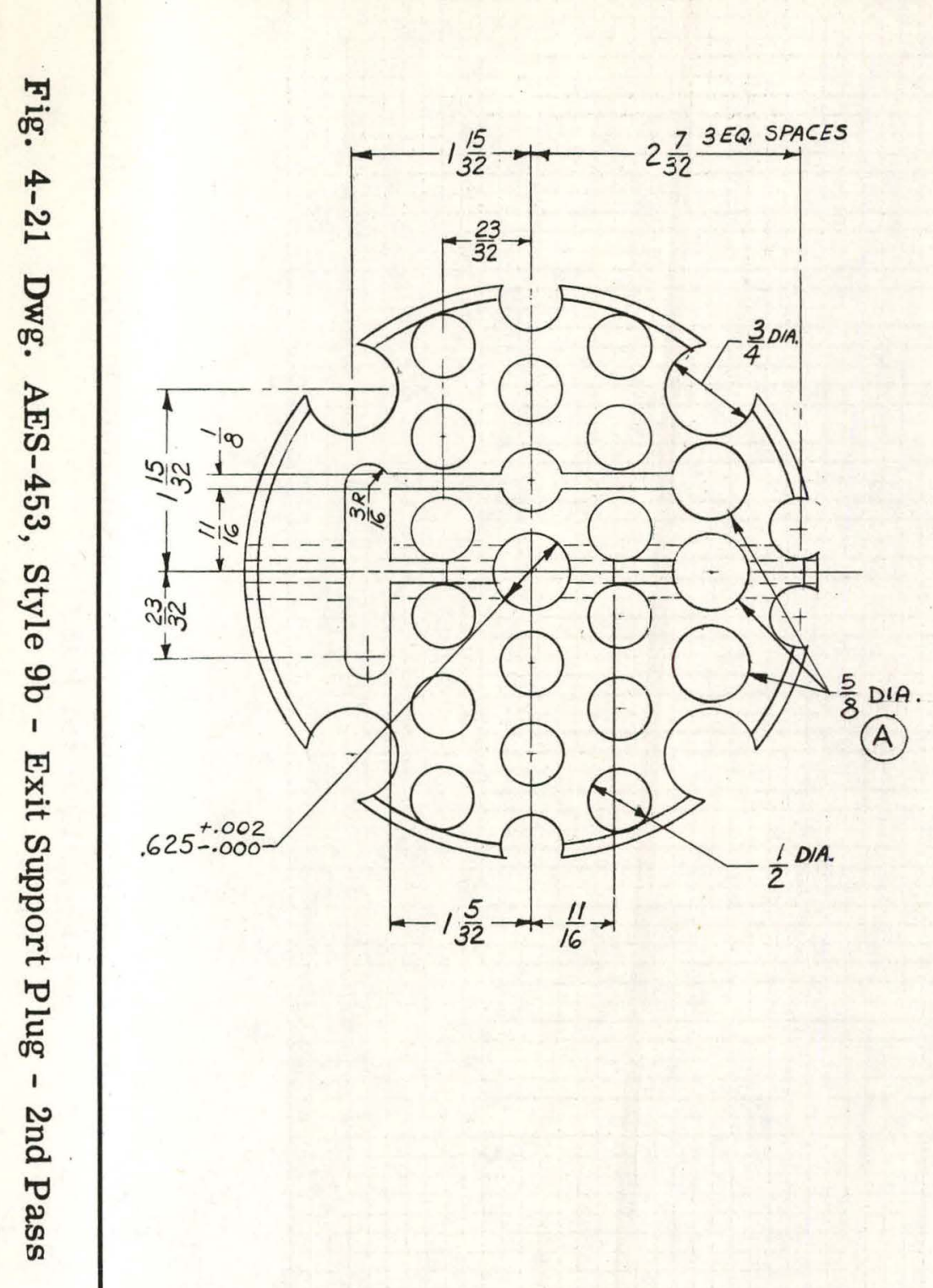

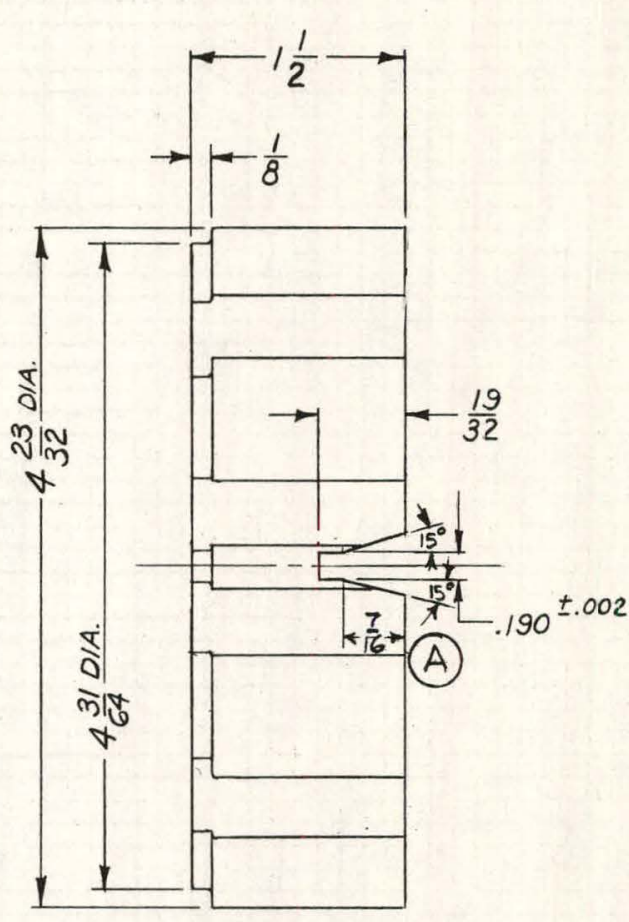

OUTLET

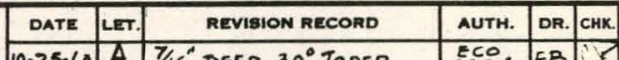

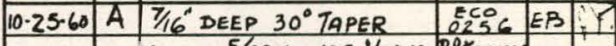
ADDED, 5/8DIA. WAS $1 / 2$ D/A. PRE Fraung 


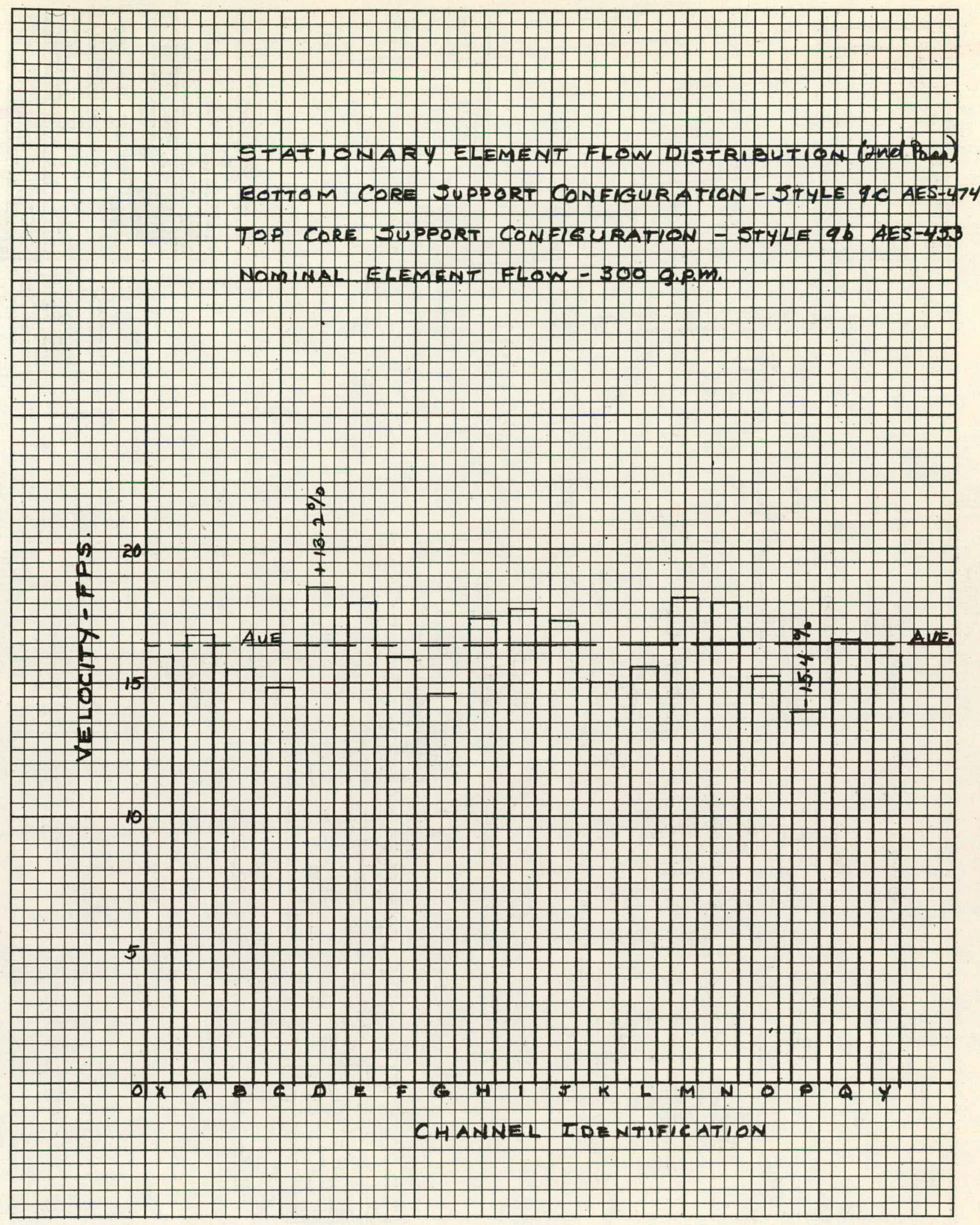

Fig. 4-22 Stationary Element Flow Distribution (Style 9c Inlet and 9b Exit) - 2nd Pass 


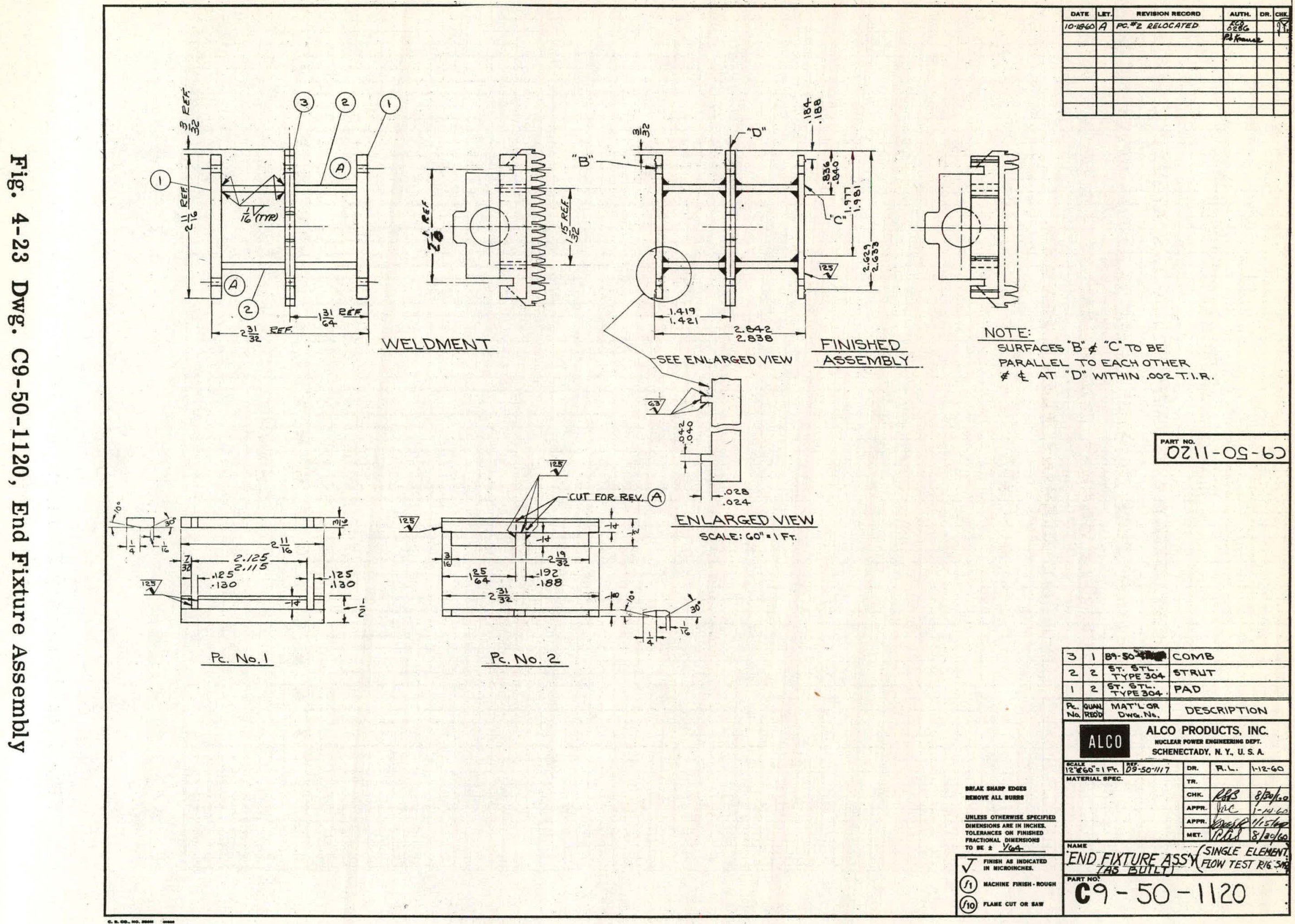




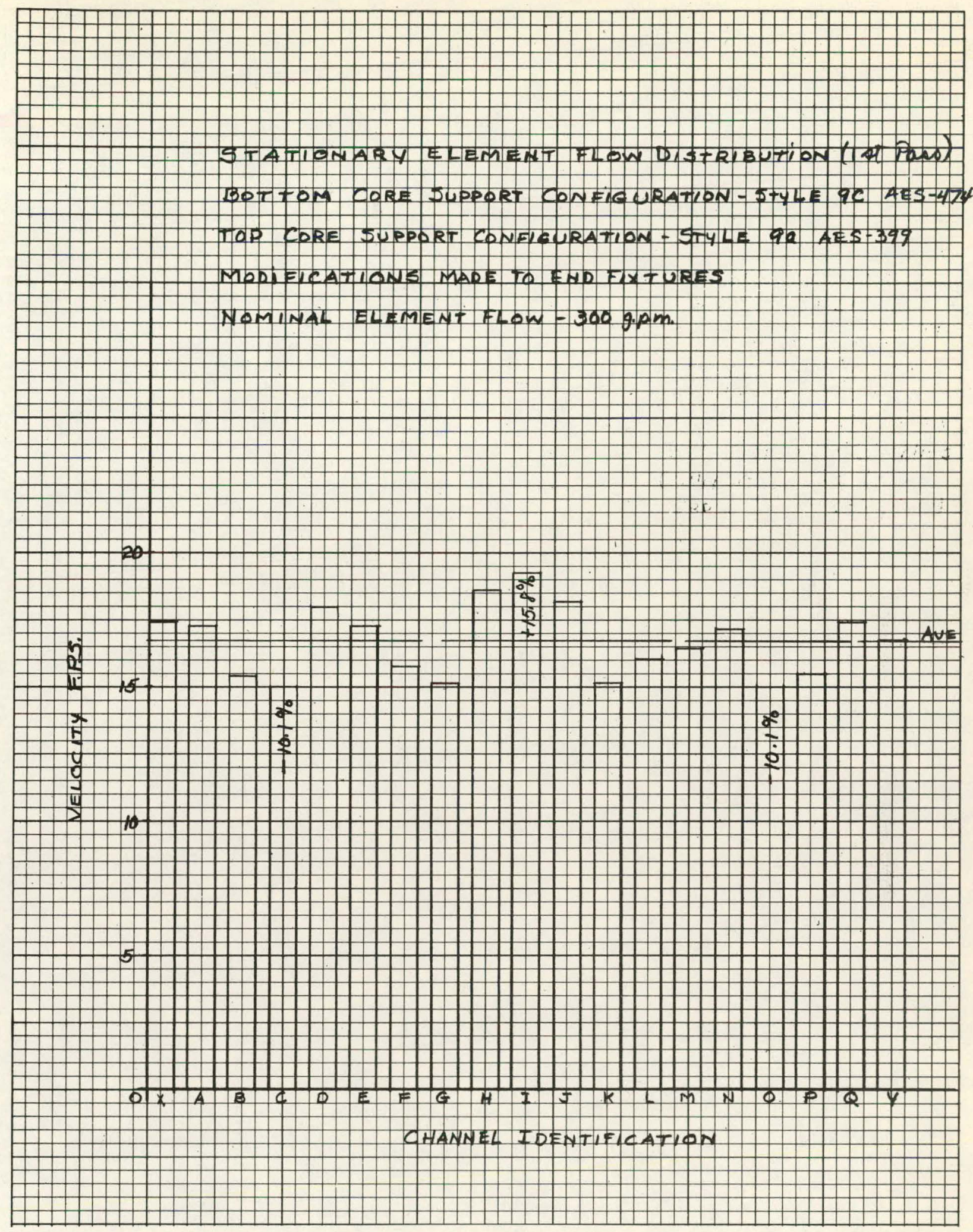

Fig. 4-24 Stationary Element Flow Distribution (Style 9c Inlet and 9a Exit) - 1st Pass 


\section{THIS PAGE}

\section{WAS INTENTIONALLY LEFT BLANK}




\subsubsection{Test \#10 - Style 9c Rev. A Inlet (Rotated 909) Style 9a Outlet (1st Pass)}

Since flow distribution wàs still not within acceptable limits, Style $9 \mathrm{c}$ used in test \#9 was modified as shown in Fig. 4-19. The modification consisted of enlarging the $1 / 2=\mathrm{in}$. holes to $9 / 16^{\circ} \mathrm{in}$. and adding a $3 / 64 \times 45^{\circ}$ chamfer to the $5 / 8$ in. holes in the first and fifth rows. The same exit plug (9a) was used for this test.

One further change was made for this test. The inlet plug (9c Rev. A) was rotated $90^{\circ}$ to a position shown in Fig. 4-25. The position of the inlet plug before $90^{\circ}$ rotation is also shown. This change was made because analysis of the previous test showed that the channels deficient in flow were behind solid land areas of the plug where no flow holes existed. By rotating the plug 900 , the deficient channels received better flow distribution because they were now sharing more flow holes than in the previous test.

Velocity distribution at $300 \mathrm{gpm}$ nominal flow rate, shown plotted in Fig. 4-26, was within +7 and $-9.6 \%$ of average. Overall pressure drop for this test was $24.6 \mathrm{ft}$ of water at $350 \mathrm{gpm}$ nominal flow rate.

\subsubsection{Test \#11 - Style 9c Rev. A Inlet (Original Position), Style 9a Exit (1st Pass)}

Before this test was run pads were added to both end fixture assemblies as shown in Fig $4-5$ and 4-23. The addition of these pads resulted in continuous pad support across the side plate of the fuel element. The purpose of these pads was to simplify the fabrication of the end fixtures. Testing was done to check the hydraulic effects of the change.

The results of this test are shown plotted in Fig, 4-27. Flow velocities were within $+7.7 \%$ and $-10.7 \%$ at a nominal flow rate of $300 \mathrm{gpm}$. Overall pressure drop for this combination of top and bottom core plate configurations was $22.5 \mathrm{ft}$ of water at $350 \mathrm{gpm}$ nominal flow rate.

As a result of this test, the final design of the end fixture assemblies was decided upon and is shown in Fig. 4-5 and 4-23. This combination of top and bottom plates was chosen for final first pass design. A complete tabulation of data is included in Table 4-2. 
THIS PAGE

\section{WAS INTENTIONALLY \\ LEFT BLANK}




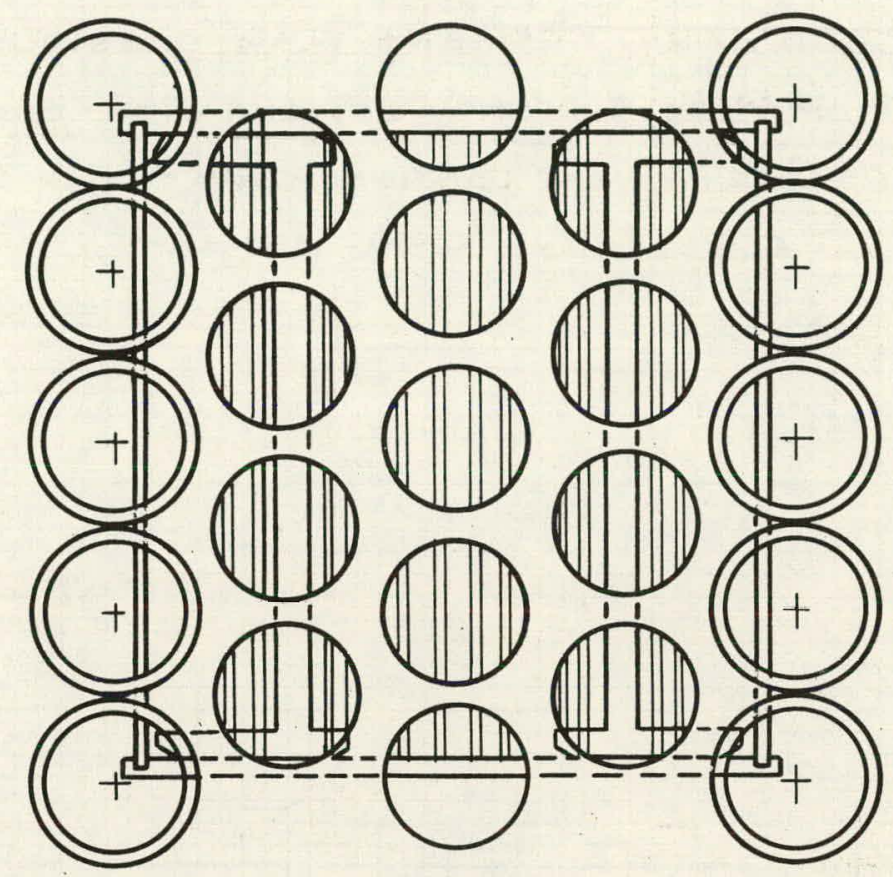

Fig. 4-25a Flowhole Orientation Before Rotation

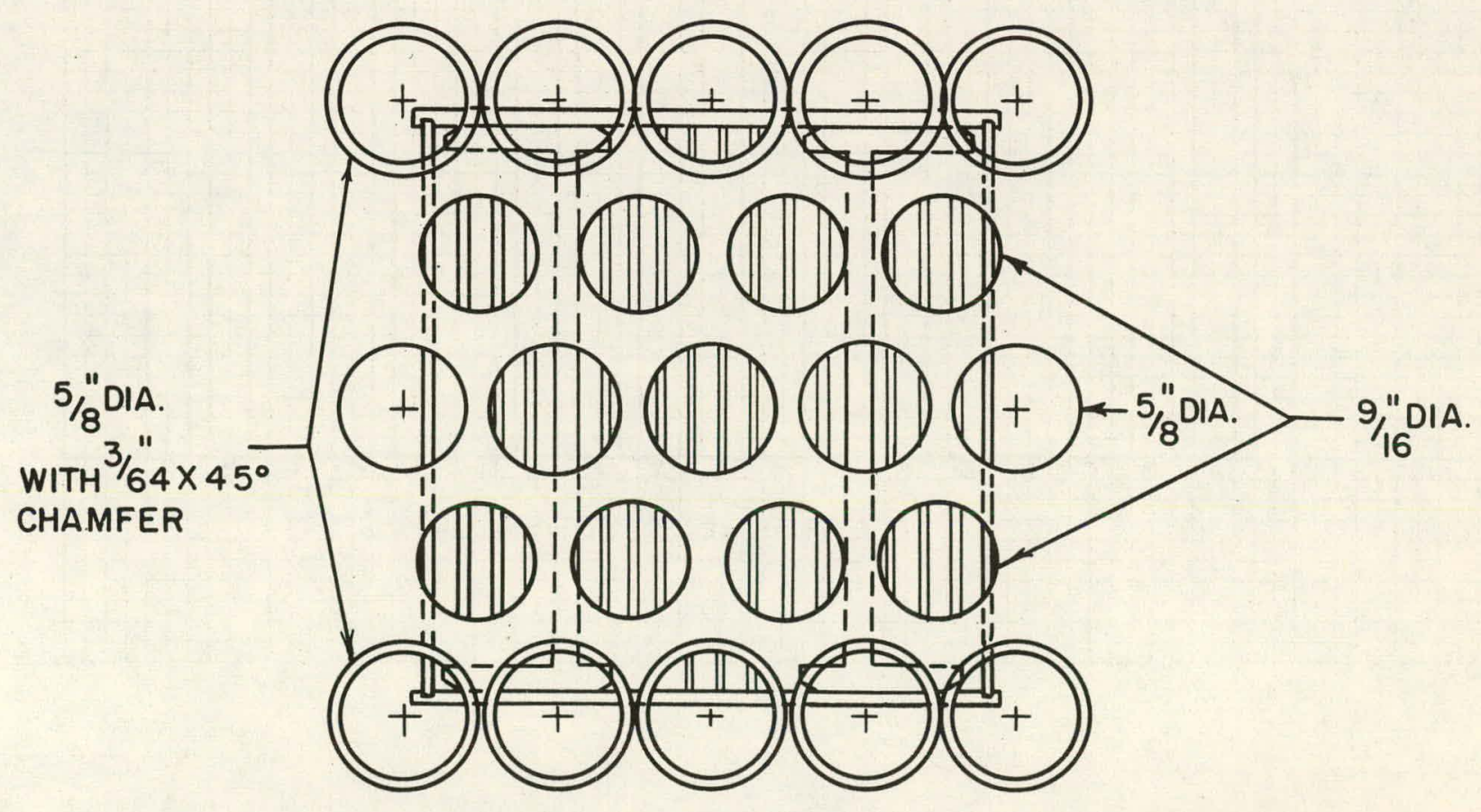

Fig. 4-25b Flowhole Orientation After $90^{\circ}$ Rotation 


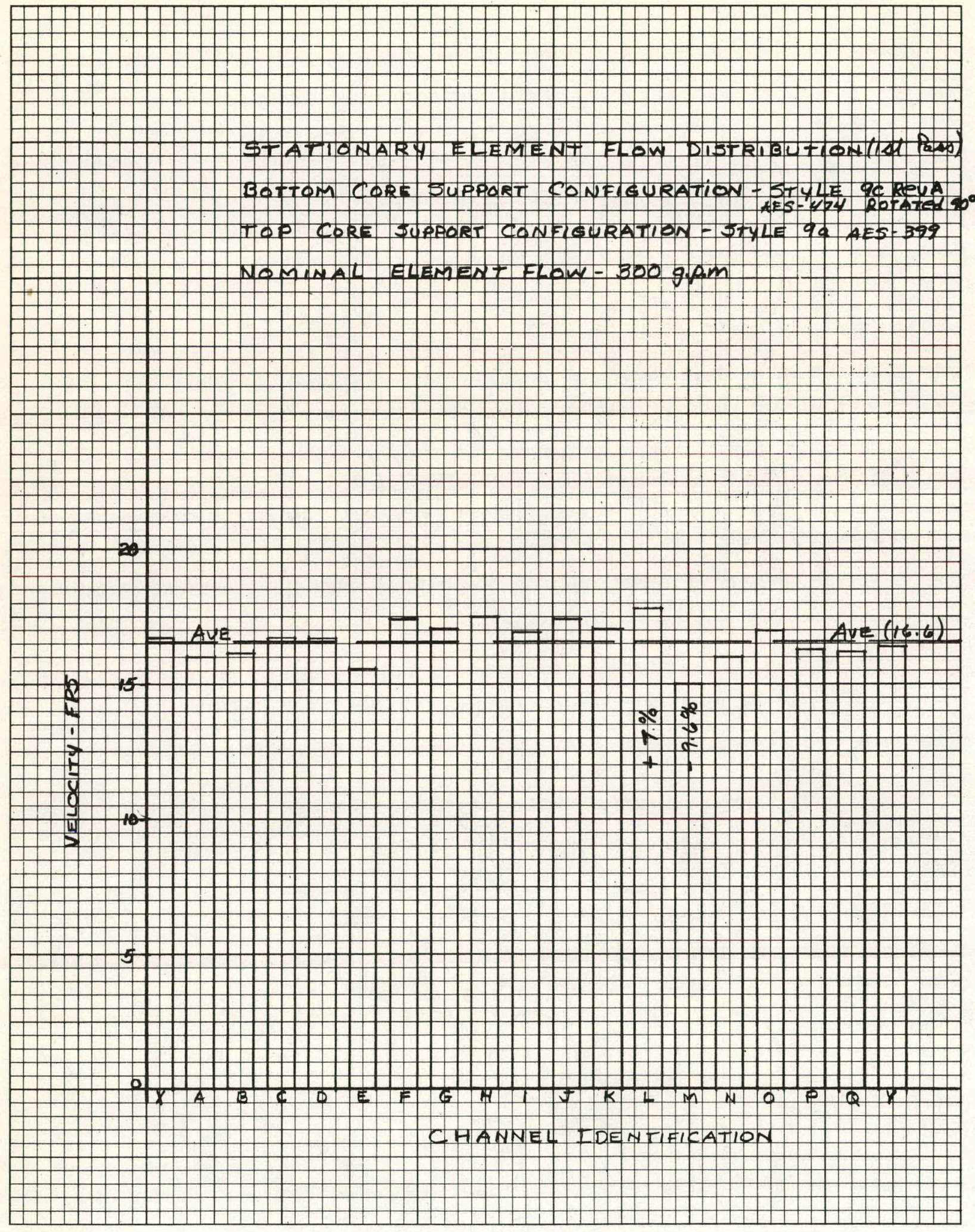

Fig. 4-26 Stationary Element Flow Distribution (Style 9c Rev. A Inlet - Rotated $90^{\circ}$ and 9a Exit) - 1st Pass 


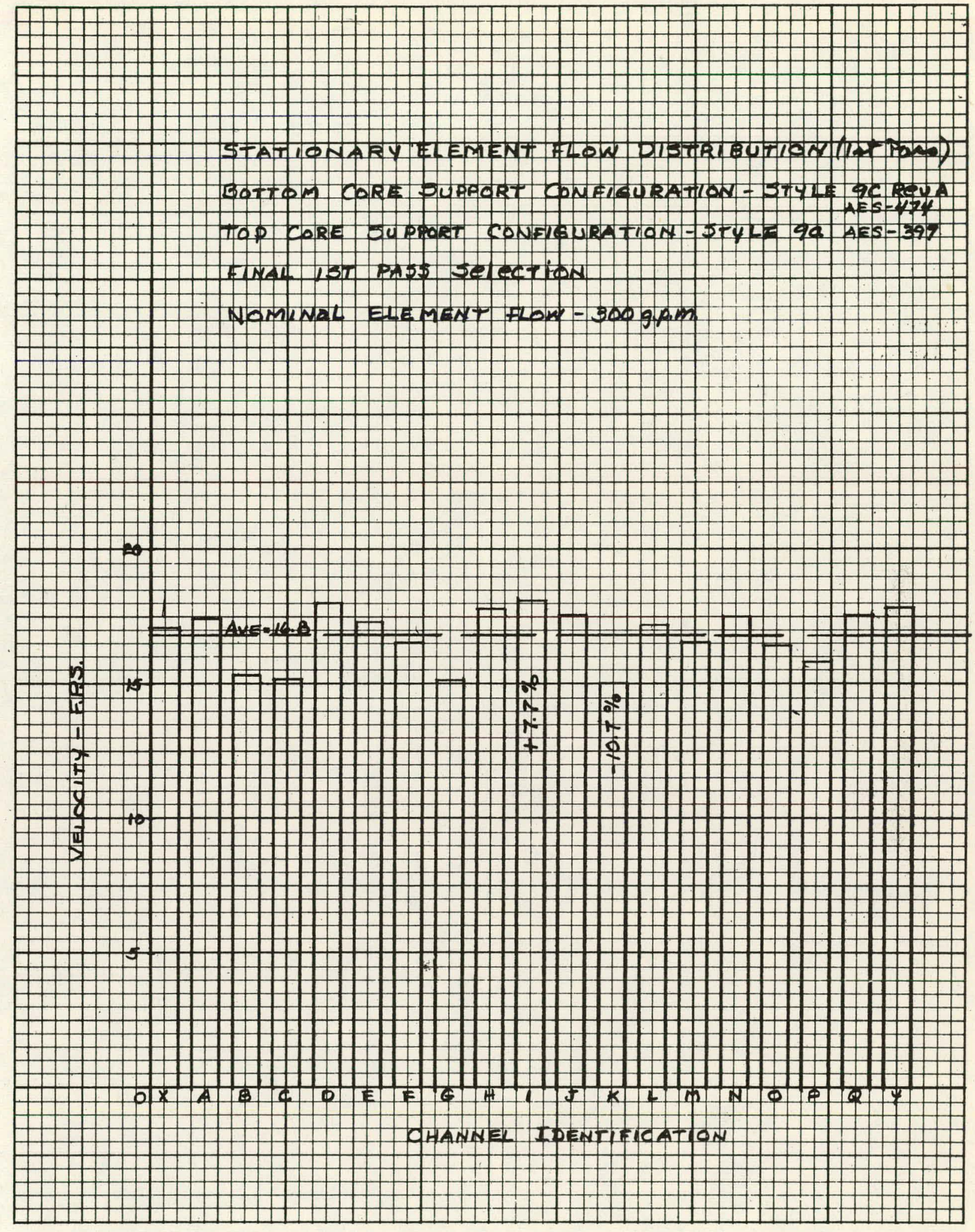

Fig. 4-27 Stationary Element Flow Distribution (Style 9c Rev. A Inlet and 9a Exit) - 1st Pass 
THIS PAGE

\section{WAS INTENTIONALLY LEFT BLANK}


Channel

Identification

$\mathbf{A}$
$\mathbf{B}$
$\mathbf{C}$
$\mathbf{D}$
$\mathbf{E}$
$\mathbf{F}$
$\mathbf{G}$
$\mathbf{H}$
$* \mathbf{I}$
$\mathbf{J}$
$\mathbf{C}$
$\mathbf{L}$
$\mathbf{M}$
$\mathbf{N}$
$\mathbf{O}$
$\mathbf{P}$
$\mathbf{Q}$
Lattice
$\mathbf{X}$
$\mathbf{X}$
Average
$*=$ High $+7.07 \%$

Static Pressure

Drop Across

Element, $\mathrm{ft} \mathrm{H}_{2} \mathrm{O}$ at $80^{\circ} \mathrm{F}$
Nominal Element Flow, GPM

200 $\underline{250}$

300

350

$\underline{400}$.

11.5

10.3

14. 5

12. 8

12. 7

15. 1

14. 4

13. 8

12. 7

15. 0

15. 2

14. 8

12.6

14. 4

14.0

14. 6

13.8

13. 2

14. 8

14. 3

15. 0

14. 1
17. 4

15. 3

15.2

18. 0

17. 3

16. 5

15. 1

17.8

18. 1

17.6

15. 0

17. 2

16. 6

17.5

16. 4

15. 8

17. 6

17. 1

17.8

16. 8
20.5

17.8

17.4

21. 0

20. 1

19.1

17.5

20.7

21. 0

20. 5

17. 3

19.8

19.3

20. 3

19.0

18. 3

20,6

19. 6

20.6

19.5
23. 6

20.5 .

19. 9

24. 0

22. 9

21.8

19. 8

23. 6

23. 9

23. 4

19.5

22.6

21. 9

23. 1

21.4

20.8

23. 5

22.4

23. 5

22.2

11.2

$$
\not=\text { Low }-10.7 \%
$$

7.96

12.3

17.1

22.4

28.6 


\subsubsection{Test \#12 Style 12a Inlet, Style 9a Exit (1st Pass)}

For this test, a combination of style $12 \mathrm{a}$ inlet and $9 \mathrm{a}$ outlet was used to simulate the top and bottom core plate configurations. The inlet plug (see Fig. 4-28) was rotated $90^{\circ}$ from the position shown. $\quad$ The outlet plug is shown in Fig. 4-15. This combination was used in an attempt to better the distribution results obtained in the previous test with $90^{\circ}$ inlet plug rotation (Sec. 4.4.10),

Overall pressure drop at $350 \mathrm{gpm}$ nominal flow rate was $22.9 \mathrm{ft}$ of water. Velocity distribution was within $+6 \%$ and $-8,4 \%$ of average and is shown in Fig. 4-29 (reading in channel 0 should be discarded because a faulty instrument probe was discovered after testing. Flow velocity in the active " $\mathrm{x}$ " lattice was $6 \%$ below average.

\subsubsection{Test \#13 - Style 9c Rev。A (modified) Inlet, Style 9a Outlet (1st Pass)}

For this test style 9c Rev. A inlet was modified and used in combination with a style 9 a outlet (Fig, 4-15). The inlet plug was identical to style 9c Rev. A except that four breakout holes were added in an attempt to im prove upon flow distribution results obtained in test \#11 (Sec。4.4.11),

- Distribution results are shown plotted in Fig. 4-31. Velocities were within $+9.3 \%$ and $-14.4 \%$ of average. Overall pressure drop for this combination of top and bottom plates was $21.7 \mathrm{ft}$ of water at a nominal flow rate of $350 \mathrm{gpm}$.

\subsubsection{Test \#14 - Style 9c Rev. A (modified) Inlet, Style 9b Outlet (2nd Pass)}

Bottom and top core configurations were style $9 \mathrm{c}$ Rev $_{\text {. }}$ A (modified) and style $9 \mathrm{~b}$ respectively. This test was conducted to find out what a combination made up of first and second pass inlet and exit would give in the way of pressure drop. Distribution results are shown plotted in Fig, 4-31 and were within $+10 \%$ and $-8.2 \%$ of average. However, both " $\mathrm{x}$ " and " $\mathrm{y}$ " lattices received below average flow.

Overall pressure drop at $350 \mathrm{gpm}$ nominal flow: rate was $32.8 \mathrm{ft}$ of water which was $10.3 \%$ higher than the required $29 \mathrm{ft}$ of water. 


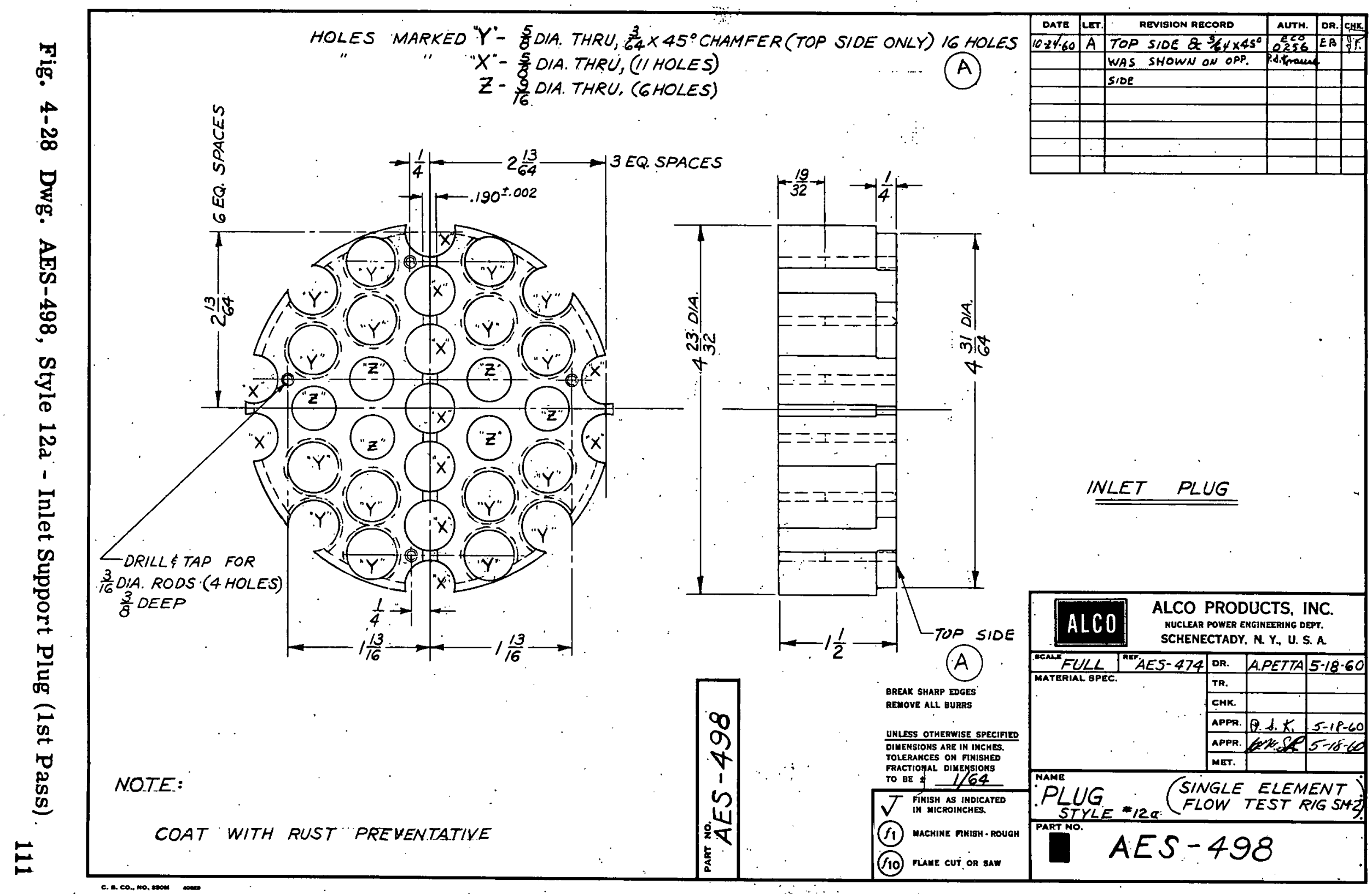

- $2 z^{2}$ 


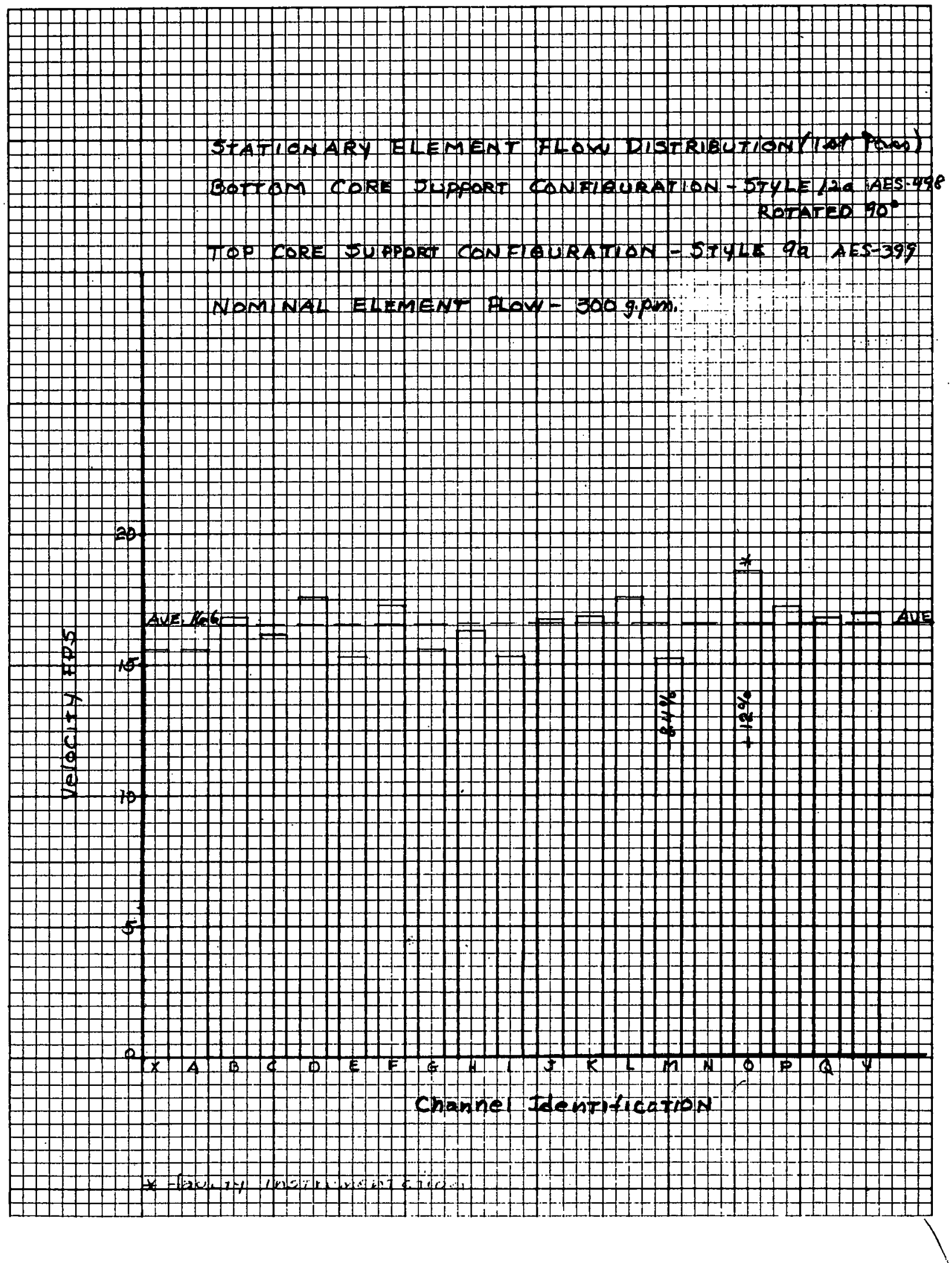

Fig. 4-29 Stationary Element Flow Distribution (Style 12a Inlet and 9a Exit) - 1st Pass 


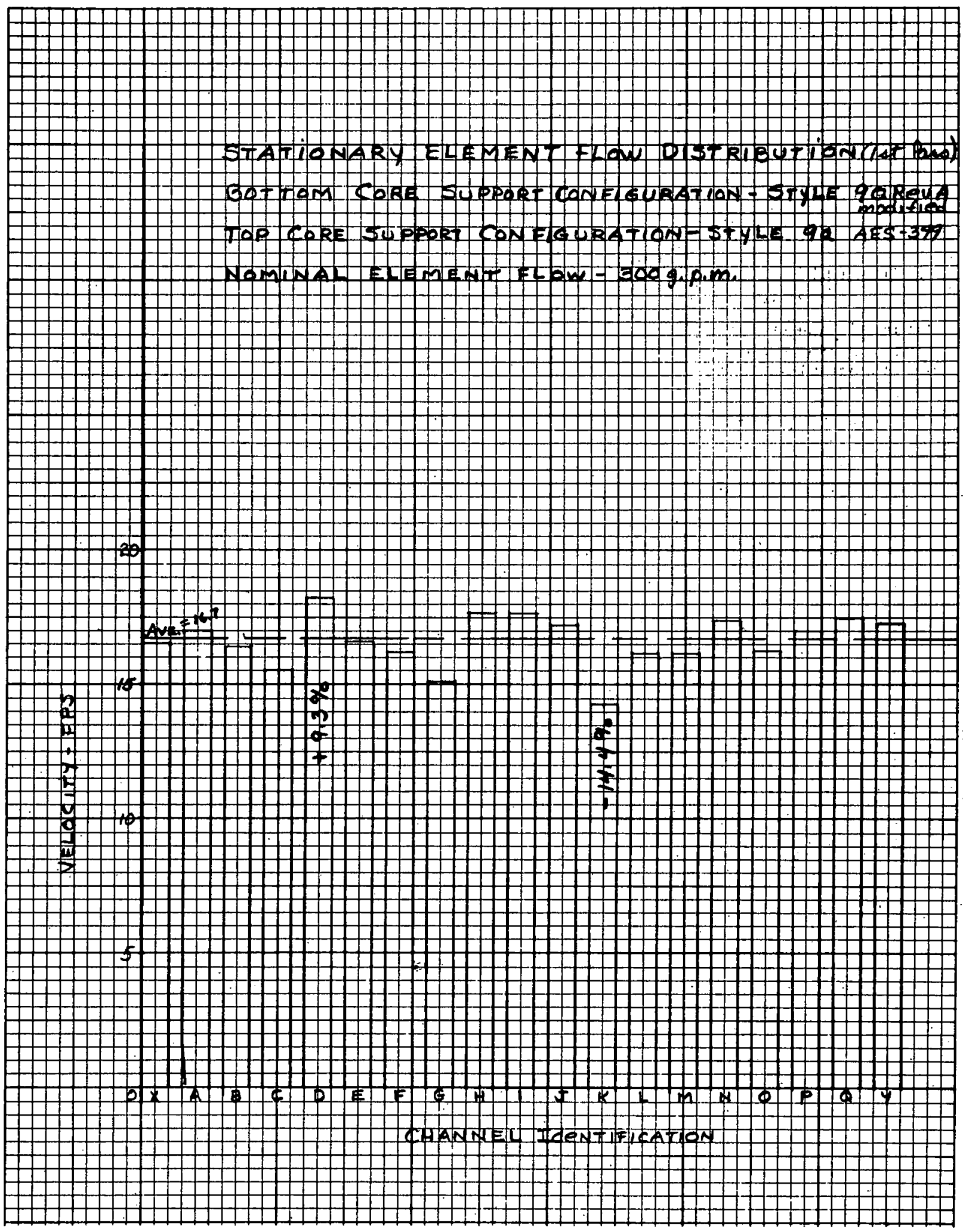

Fig. 4-30 Stationary Element Flow Distribution (Style 9c Rev. A Modified Inlet and 9a Exit) - 1st Pass 


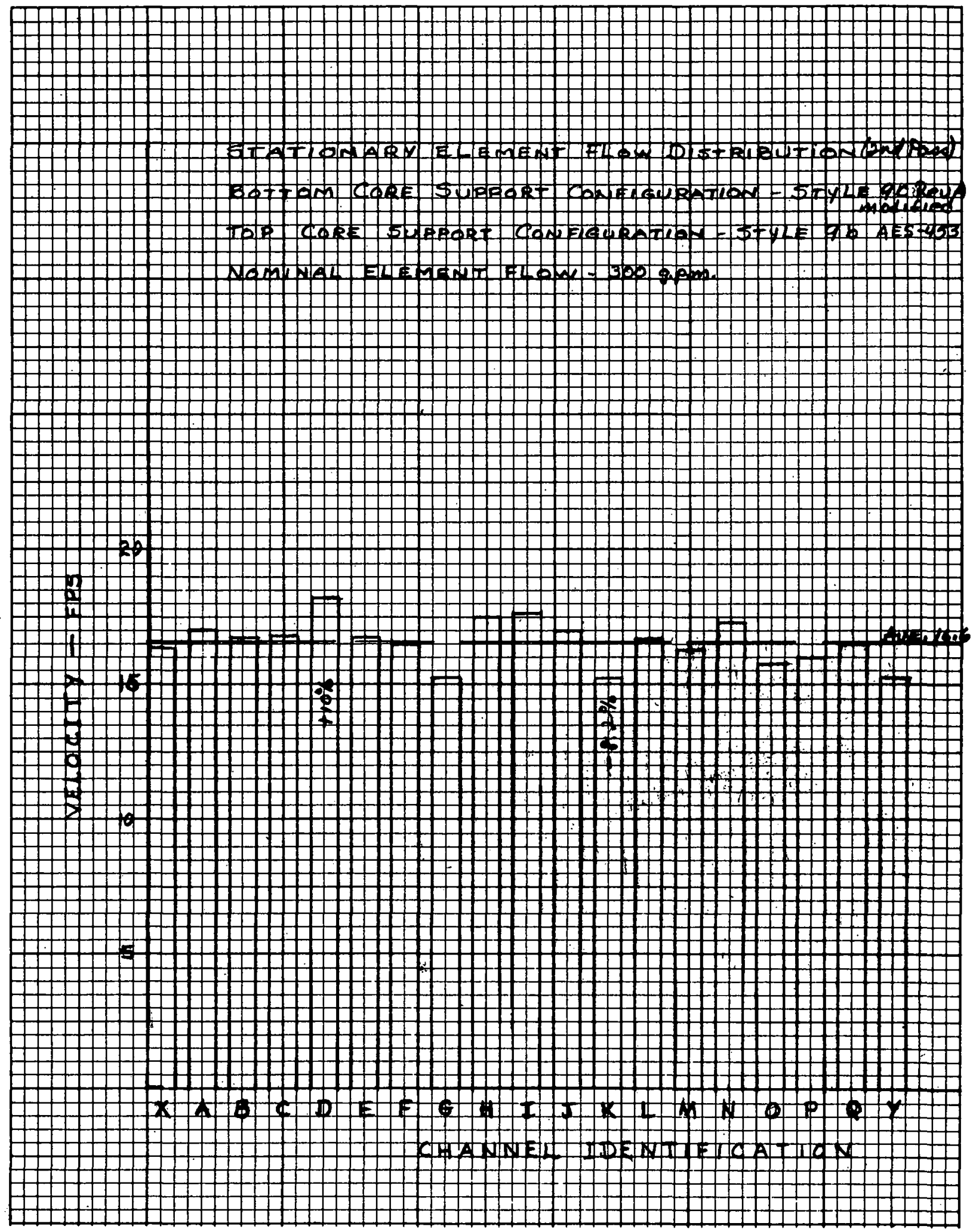

Fig. 4-31 Stationary Element Flow Distribution (Style 9c Rev. A Modified Inlet and 9b Exit) - 2nd Pass 


\subsubsection{Test \#15 - Style 13 Inlet, Style 9b Outlet (2nd Pass)}

For this test a style 13 inlet plug (Fig.4-32) was used in combination with a style $9 \mathrm{~b}$ outlet plug (Fig. 4-21). This style 13 design featured both chamfer and full taper on the majority of flow holes. This was done in an attempt to improve flow distribution and reduce overall pressure drop.

Velocity distribution at $350 \mathrm{gpm}$ nominal flow rate is shown plotted in Fig. 4-33. Flow velocities were within $+5.8 \%$ and $-8.2 \%$ with only two channels (channel 0 and $Y$ ) reading lower than the required $6 \%$ minimum: At $350 \mathrm{gpm}$ nominal flow rate, the overall pressure drop was $31.6 \mathrm{ft}$ of water.

\subsubsection{Test \#16 - Style 13 Revi. A Inlet, Style 9b Eẍit (2nd Pass)}

A modification was made to the style 13 inlet plug for this test (see Fig. 4-32).. The modification consisted of enlarging the four holes around the central locating hole and tapering the element positioning slot. The modification was made to improve both flow distribution and pressure drop results obtained in the previous test. The exit plug was the same as used in the previous test (sec. 4.4.15)。

Overall pressure drop for this combination of bottom and top core support configurations was $31.1 \mathrm{ft}$ of water at the nominal flowirate of 350 gpm. Velocity flow distribution was within $+5.0 .1 \%$ and $-9.0 \%$ of average at a nominal $350 \mathrm{gpm}$ flow rate. The modification made above brought a low channel up but further reduced the "Y" lattice: The results are plotted in Fig. 4-34.

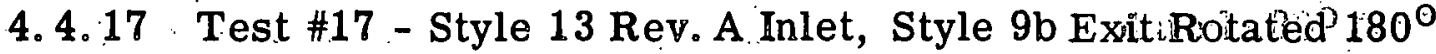 (2nd Pass)}

This test was run to provide verification of proper instrumentation or probe readout. By rotating the unsymmetrical exit plug $180^{\circ}$, the hydraulic flow pattern was rotated $180^{\circ}$, since everything else was symmetrical. The results of this test are plotted in Fig。 4-35 and when compared with the results of the previous test (test \#16. Fig。4-34), indicates only a very slight difference which can be attributed to the instruments and probes.. Thus the validity of the instrumentation was established.

4.4.18 Test \#18. - Style 13 Rev。A Inlet, Style 9b Rev。A Exit (2nd Pass)

For the final second pass configuration tested, the exit plug (style 9b) was modified as shown in Fig, 4-21. This modification was made in an attempt to match the control rod pressure drop of $29 \mathrm{ft}$ of water and also 


\section{THIS PAGE \\ WAS INTENTIONALLY \\ LEFT BLANK}




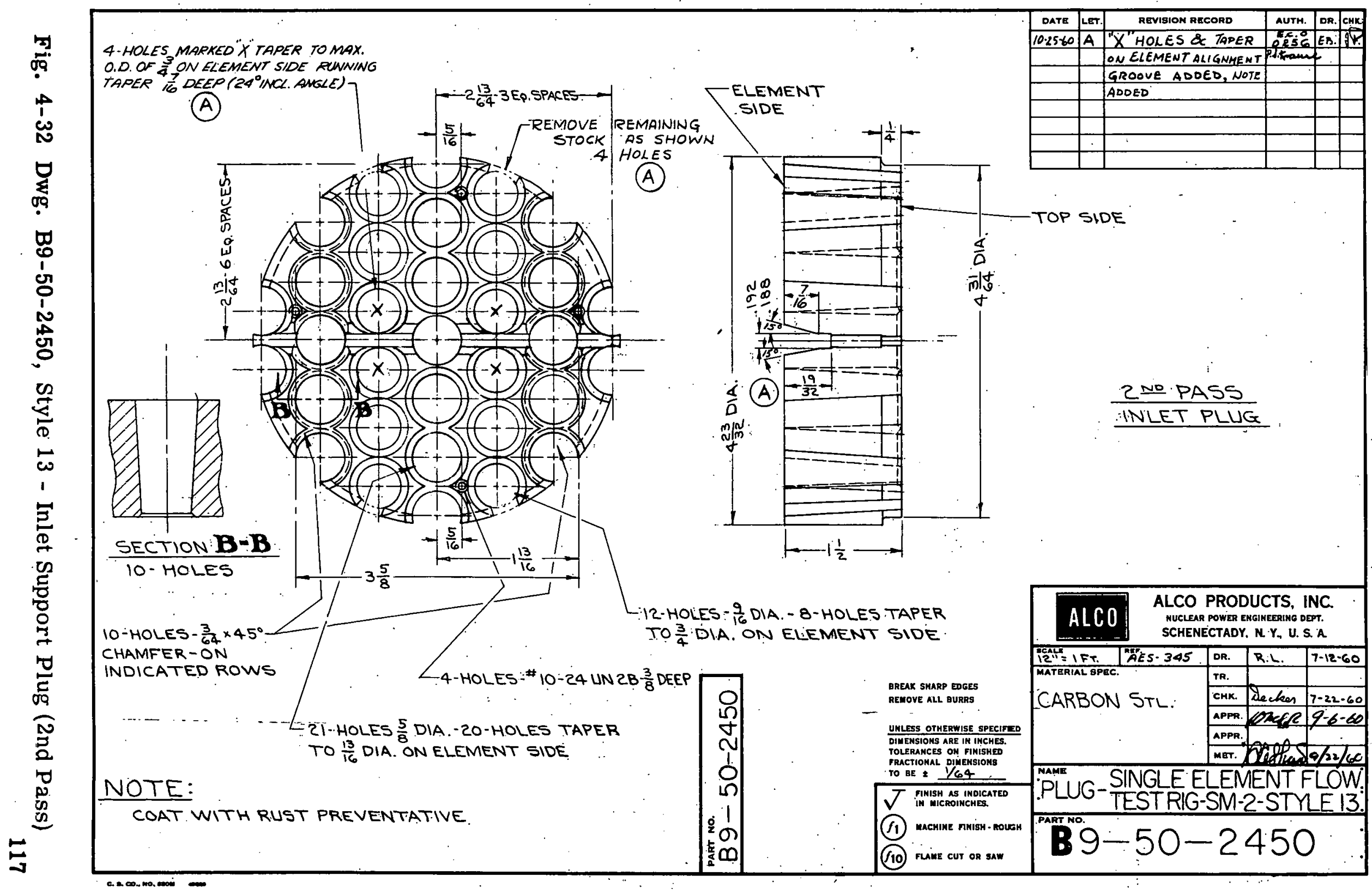




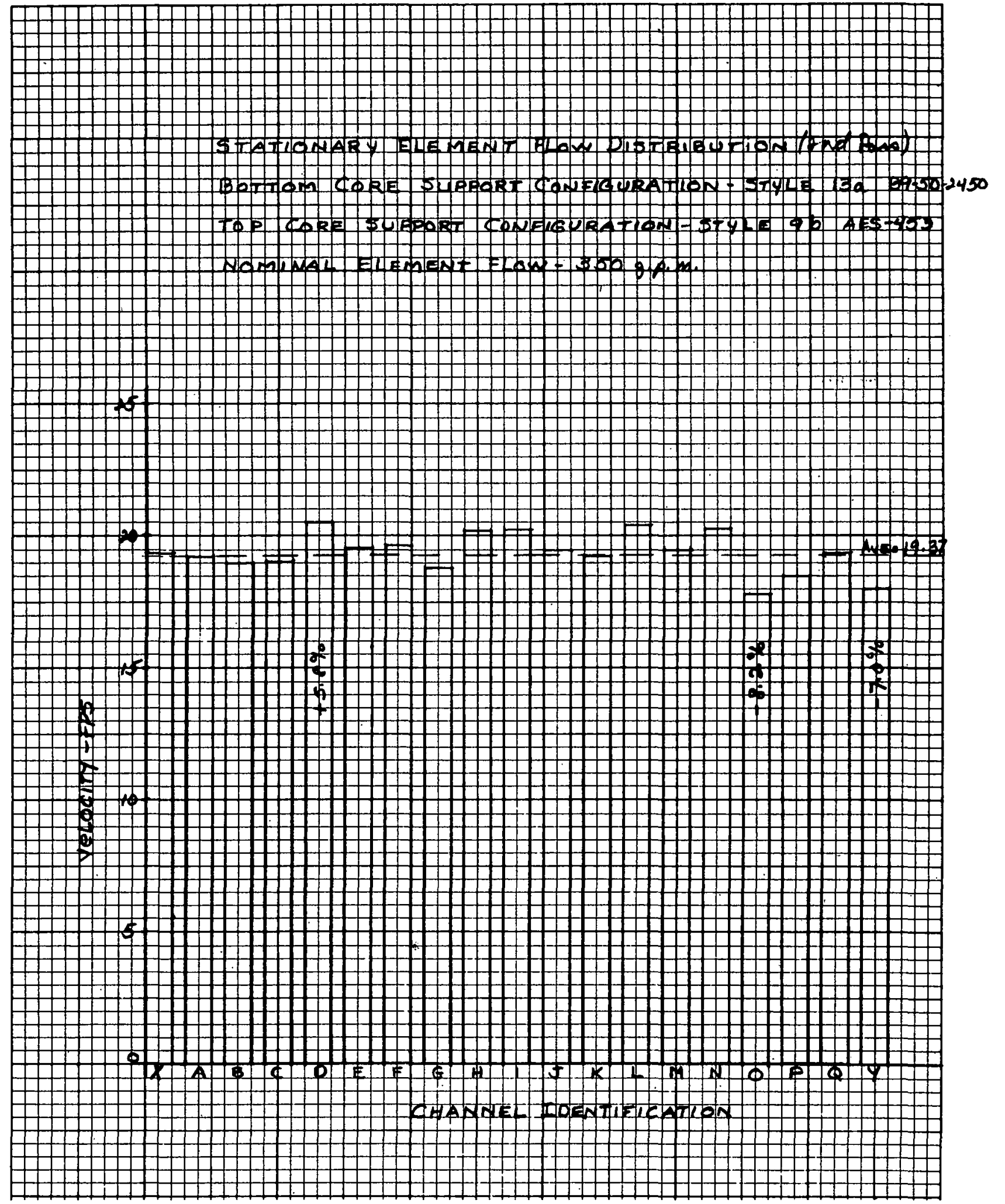

Fig. 4-33 Stationary Element Flow Distribution (Style 13 Inlet and 9b Exit) - 2nd Pass 


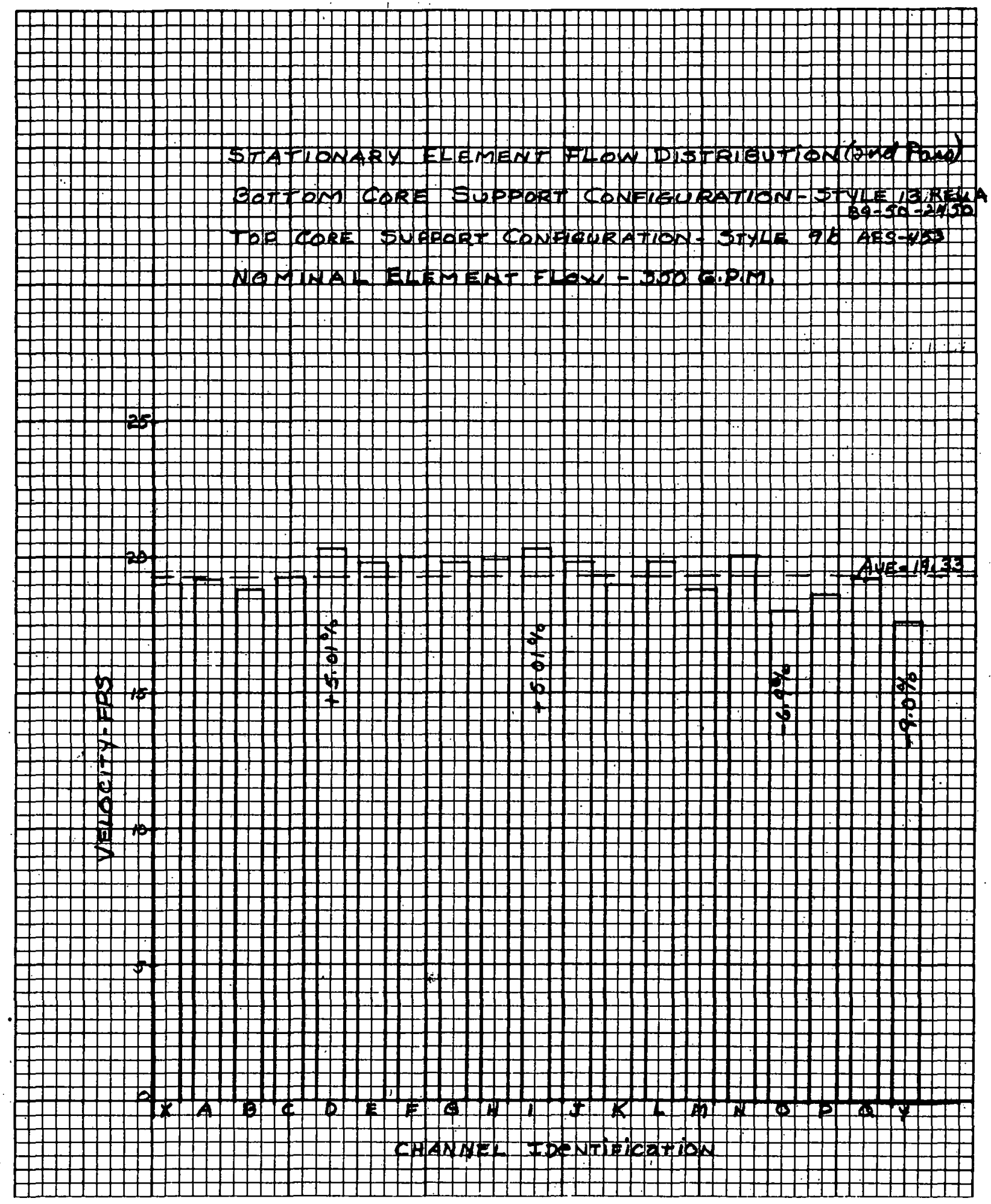

Fig. 4-34 Stationary Element Flow Distribution (Style 13 Rev. A Inlet and 9b Exit) - 2nd Pass 


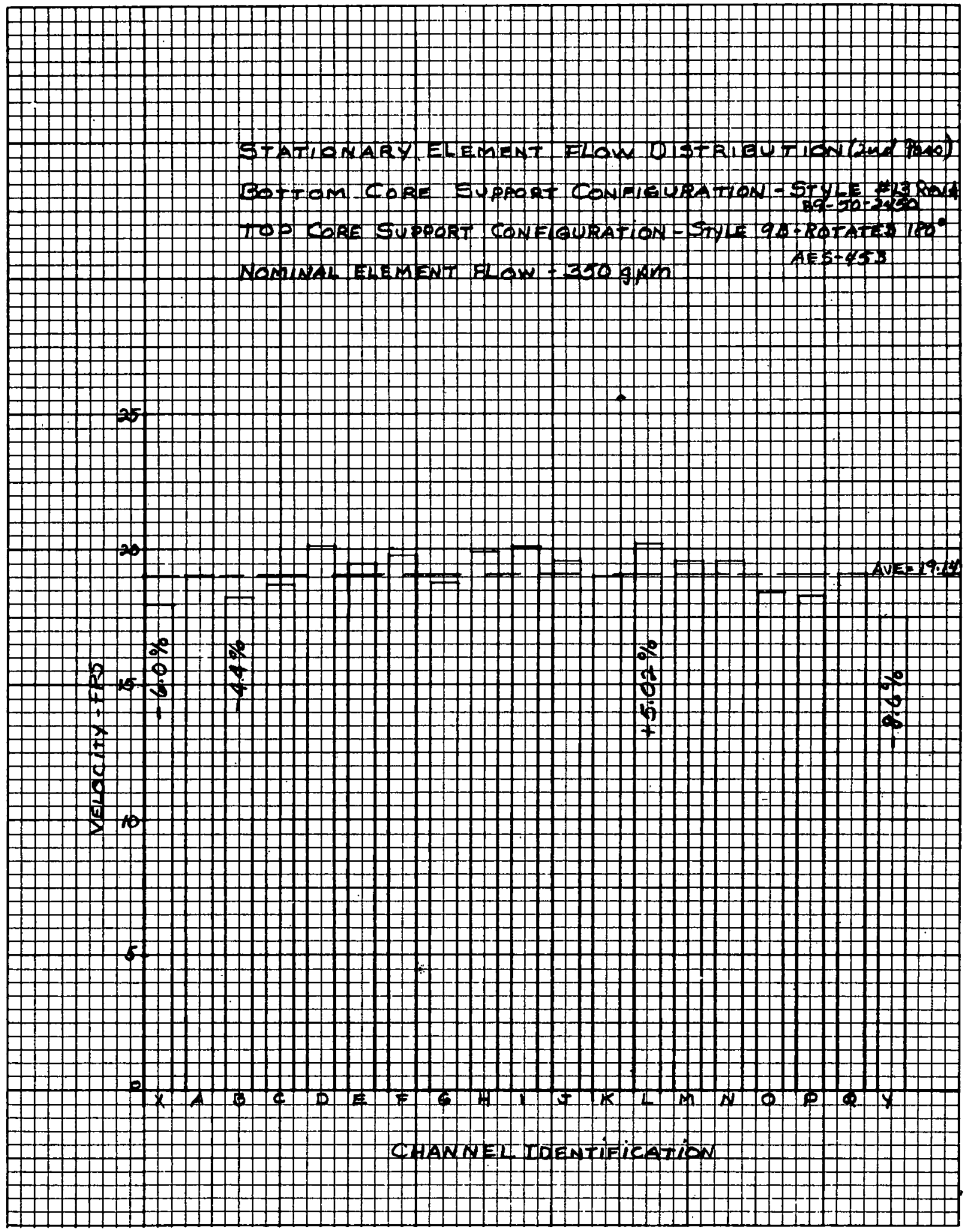

Fig. 4-35 Stationary Element Flow Distribution (Style 13 Rev. A Inlet and 9b Exit Rotated $180^{\circ}$ ) - 2nd Pass 
to improve upon the low velocity distribution in the " $Y$ " lattice and adjacent channels. The modification consisted of enlarging flow holes which distribute flow to the "Y" lattice and adjacent channels.

Flow distribution results are plotted in Fig. 4-36. Flow velocities were within $+4.3 \%$ and $-4.5 \%$ of average with definite improvement seen in the : $Y$ " lattice and adjacent flow channels. Overall pressure drop at 350 gpm nominal flow rate was $28.8 \mathrm{ft}$ of water which was within $0.6 \%$ of the target value. A complete tabulation of data at various flow rates is given in Table 4.3 .

Testing terminated when the results of this test were obtained. The final second pass combination of top and bottom core support configuration is based on this combination of style 13 Rev. A (Fig.4-32) inlet and style 9b Rev. A (Fig. 4-21) exit. 
THIS PAGE

\section{WAS INTENTIONALLY LEFT BLANK}




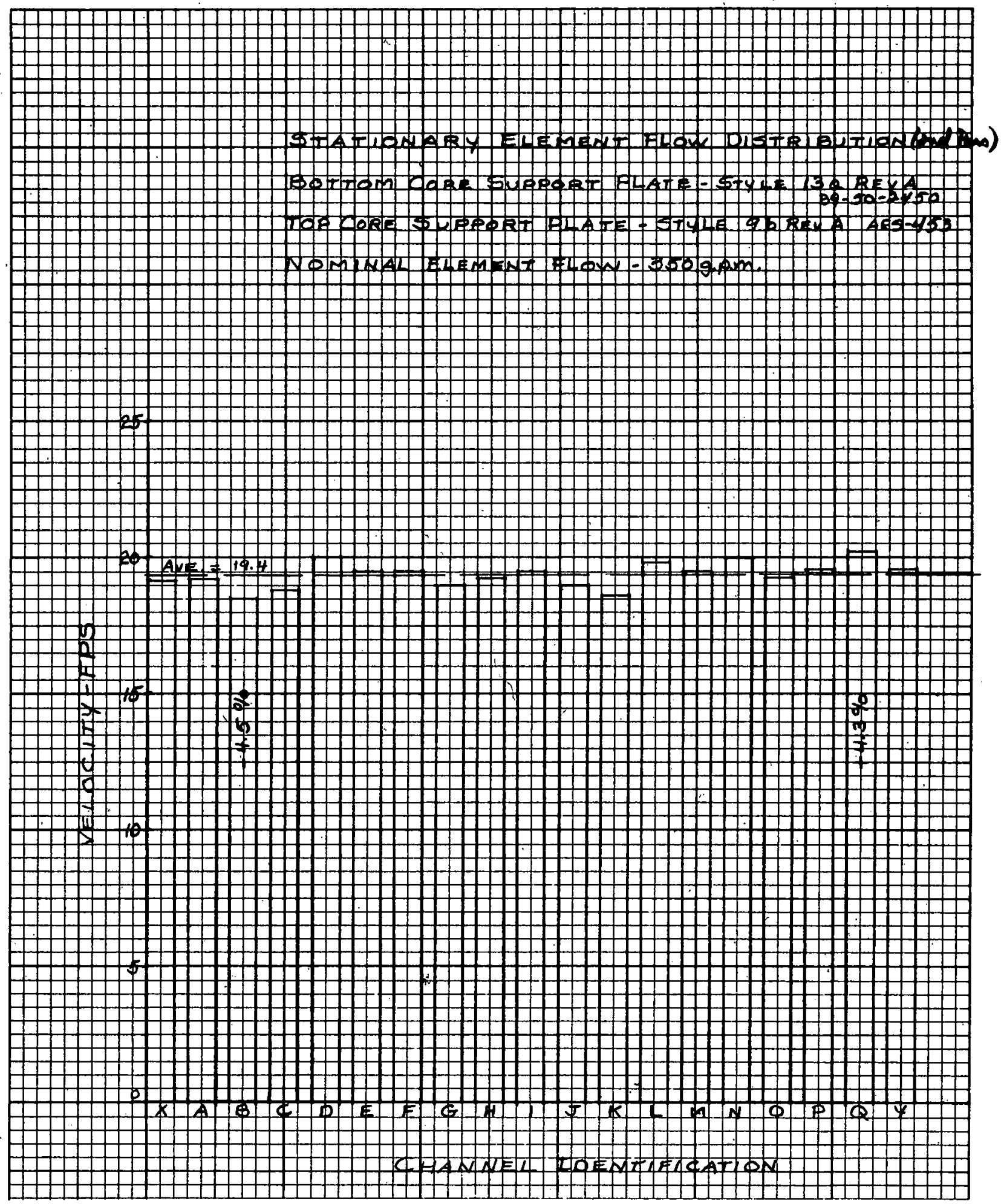

Fig. 4-36 Stationary Element Flow Distribution (Style 13 Rev. A Inlet $A$ and $9 b$ Rev. A Exit) - 2nd Pass 
THIS PAGE

\section{WAS INTENTIONALLY \\ LEFT BLANK}


TABLE 4-3

VELOCITY (F。P.S.) FLOW DISTRIBUTION FOR COMBINATION OF 2ND PASS BOTTOM AND TOP PLATE CONFIGURATIONS

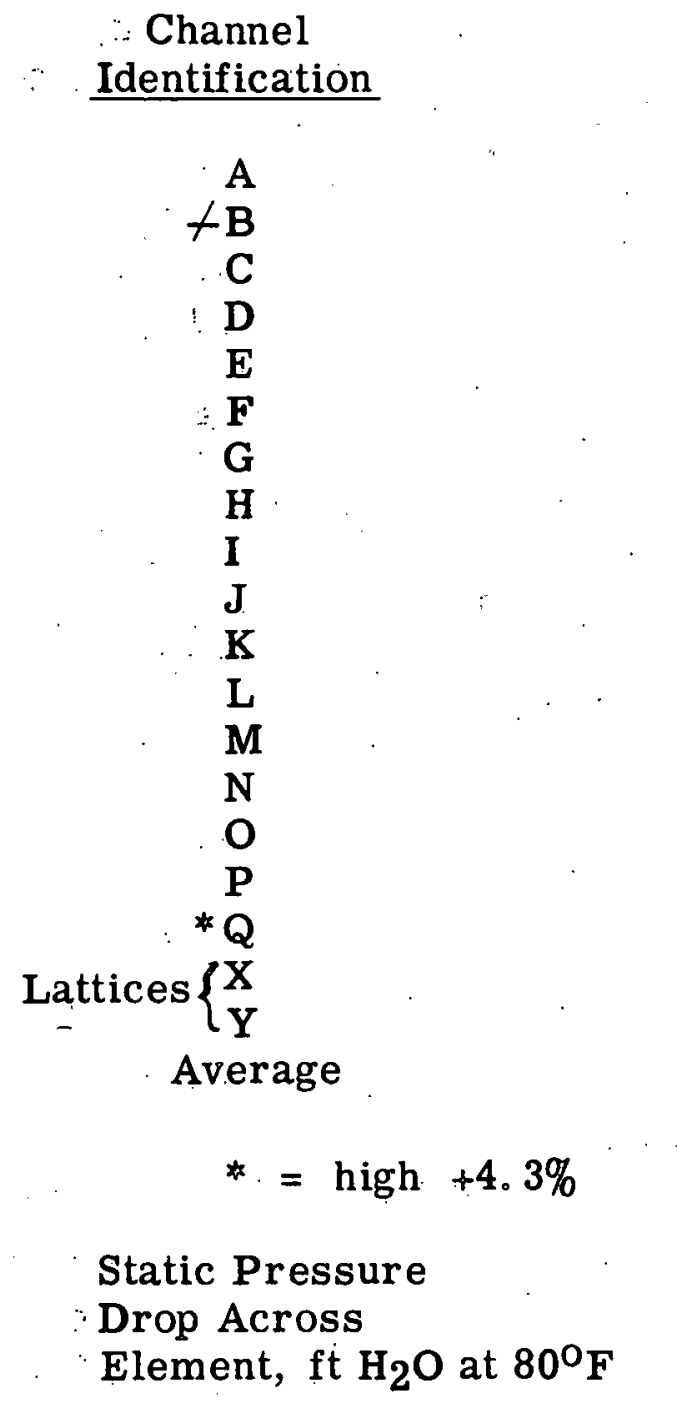

Channel

Identification

200

10,9

10. 75

11.10

11.6

11.4

11.4

10.9

11.4

11.4

11.1

10.75

11. 3

11.1

11. 5

11. 3

11. 1

11.5

11.1

11.4

11.3

$$
\text { * }=\text { high }+4.3 \%
$$

Drop Across

Element, $\mathrm{ft} \mathrm{H}_{2} \mathrm{O}$ at $80^{\circ} \mathrm{F}$

10.3

\section{Nominal Element Flow, GPM}

$\begin{array}{llll}\frac{250}{1} & 300 & \underline{350} & \underline{400} \\ 13.8 & 16.5 & 19.3 & 21.9 \\ 13.3 & 16.0 & 18.5 & 21.1 \\ 13.6 & 16.3 & 18.8 & 21.1 \\ 14.4 & 17.3 & 20.0 & 22.6 \\ 14.1 & 16.7 & 19.5 & 22.2 \\ 14.2 & 16.8 & 19.5 & 22.3 \\ 13.3 & 16.1 & 19.0 & 21.5 \\ 14.1 & 16.7 & 19.3 & 21.6 \\ 14.2 & 16.75 & 19.5 & 21.9 \\ 13.6 & 16.3 & 19.0 & 21.3 \\ 13.4 & 16.2 & 18.6 & 21.0 \\ 14.2 & 17.1 & 19.8 & 22.5 \\ 14.1 & 16.8 & 19.5 & 22.0 \\ 14.5 & 17.3 & 19.9 & 22.7 \\ 14.1 & 16.7 & 19.3 & 21.8 \\ 13.9 & 16.8 & 19.6 & 22.2 \\ 14.4 & 17.3 & 20.2 & 22.6 \\ 13.9 & 16.6 & 19.2 & 21.6 \\ 14.2 & 16.8 & 19.6 & 22.2 \\ 13.9 & 16.6 & 19.3 & 22.0\end{array}$

$$
t=\text { Low }-4.5 \%
$$

15.7

21.6

$28: 8$

36.2 
THIS PAGE

\section{WAS INTENTIONALLY LEFT BLANK}




\subsection{CONCLUSIONS}

The basic objectives of this test program were successfully attained. Final bottom and top core support configurations for the first pass were styles 9c' (Fig. 4-19) and 9a (Fig。 4-15) respectivelyo. Flow distribution for this combination of bottom and top plates was within $+7.7 \%$ and $-10.7 \%$ of average. The low pressure drop was a predominant factor in choosing this combination. This pressure drop was $17.1 \mathrm{ft}$ of water $\left(80^{\circ} \mathrm{F}\right)$ at a flow rate of $272 \mathrm{gpm}$. Final second pass top and bottom plate configurations were style $13 \mathrm{Rev}$. A (Fig。 4-32) and style 9b (Rev。A (Fig.4-21) with overall pressure drop of $28.8 \mathrm{ft} \mathrm{H}_{2} \mathrm{O}$ across this combination, missing the target value of $29 \mathrm{ft}$ of water by only $0.6 \%$. Velocity distribution for this combination was $+4.3 \%$ and $-4.5 \%$ of average which was within the design requirements of $+6 \%$ for second pass. The target value of $29 \mathrm{ft}$ of water across the second pass stationary element was arrived at by matching the control rod pressure drop which was experimentally determined before stationary element testing commenced。 
THIS PAGE

\section{WAS INTENTIONALLY \\ LEFT BLANK}




\subsection{BIBLIOGRAPHY}

1. APAE Memo No. 235, "SM-2 Reactor Core and Vessel Review: Report, August 25, 1959 to December 14, 1959," December 24, 1959.

2. APAE Memo No. 223, "SM-2 Reactor Core and Vessel Review Report, May 28, 1959 to August 24, 1959.," September 8, 1959 .

3. APAE Memn No, 243, "SM+2 Rcactor Coré alld Vessel Monthly Report, December 15, 1959 to February 5, 1960, "February 19, 1960 . 